\title{
Micro-computed tomography for natural history specimens: a handbook of best practice protocols
}

\author{
Kleoniki KEKLIKOGLOU ${ }^{1, *}$, Sarah FAULWETTER ${ }^{2}$, Eva CHATZINIKOLAOU ${ }^{3}$, \\ Patricia WILS ${ }^{4}$, Jonathan BRECKO ${ }^{5}$, Jiří KVAČEK ${ }^{6}$, \\ Brian METSCHER ${ }^{7} \&$ Christos ARVANITIDIS ${ }^{8}$ \\ ${ }^{1,3,8}$ Institute of Marine Biology, Biotechnology and Aquaculture, Hellenic Centre for Marine Research, \\ Thalassocosmos, 71003 Heraklion, Crete, Greece. \\ ${ }^{2}$ University of Patras, Department of Zoology, Section of Marine Biology, 26504 Patras, Greece. \\ ${ }^{4}$ CNRS UMS 2700, Muséum national d'Histoire naturelle, Paris, France. \\ ${ }^{5}$ Scientific Heritage Service, Royal Belgian Institute of Natural Sciences, Vautierstraat 29, \\ B-1000 Brussels, Belgium and Biological Collection and Data Management, \\ Royal Museum for Central Africa, Leuvensesteenweg 13, B-3080 Tervuren, Belgium. \\ ${ }^{6}$ Department of Palaeontology, National Museum Prague, \\ Václavské náměstí 68, 110 00, Praha 1, Czechia. \\ ${ }^{7}$ Department of Theoretical Biology, University of Vienna, Althanstrasse 14, 1090 Vienna, Austria. \\ *Corresponding author: keklikoglou@hcmr.gr \\ 2Email: sarahfaulwetter@gmail.com \\ 3Email: evachatz@hcmr.gr \\ [4Email: patricia.wils@mnhn.fr \\ Email: jbrecko@naturalsciences.be \\ ${ }^{6}$ Email: jiri_kvacek@nm.cz \\ ${ }^{7}$ Email: brian.metscher@univie.ac.at \\ 8Email: arvanitidis@hcmr.gr

\footnotetext{
${ }^{1}$ urn:1sid:zoobank.org:author:5EBBC94A-66D3-45EE-9E38-EDF7CF8B17D1

${ }^{2}$ urn:lsid:zoobank.org:author:9BF02566-AF30-47EB-840E-DFC841B6FF84

${ }^{3}$ urn:1sid:zoobank.org:author:BBFE2A72-6704-4446-9884-AFB1F6B09A68

${ }^{4}$ urn:lsid:zoobank.org:author:CC392691-1414-4624-9965-867BE05CDBAF

${ }^{5}$ urn:1sid:zoobank.org:author:7AC9797B-88EB-4844-86B9-C88DF7C06B2E

${ }^{6}$ urn:1sid:zoobank.org:author:C2C49FC5-2D9F-4712-A029-9BF2FA9489A9

${ }^{7}$ urn:lsid:zoobank.org:author:8777DCF2-AF42-4D51-A640-ABC1770B8572

${ }^{8}$ urn:1sid:zoobank.org:author:737F149F-C30C-42EB-A690-5E693AD95427
}

\begin{abstract}
Micro-computed tomography (micro-CT or microtomography) is a non-destructive imaging technique using X-rays which allows the digitisation of an object in three dimensions. The ability of micro-CT imaging to visualise both internal and external features of an object, without destroying the specimen, makes the technique ideal for the digitisation of valuable natural history collections. This handbook serves as a comprehensive guide to laboratory micro-CT imaging of different types of natural history specimens, including zoological, botanical, palaeontological and geological samples. The basic
\end{abstract}


principles of the micro-CT technology are presented, as well as protocols, tips and tricks and use cases for each type of natural history specimen. Finally, data management protocols and a comprehensive list of institutions with micro-CT facilities, micro-CT manufacturers and relative software are included.

Keywords. Micro-CT, microtomography, museum specimens, 3D visualisation, virtual specimens.

Keklikoglou K., Faulwetter S., Chatzinikolaou E., Wils P., Brecko J., Kvaček J., Metscher B. \& Arvanitidis C. 2019. Micro-computed tomography for natural history specimens: a handbook of best practice protocols. European Journal of Taxonomy 522: 1-55. https://doi.org/10.5852/ejt.2019.522

\section{Table of contents}

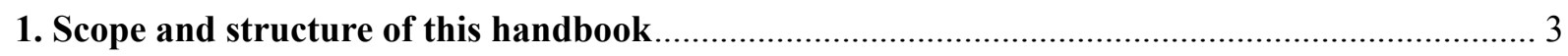

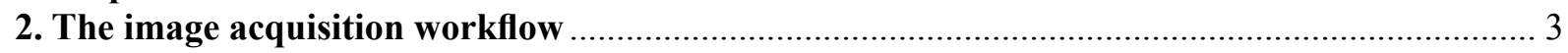

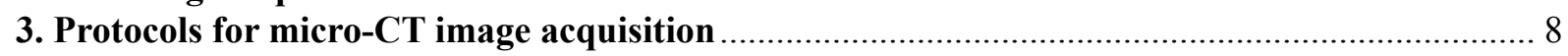

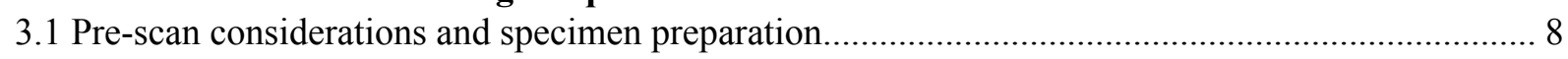

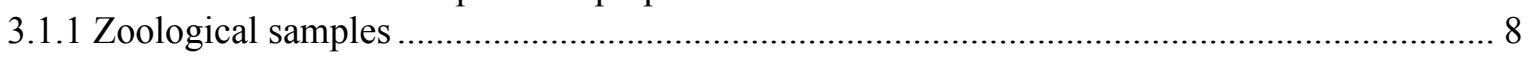

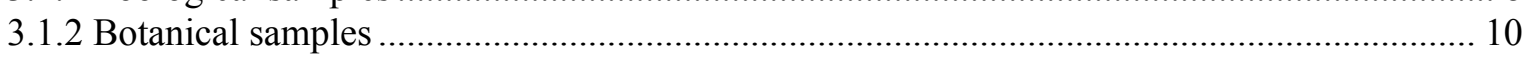

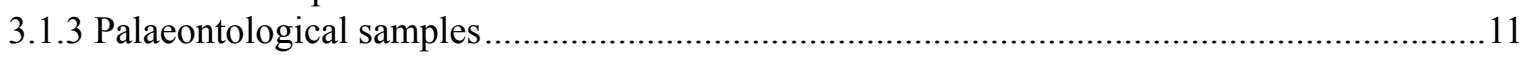

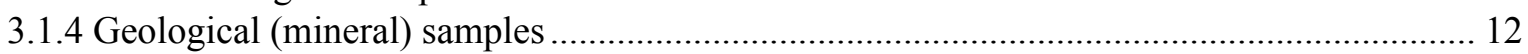

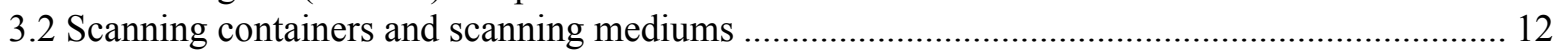

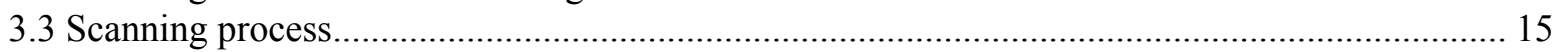

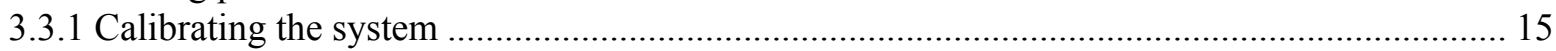

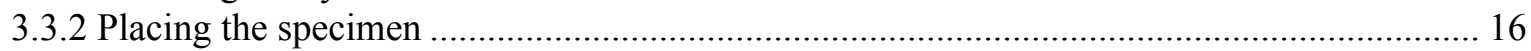

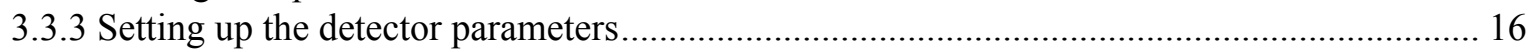

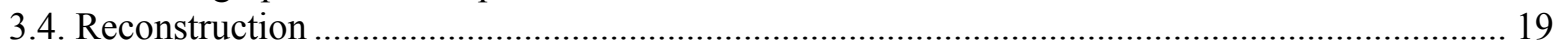

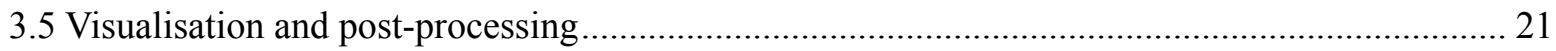

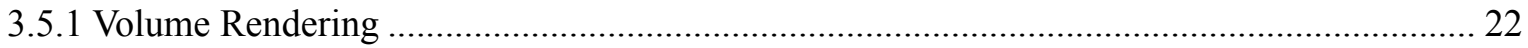

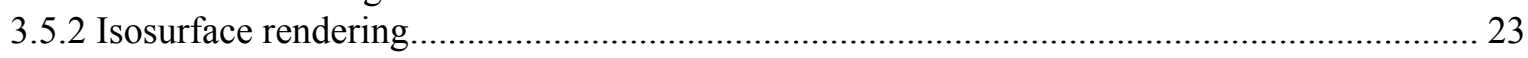

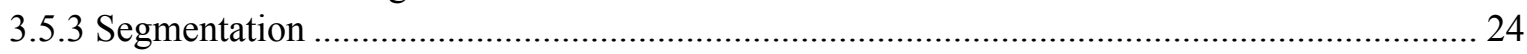

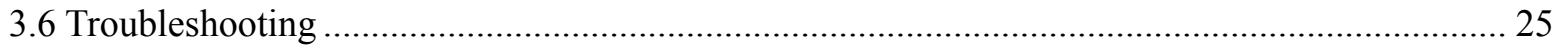

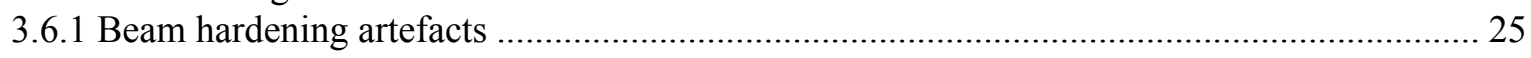

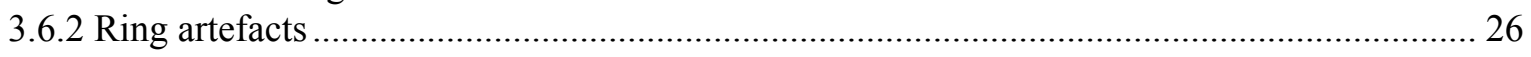

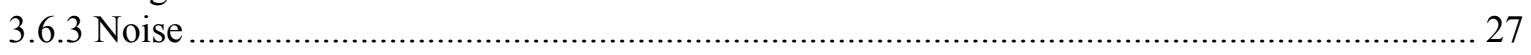

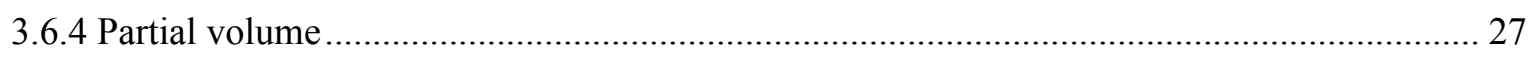

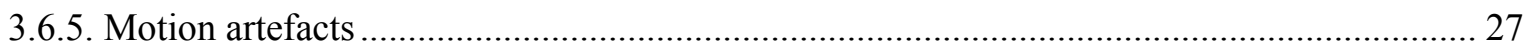

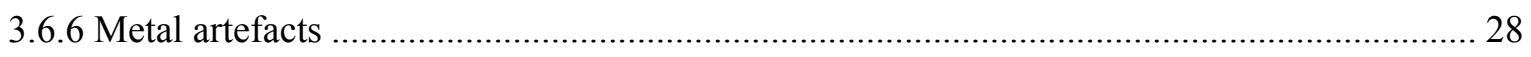

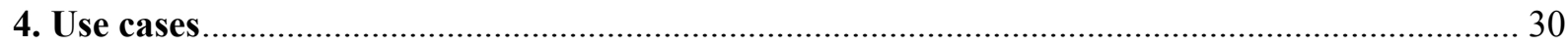

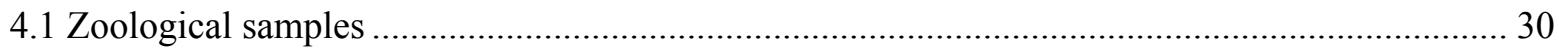

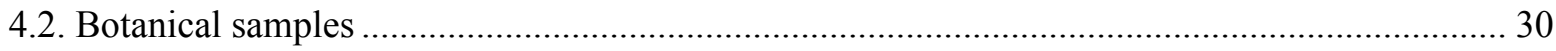

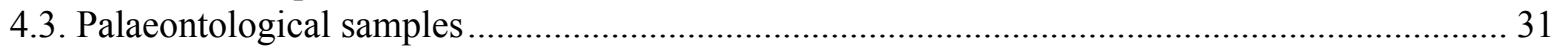

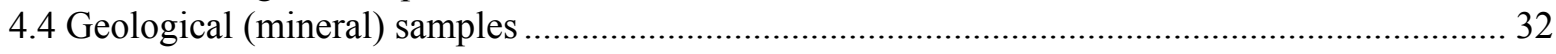

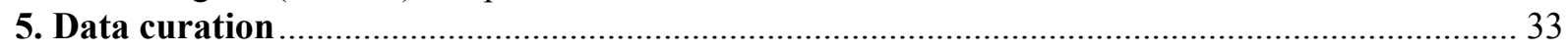

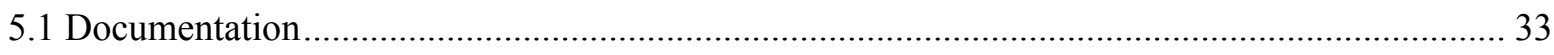

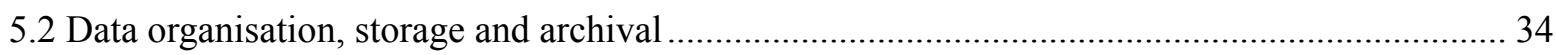

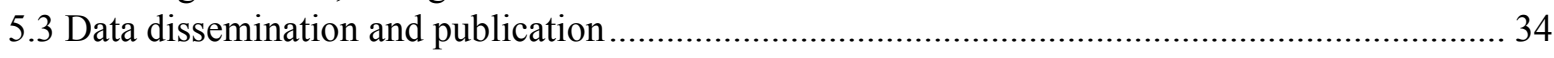

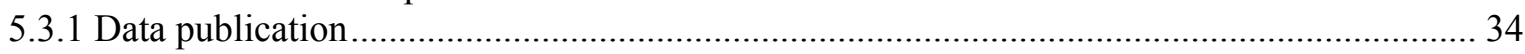

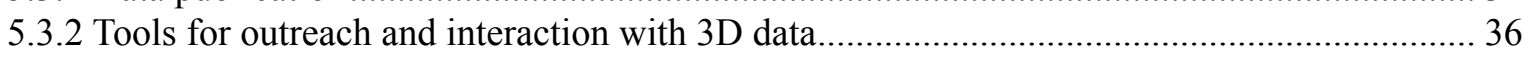

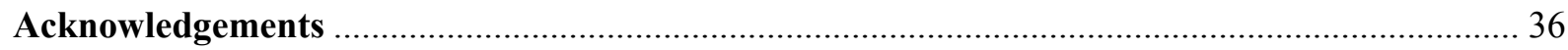

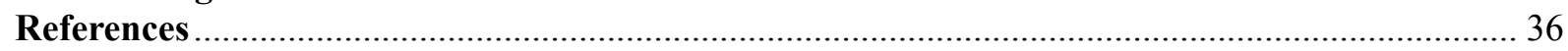

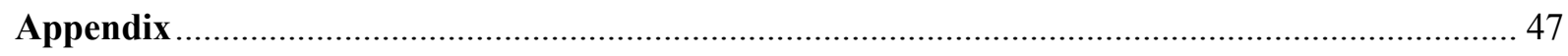




\section{Scope and structure of this handbook}

Micro-computed tomography (micro-CT, X-ray computed tomography, high-resolution X-ray computed tomography, HRXCT/HRCT, high resolution CT, X-ray microscopy) is a non-destructive imaging technique which allows the creation of high-resolution three-dimensional data. Based on X-ray imaging, it creates a full virtual representation of both internal and external features of the scanned object. These resulting 3D models can then be either interactively manipulated on screen (rotation, zoom, virtual dissection, isolation of features or organs of interest), or an array of sophisticated 3D measurements can be performed - from simple length and volume measurements to density, porosity, thickness and other material-related parameters.

While already having been used in geology and palaeontology for decades (e.g., Carlson \& Denison 1992; Simons et al. 1997; Rivers et al. 1999; Sutton et al. 2001; Carlson et al. 2003; Rossi et al. 2004; Burrow et al. 2005; Cnudde et al. 2006; DeVore et al. 2006), in recent years micro-CT has seen a steep increase of usage in a variety of biological research fields such as taxonomy and systematics, evolutionary and developmental research and functional morphology (see, e.g., Faulwetter et al. 2013a and references therein).

The ability of micro-CT imaging to create accurate, virtual representations of both internal and external features of an object, at micrometer resolution, without destroying the specimen, makes the technique an interesting tool for the digitisation of valuable natural history collections. Digitisation efforts have become an important research activity of museums and herbaria, since collections represent a vast source of biodiversity information which is often underexploited due to the traditionally slow process of re-visiting physical specimens (Blagoderov et al. 2012). Digitised specimens, however, are available at the click of a mouse from any internet-enabled computer worldwide, protect the specimen from loss or damage through handling or shipping and thus have the potential to accelerate taxonomic and systematic research and allow for large-scale comparative morphological studies (Faulwetter et al. 2013a). MicroCT imaging technology may give rise to the elaboration of 'virtual museums' or 'virtual laboratories' where digital data are shared widely and freely around the world, while the original material is stored safely (Abel et al. 2011; Keklikoglou et al. 2016). In addition, 3D models created through micro-CT scanning can be either printed or made available via interactive touch screens to be used for public display and outreach efforts.

This handbook acts as a comprehensive guide to laboratory micro-CT imaging of different types of natural history specimens, from geological and palaeontological to zoological and botanical specimens. First, a general overview of the image acquisition workflow is given, presenting the basic principles of the micro-CT technology. Then, a comprehensive section on best practice protocols follows. For each of the above categories of natural history specimens, a detailed description of best practices, protocols, tips and tricks and use cases are given, from specimen preparation to final use of the resulting models. However, each specimen is different, and each study has a different scope, so naturally there is no standard protocol that can be universally applied. The information given in this handbook merely acts as a starting point. The last section of the main text comprises information on the data management of the micro-CT datasets, including best practices on metadata, storage and dissemination. Finally, an appendix includes a glossary which explains the domain-specific terms used throughout the text and additional useful information, such as lists of institutions with micro-CT facilities, micro-CT manufacturers and annotated list of software.

\section{The image acquisition workflow}

The basic principle of the micro-CT technique is related to the acquisition of a large set of radiographic projections (2D images) of an object around a rotation axis. The rotated object is placed between an 
X-ray source and an X-ray detector (Fig. 1) and the free adjustment of the source-object distance (SOD) and object-detector distance (ODD) allows greater resolution in comparison to clinical CT scanners (Schambach et al. 2010).

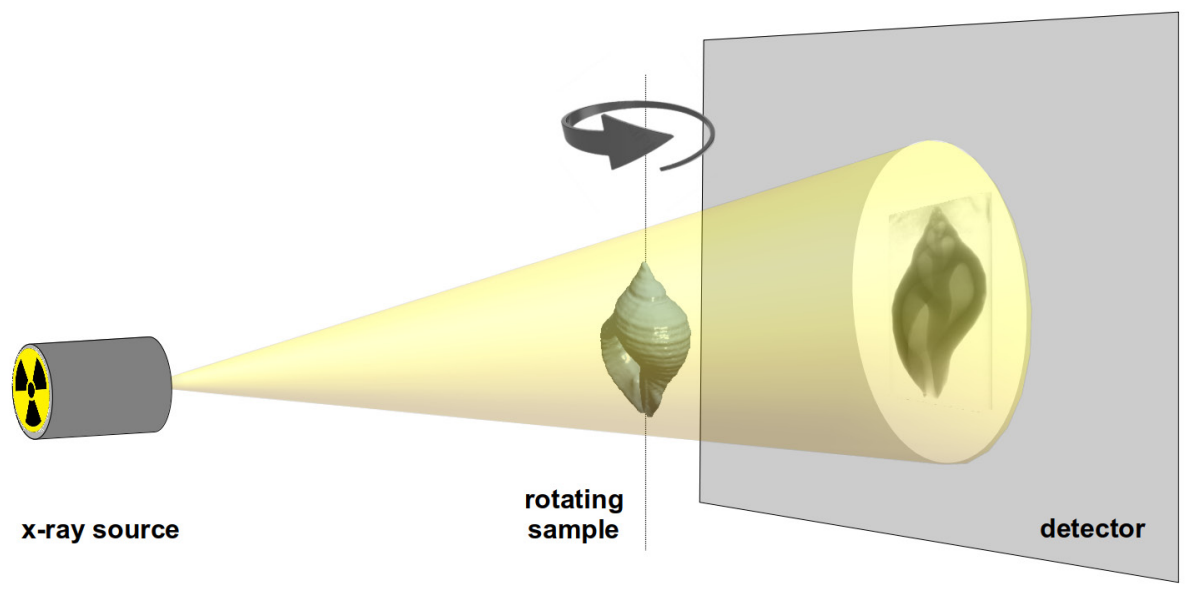

Fig. 1. Schematic overview of the image acquisition process. Image by the Hellenic Centre for Marine Research (HCMR) micro-CT lab.

The micro-CT technique depends on X-rays which are high energy electromagnetic radiation ranging from hundreds of $\mathrm{eV}$ to hundreds of $\mathrm{keV}$. X-rays photons are generated by electron beams. The X-ray source contains an X-ray generator (a vacuum tube) in which electrons are released from a filament (the cathode) and are highly accelerated by an electric potential difference (Fig. 2). Then, the electronic beam is focused on a metal target (the anode) and produce X-rays according to two different processes:

The electrons are decelerated by the atomic nucleus of the target and part of their kinetic energy is converted into an emitted X-ray photon. This phenomenon is called 'braking radiation' or Bremsstrahlung. The output spectrum consists of a continuous spectrum of X-ray energies ranging from 0 to the voltage of the X-ray source.

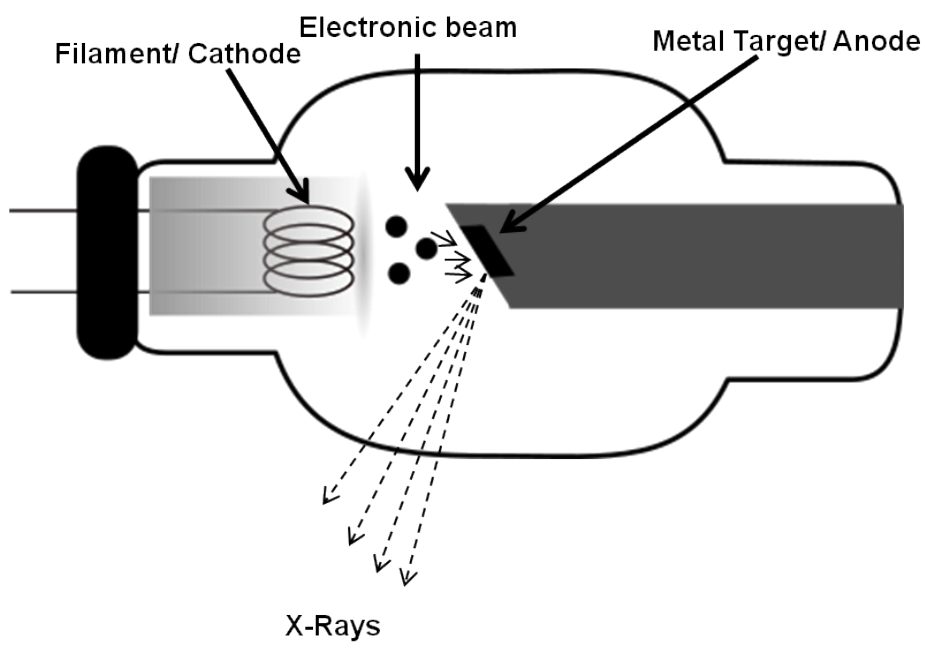

Fig. 2. Schematic overview of the X-Ray generator. 
The electrons may collide with target orbital electrons and be ejected from the orbit. Subsequently, an electron from a higher energy level will replace the ejected electron and the energy left by this displacement will be transferred to an emitted X-ray photon. The energy of the X-ray photon (fluorescent photon) is the difference between the two energy levels, a characteristic of the target's material.

The appropriate choice of the target's material aims to ensure that the energy efficiency of the braking radiation is high (its atomic number is high) and the fusion point is high enough to endure high power. Tungsten is used as the main material for high power applications. Another typical material is molybdenum for finer resolution applications. Sutton et al. (2014) mention that a tungsten target source is considered ideal for palaeontological specimens and a molybdenum target source for specimens which are included in amber.

Filters (e.g., aluminium, copper, aluminium and copper combined) can be used to prevent the lowest X-ray photon's energy reaching the specimen, thus avoiding artefacts during the reconstruction procedure (beam hardening; Section 3.6). Figure 3 shows a typical spectrum generated by an X-ray generator for $100 \mathrm{kV}$, along with the spectrum when it is filtered with a $0.5 \mathrm{~mm}$ copper plate.

X-rays are attenuated along their paths through the specimen due to three types of interactions: photoelectric absorption, Rayleigh scattering and Compton scattering. This attenuation is characterised

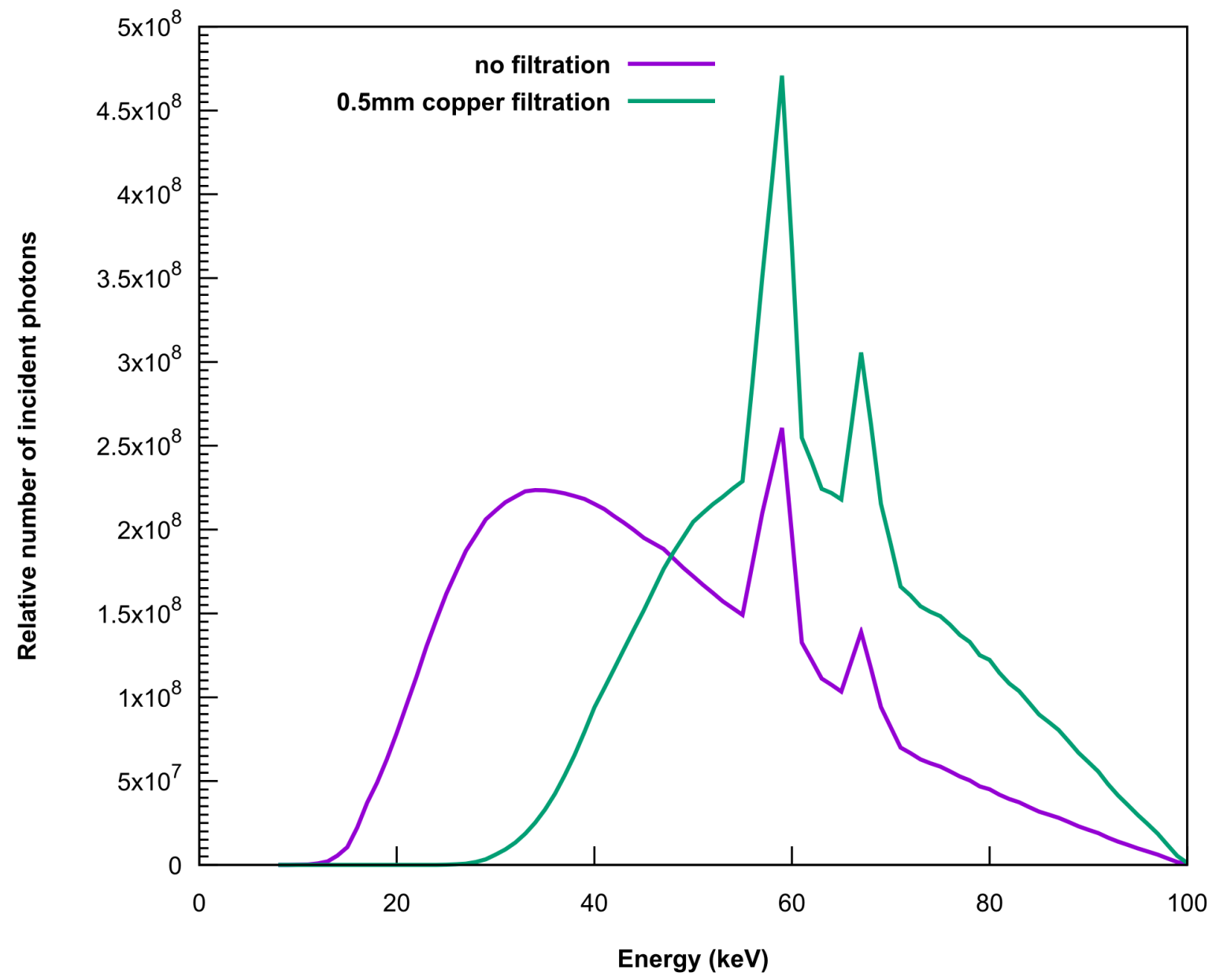

Fig. 3. The spectrum generated by an $\mathrm{X}$-ray generator at $100 \mathrm{kV}$ with and without filtering. Image generated by the simulation environment https://www.oem-xray-components.siemens.com/x-ray-spectra-simulation. 
by a linear coefficient $\mu(\mathrm{E}, \mathrm{Z})$ in $\mathrm{cm}^{-1}$ that corresponds to the contribution of each type of interaction and depends on the energy of the incident beam and the atomic number of the material encountered.

The total attenuation of an incident beam passing through a well-defined specimen can be computed as a sum or an integration of individual attenuations. This property is a key to tomographic reconstruction, called an inverse problem, as the measurement of the total attenuations on different angles will lead to knowledge of a discrete set of attenuations (in a voxel grid) along the path through the specimen.

The X-rays photons that have been transmitted through the specimen are then collected on a detection device. A scintillator screen absorbs the X-ray beam and re-emits it in the form of light. This light may be captured by CCD or CMOS cameras, digitised by a photodiode array in a flat-panel detector. The choice of a detector is usually a trade-off between its pixel resolution and its field of view.

The resulting image is a radiograph (projection image) whose pixel values are the X-ray transmission as measured by the detector, usually mapped to 16-bit gray values (ranging from 0 to 65535). This type of acquisition is called absorption-contrast. When displayed as a positive image, the darkest parts of an $\mathrm{X}$-ray image are the most absorbing ones and the lightest parts are those with the lowest absorption (e.g., air) (Fig. 4). The reconstructed tomographic image consists of voxels whose values correspond to the $\mathrm{X}$-ray attenuation at each point in the sample.

The aforementioned projection images are reconstructed into cross-section images using specific reconstruction software. A reconstruction algorithm is run to get a volumetric representation of the density of the specimen, including its inner features. The most common reconstruction software use filtered back projection algorithms for the recovery of the attenuation maps of the radiographs.
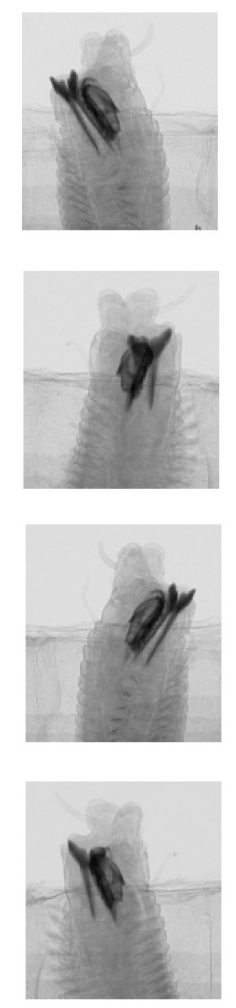
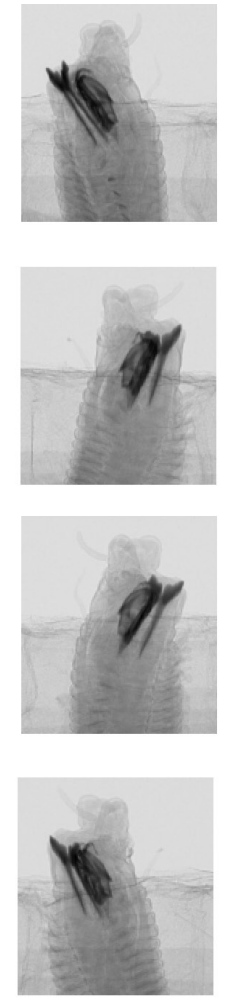
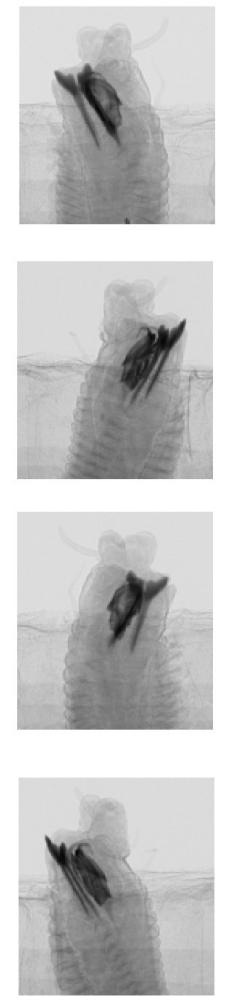
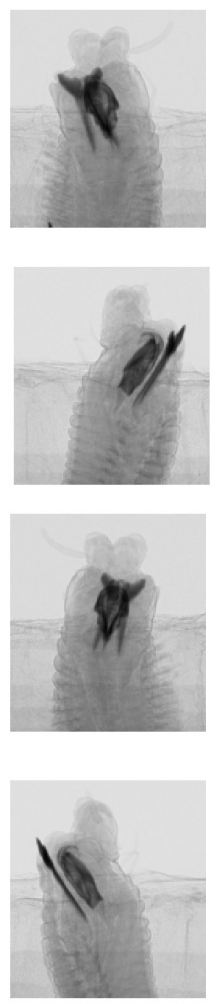
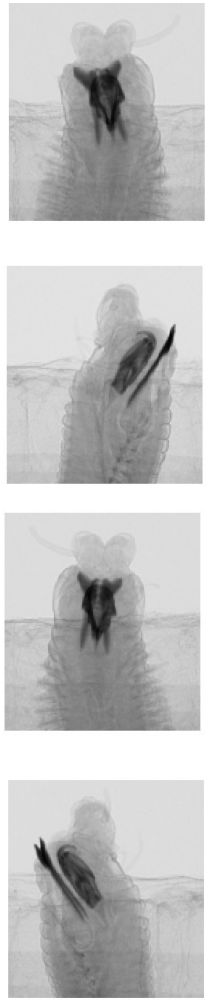
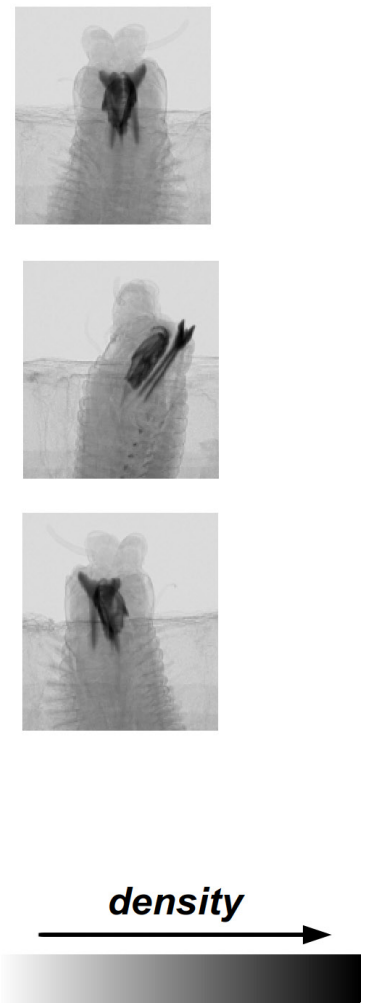

Fig. 4. Example of the projection images resulting from the scanning process. Image by HCMR microCT lab. 
Specifically, projection images, which are taken from every angle of the sample, results in sinograms which represents the aforementioned attenuation maps (Betz et al. 2007). The cross-section images (slices) are created by these sinograms using back-filter algorithms. Each projection image is smeared back across the reconstructed image and creates the back-projection images which transmit the measured sinogram back into the image space along the projection paths. The back-projection image is a blurred cross-sectional image. This blurring effect can be moderated using mathematical filters (Sutton et al. 2014) and the algorithms that use the combination of back projection and filtering are known as filtered back-projection algorithms. The combination of the back-projection images will localise the position of the sample. As the number of projections increase, the position and shape of the object becomes more defined (Fig. 5).

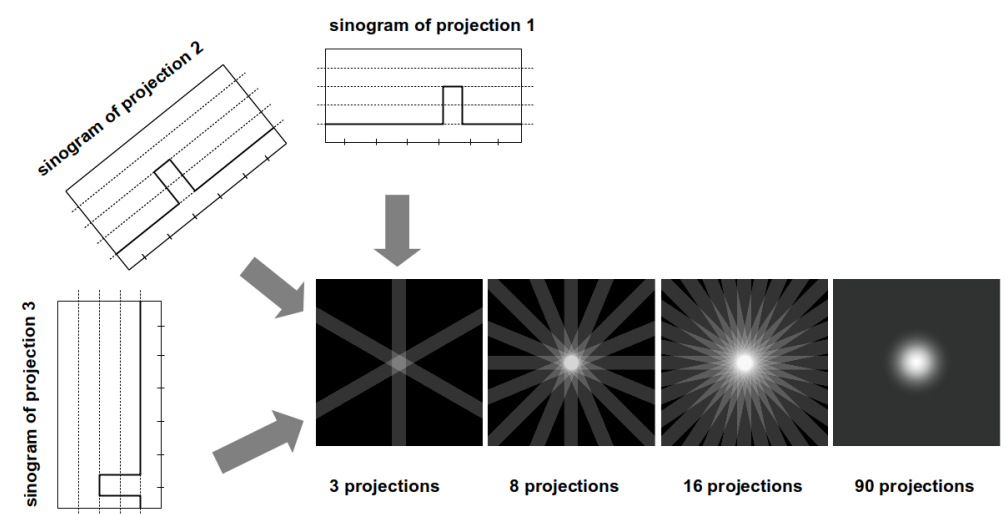

Fig. 5. Schematic overview of the reconstruction procedure. Image by HCMR micro-CT lab.

The reconstruction procedure results in a 3D image where each voxel codes the local density of the specimen. It is usually exported as a stack of 2D images in a given orientation (Fig. 6). The microCT dataset can then be processed with dedicated software for 3D visualisation (either through volume rendering or isosurface rendering, see Section 3.5) or further analysis (see Tables 8 and 9 for comprehensive lists of software). The rendered images can be also used for the creation of $3 \mathrm{D}$ videos which are an excellent tool for sharing a preview of a micro-CT dataset (Abel et al. 2012).

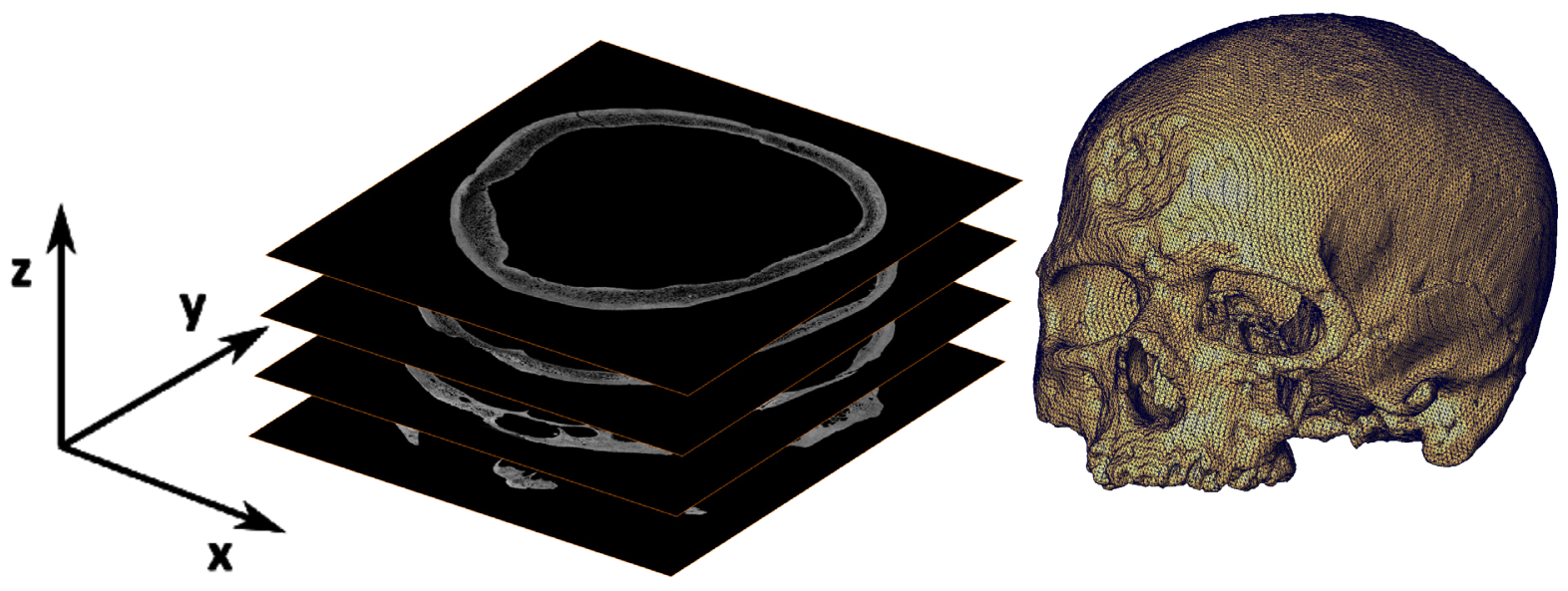

Fig. 6. Data processing from a stack of 2D images to a 3D model. Image by MNHN. 


\section{Protocols for micro-CT image acquisition}

\subsection{Pre-scan considerations and specimen preparation}

The selection of micro-CT as a technique for specimen visualisation depends on the aim of the specific study. The limitations of the method must be considered, e.g., colour cannot be represented and structures below a certain size cannot be detected. An additional consideration when working with museum specimens is to ensure that the museum curator will allow imaging with micro-CT (including contrast enhancement through staining, if needed).

The first and major step to obtain good results is to achieve a sound contrast difference between the specimen and its surrounding medium. Contrast enhancement agents can be used to improve the quality and clarity of the scanning result: 1) when the specimen has inadequate contrast, 2) when extreme attenuation differences between soft and hard tissue need to be reduced (setting of the contrast level in the scan becomes easier), 3) to segment tissues or organs more easily, and 4) to identify specific target features of the specimen.

Rehydration or dehydration procedures may be needed before staining, depending on the preservation medium of the specimen, or after staining and on the medium in which the specimen will be scanned.

\subsubsection{Zoological samples}

Dense material, such as bones and other calcified tissues, usually does not require any specific preparation. In soft tissue specimens, where visualisation can be difficult due to the low X-ray absorption of unmineralised tissues (Metscher 2009a; Gignac \& Kley 2014), contrast enhancement agents are commonly applied.

A series of the most common contrast agents used in zoological samples is presented in Table 1. In general, contrast agents with a high atomic number are more efficient since they result in an increased X-ray absorption (Pauwels et al. 2013). However, the selection of an appropriate and efficient contrast enhancement agent is a combination of several considerations such as the type of the target tissue (see Table 1), the medium in which the specimen was fixed and stored (Metscher 2009a), the acidity and the penetration rate of the contrast agent (Metscher 2009b; Pauwels et al. 2013; Paterson et al. 2014), as well as the price and toxicity of the staining used. Contrast agents with low penetration rate are more effective when used in relatively small specimens with a sample size of only a few $\mathrm{cm}^{3}$ (Pauwels et al. 2013). Staining larger specimens may require longer staining time, as the penetration rate in larger samples may be slower. Contrast agents dissolved in buffered formalin could prevent potential tissue deterioration due to the long staining period for large specimens (Li et al. 2015).

Staining of fresh samples will usually give optimal results. However, the results of the staining can be influenced by certain treatments, such as freezing prior to fixation and the fixation process (Gignac et al. 2016). If possible, long-term storage in ethanol or unbuffered formalin between fixation and staining should be avoided, as this may affect the morphology of the specimen or alter tissue characteristics which in turn affect staining properties (e.g., iodine stains bind to lipids, which can be dissolved in alcohols (Gignac et al. 2016), and unbuffered formalin or other acidic liquids may decalcify tissues). However, this is not always possible for museum specimens, and good results have been also achieved with museum specimens stored for years and decades. These finer details of fixative, storage medium, tissue characteristics and staining properties are still insufficiently known and will require further studies in the future.

Micro-CT scanning is a powerful visualisation method with several advantages, but might not be appropriate for all kinds of specimens. Some contrast enhancement agents are acidic (e.g., PTA, PMA, $\mathrm{FeCl}_{3}$ ) and when used in high concentrations they may dissolve calcified tissues, such as bones, and destroy the specimen structure (Pauwels et al. 2013). Therefore, in cases where calcified structures are 
KEKLIKOGLOU K. et al., Micro-computed tomography for natural history specimens

Table 1 (continued on next page). Overview of the most common contrast agents for soft zoological tissues.

\begin{tabular}{|c|c|c|c|c|}
\hline Contrast agent & Tissue & Limitations & Dissolved in & References \\
\hline $\begin{array}{l}\text { Osmium }(\text { osmium } \\
\left.\text { tetroxide, } \mathrm{OsO}_{4}\right)\end{array}$ & $\begin{array}{l}\text { membrane lipids, proteins } \\
\text { and nucleic acids }\end{array}$ & $\begin{array}{c}\text { toxic, volatile, expensive, } \\
\text { does not work for tissues } \\
\text { preserved in ethanol, slow } \\
\text { penetration }\end{array}$ & $\begin{array}{l}\text { phosphate } \\
\text { buffer }\end{array}$ & $\begin{array}{l}\text { Metscher 2009b; } \\
\text { Kamenz \& } \\
\text { Weidemann 2009; } \\
\text { Faraj et al. } 2009\end{array}$ \\
\hline $\begin{array}{c}\text { Phosphotungstic acid } \\
\text { (PTA) }\end{array}$ & $\begin{array}{l}\text { various proteins (overall } \\
\text { structure), connective } \\
\text { tissue (collagen), muscle }\end{array}$ & $\begin{array}{l}\text { cartilage matrix does } \\
\text { not stain strongly, slow } \\
\text { penetration, potential } \\
\text { dissolution of calcified } \\
\text { tissues if high concentration } \\
\text { of contrast agent is used }\end{array}$ & $\begin{array}{l}\text { water or } \\
\text { ethanol- } \\
\text { methanol }\end{array}$ & $\begin{array}{l}\text { Metscher 2009b; } \\
\text { Pauwels et al. } 2013\end{array}$ \\
\hline $\begin{array}{l}\text { Phosphomolybdic acid } \\
\text { (PMA) }\end{array}$ & $\begin{array}{l}\text { cartilage structures, } \\
\text { fibrous collagen tissue }\end{array}$ & $\begin{array}{l}\text { slow penetration, potential } \\
\text { dissolution of bone structure } \\
\text { if high concentration of } \\
\text { contrast agent is used }\end{array}$ & water & $\begin{array}{l}\text { Golding \& Jones } \\
\text { 2007; Pauwels et al. } \\
2013\end{array}$ \\
\hline Iodine & $\begin{array}{l}\text { overall structure of soft } \\
\text { tissues }\end{array}$ & $\begin{array}{l}\text { may overstain some } \\
\text { mineralised tissues }\end{array}$ & $\begin{array}{l}\text { ethanol or } \\
\text { methanol }\end{array}$ & $\begin{array}{l}\text { Metscher } 2009 \mathrm{~b} ; \\
\text { Gignac et al. } 2016\end{array}$ \\
\hline $\begin{array}{l}\text { Iodine potassium } \\
\text { iodide (IKI) }\end{array}$ & $\begin{array}{l}\text { overall structure of soft } \\
\text { tissues }\end{array}$ & $\begin{array}{l}\text { may overstain some } \\
\text { mineralised tissues }\end{array}$ & water & Metscher 2009b \\
\hline $\begin{array}{l}\text { Iodine-based buffered } \\
\text { formalin }\end{array}$ & $\begin{array}{l}\text { overall structure of soft } \\
\text { tissues }\end{array}$ & $\begin{array}{l}\text { tissue shrinkage at high } \\
\text { concentrations }\end{array}$ & $\begin{array}{l}\text { neutral buffered } \\
\text { formalin }\end{array}$ & $\begin{array}{l}\text { Li et al. } 2015 ; \\
\text { Bribiesca-Contreras } \\
\quad \text { \& Sellers } 2017\end{array}$ \\
\hline Lugol's iodine $\left(\mathrm{I}_{2} \mathrm{KI}\right)$ & $\begin{array}{l}\text { glycogen, lipids } \\
\text { (carbohydrates) }\end{array}$ & $\begin{array}{c}\text { tissue shrinkage at high } \\
\text { concentrations, may } \\
\text { overstain some mineralised } \\
\text { tissues }\end{array}$ & water & Gignac \& Kley 2014 \\
\hline $\begin{array}{l}\text { Gold (Bodian } \\
\text { impregnation) }\end{array}$ & neuron (neuropils) & $\begin{array}{l}\text { penetration at } 100 \mu \mathrm{m}, \\
\text { complex creation of the } \\
\text { staining solution }\end{array}$ & $\begin{array}{l}\text { complex, see } \\
\text { Mizutani \& } \\
\text { Suzuki (2012) }\end{array}$ & $\begin{array}{l}\text { Mizutani \& Suzuki } \\
\text { 2012; Mizutani et al. } \\
2007\end{array}$ \\
\hline $\begin{array}{l}\text { Silver (Golgi silver } \\
\text { impregnation) }\end{array}$ & $\begin{array}{c}\text { neuron, cerebral } \\
\text { cortex, proteins in } \\
\text { polyacrylamide gels, lung } \\
\text { tissue }\end{array}$ & $\begin{array}{l}\text { visualisation only } 10 \% \text { of } \\
\text { neuron, complex creation of } \\
\text { the staining solution }\end{array}$ & $\begin{array}{l}\text { complex, see } \\
\text { Mizutani \& } \\
\text { Suzuki (2012) }\end{array}$ & $\begin{array}{l}\text { Mizutani \& Suzuki } \\
\text { 2012; Paterson } \text { et al. } \\
2014\end{array}$ \\
\hline Platinum & neuron (substitute of gold) & $\begin{array}{l}\text { complex creation of the } \\
\text { staining solution }\end{array}$ & $\begin{array}{l}\text { complex, see } \\
\text { Mizutani et al. } \\
\text { (2008a, 2008b) }\end{array}$ & $\begin{array}{l}\text { Mizutani et al. 2008a, } \\
2008 \mathrm{~b}\end{array}$ \\
\hline $\begin{array}{l}\text { Mercury(II) chloride } \\
\quad\left(\mathrm{HgCl}_{2}\right)\end{array}$ & $\begin{array}{c}\text { cerebral cortex tissue, } \\
\text { muscle, fibrous collagen } \\
\text { tissue, ligaments, large } \\
\text { blood vessels }\end{array}$ & slow penetration & $\begin{array}{l}\text { complex, see } \\
\text { Mizutani et al. } \\
\text { (2009) }\end{array}$ & $\begin{array}{l}\text { Pauwels et al. 2013; } \\
\text { Mizutani et al. } 2009\end{array}$ \\
\hline Lead & $\begin{array}{l}\text { muscle, fibrous collagen } \\
\text { tissue }\end{array}$ & $\begin{array}{l}\text { precipitations in and around } \\
\text { structures }\end{array}$ & water & $\begin{array}{l}\text { Faraj et al. 2009; } \\
\text { Pauwels et al. } \\
\text { 2013; Kamenz \& } \\
\text { Weidemann } 2009\end{array}$ \\
\hline $\begin{array}{l}\text { Barium based (e.g., } \\
\left.\qquad \mathrm{BaSO}_{4}, \mathrm{BaCl}_{2}\right)\end{array}$ & $\begin{array}{l}\text { biofilm in porous media, } \\
\text { fibrous collagen tissue }\end{array}$ & $\begin{array}{l}\text { precipitations in and around } \\
\text { bone structure }\end{array}$ & water & $\begin{array}{l}\text { Davit et al. 2011; } \\
\text { Pauwels et al. } 2013\end{array}$ \\
\hline Iron based (e.g. $\mathrm{FeCl}_{3}$ ) & nucleic acids, proteins & $\begin{array}{c}\text { slow penetration, dissolution } \\
\text { of bone structure }\end{array}$ & water & $\begin{array}{l}\text { Pauwels et al. 2013; } \\
\text { Paterson et al. } 2014\end{array}$ \\
\hline $\begin{array}{c}\text { Hexamethyldisilizane } \\
\text { (HMDS) }\end{array}$ & $\begin{array}{c}\text { removes water from } \\
\text { tissues, increasing clarity } \\
\text { of boundaries between air } \\
\text { and tissue }\end{array}$ & $\begin{array}{l}\text { possible internal tissue } \\
\text { damage, renders specimens } \\
\text { fragile, may react with metal } \\
\text { stains previously used on } \\
\text { specimen }\end{array}$ & air & $\begin{array}{l}\text { Alba-Tercedor \& } \\
\text { Sánchez-Tocino 2011; } \\
\text { Paterson et al. } 2014\end{array}$ \\
\hline
\end{tabular}


Table 1 (continued).

\begin{tabular}{ccccc}
\hline Contrast agent & Tissue & Limitations & Dissolved in & References \\
\hline Zinc chloride $\left(\mathrm{ZnCl}_{2}\right)$ & $\begin{array}{c}\text { muscle, fibrous collagen } \\
\text { tissue }\end{array}$ & slow penetration & water & Pauwels et al. 2013 \\
\hline $\begin{array}{c}\text { Ammonium } \\
\text { molybdate tetrahydrate } \\
\left(\mathrm{NH}_{4}\right)_{2} \mathrm{MoO}_{4}\end{array}$ & $\begin{array}{c}\text { muscle, fibrous collagen } \\
\text { tissue }\end{array}$ & slow penetration & water & Pauwels et al. 2013 \\
\hline $\begin{array}{c}\text { Sodium tungstate } \\
\left(\mathrm{Na}_{2} \mathrm{WO}_{4}\right)\end{array}$ & $\begin{array}{c}\text { muscle, fibrous collagen } \\
\text { tissue }\end{array}$ & unknown & water & $\begin{array}{c}\text { Pauwels } \text { et al. 2013; } \\
\text { Kim } \text { et al. 2015 }\end{array}$ \\
\hline $\begin{array}{c}\text { Gallocyanin- } \\
\text { chromalum }\end{array}$ & nucleic acids & low overall contrast & water & $\begin{array}{c}\text { Schreibman } 1997 ; \\
\text { Metscher 2009b }\end{array}$ \\
\hline
\end{tabular}

included in the specimen tissue the minimum, but still effective concentration of acidic agents needs to be identified prior to staining, or alternatively other non-acidic agents should be used for contrast enhancement.

Contrast agents dissolved in ethanol (e.g., PTA, iodine) may cause shrinkage when used on specimens which are not stored in ethanol. In such cases a water based contrast enhancement agent may be more appropriate and safe to use; otherwise a gradual dehydration procedure needs to be followed prior to staining. Shrinkage due to desiccation may destroy the sample and in addition it can create movement artefacts during scanning (Johnson et al. 2011). Samples can also be critical point dried, freeze-dried or chemically dried with Hexamethyldisilazane (HMDS) and then scanned without any surrounding liquid medium in order to increase the contrast between tissues. Generally, these methods can dry the samples without inducing morphological changes to the tissues, although they might render the sample fragile or cause moderate shrinkage (Faulwetter et al. 2013b; Pauwels et al. 2013; Krings et al. 2017). The drying can be performed both on stained and unstained samples, but care needs to be taken with HMDS, which may react chemically if applied in combination with certain stains (e.g., silver stains, see Paterson et al. 2014).

Specimens from museum collections usually need to remain completely intact, and thus any alterations that might be caused by the staining procedure need to be taken into account. Besides the alterations previously mentioned (decalcification, shrinkage) the removal of the contrast enhancement agents after scanning is an additional important consideration before using this method on museum specimens. The stability of the stain might depend on the fixation or preservation medium, the age of the specimen, and the type of tissue (e.g., chitin, muscles, calcified tissue) (Schmidbaur et al. 2015). Iodine staining was successfully removed from insects (Alba-Tercedor 2012) and from millipedes (Akkari et al. 2015) by re-immersion into $70 \%$ ethanol, and from polychaete tissues using $96 \%$ ethanol for 48 hours, while PTA stain was removed using $\mathrm{NaOH}$ for 6 hours (Schmidbaur et al. 2015). However, treatment of iodine stained tissues with sodium thiosulfate and of PTA stained tissues with $0.1 \mathrm{M}$ phosphate buffer ( $\mathrm{pH} 8.9$ ) destained the samples even more than their initial unstained status, thus indicating an actual alteration of the tissues characteristics (Schmidbaur et al. 2015). Gignac et al. (2016) also indicated that destaining does not really restore a specimen to its original chemical state, e.g., when iodine stained tissues are treated with sodium thiosulfate, the iodine is transformed to iodide, which is colorless and remains in the tissues.

\subsubsection{Botanical samples}

Micro-CT scanning of botanical specimens is usually restricted to non-pressed specimens, i.e., those that possess a certain three-dimensional structure. Technically, pressed herbarium specimens can also 
KEKLIKOGLOU K. et al., Micro-computed tomography for natural history specimens

be scanned under certain circumstances, but the results will likely be of limited research value. Suitable botanical specimens include soft tissues (e.g., flowers, leaves, buds, fruits) and hard tissues (e.g., stems, twigs, roots, nuts). Generally, ligneous hard tissues are more easy to scan than soft tissues, as they do not dry out easily and provide a good contrast due to the higher density of their secondary cell walls. Plant tissues can often be scanned without any need for fixing, preservation of sample, or application of contrast agents. Fruits, nuts, thick roots and wooden structures and even flowers, if provided with a liquid environment around the stem (van der Niet et al. 2010) can often simply be scanned fresh without any further preparation. However, if a high resolution of these tissues is required, smaller pieces may be cut from the original sample to decrease the camera-sample distance. Such smaller samples dry out faster and thus may require additional means to prevent dehydration such as wrapping in plastic or Parafilm ${ }^{\circledR}$, scanning in a sealed container, or coating the specimen with additional materials (e.g., Korte \& Porembski 2011).

Soft tissues are often transparent to X-rays and may require the use of contrast agents, as well as additional preparation to prevent shrinkage during scanning due to desiccation (Stuppy et al. 2003; Leroux et al. 2009). If the sample needs to be fixed and/or stained, a variety of solutions are available. Common fixatives for botanical samples are FAA (formalin-acetic acid-alcohol), formaldehyde, or ethanol (e.g., Leroux et al. 2009; Staedler et al. 2013). However, ethanol has been shown to induce shrinkage in plant tissues and might not be appropriate for all types of studies, e.g., vascular cylinders might be compressed or ruptured if ethanol is used (Leroux et al. 2009).

Samples fixed in a liquid substance will usually require being scanned in a liquid environment as well, either fully submerged or sealed in a small chamber to prevent drying out. Alternatively, samples can be embedded in agarose or paraplast, but as this will introduce noise and reduce contrast these media are only recommended for samples that are either naturally dense or have been treated with heavy-metal stains (see Table 2).

Table 2 (continued on next page). Overview of the most common contrast agents (heavy metals) for soft botanical tissues.

\begin{tabular}{|c|c|c|}
\hline Contrast agents & Effects and limitations & References \\
\hline Uranyl acetate & $\begin{array}{l}\text { toxic, only slight increase of contrast values compared to other } \\
\text { stains }\end{array}$ & $\begin{array}{l}\text { Leroux et al. } 2009 ; \\
\text { Staedler } \text { et al. } 2013\end{array}$ \\
\hline Iodine & no noticeable contrast increase & $\begin{array}{l}\text { Korte \& Porembski } \\
\text { 2011; Staedler et al. } \\
2013\end{array}$ \\
\hline $\begin{array}{l}\text { Potassium } \\
\text { permanganate }\end{array}$ & $\begin{array}{l}\text { permanganate caused visible damage to samples as soon as after } 2 \mathrm{~d} \\
\text { infiltration (Fig. } 5 \mathrm{~F} \text { ), and infiltration for } 8 \text { days usually resulted in } \\
\text { total sample loss; occasionally increased the contrast of only a part } \\
\text { of the sample, leaving other parts unchanged }\end{array}$ & Staedler et al. 2013 \\
\hline Lugol's solution & causes visible sample damage after several weeks of infiltration & Staedler et al. 2013 \\
\hline $\begin{array}{l}\text { Phosphotungstate } \\
\text { (PTA) }\end{array}$ & $\begin{array}{l}\text { highest contrast increase on the more cytoplasm- and protein-rich } \\
\text { tissues (ovules, ovary wall and pollen) }\end{array}$ & Staedler et al. 2013 \\
\hline Lead citrate & $\begin{array}{l}\text { work best on vacuolated tissues (petals, sepals and filaments); } \\
\text { highest contrast increase on the more cytoplasm- and protein-rich } \\
\text { tissues (ovules, ovary wall and pollen); precipitates in presence } \\
\text { of carbon dioxide in the form of lead carbonate crystals [38] that } \\
\text { accumulate on the surface of the sample }\end{array}$ & Staedler et al. 2013 \\
\hline Bismuth tartrate & $\begin{array}{l}\text { work best on vacuolated tissues (petals, sepals and filaments); } \\
\text { highest contrast increase on the more cytoplasm- and protein-rich } \\
\text { tissues (ovules, ovary wall and pollen); rendered the samples very } \\
\text { delicate and easy to damage }\end{array}$ & Staedler et al. 2013 \\
\hline
\end{tabular}


Table 2 (continued).

\begin{tabular}{|c|c|c|}
\hline Contrast agents & Effects and limitations & References \\
\hline Osmium tetroxide & $\begin{array}{l}\text { work best on vacuolated tissues (petals, sepals and filaments); } \\
\text { highest contrast increase on the more cytoplasm- and protein-rich } \\
\text { tissues (ovules, ovary wall and pollen); poor penetration for en-bloc } \\
\text { infiltration } \rightarrow \text { best on open and thin material (open buds, tissues } \\
\text { only a few cells thick) }\end{array}$ & Staedler et al. 2013 \\
\hline Iron diamine & samples could not be detected (no increase in contrast) & Staedler et al. 2013 \\
\hline
\end{tabular}

A variety of contrast enhancing heavy metal stains has been tested on plant tissues, to varying levels of success and with different tissue specificities. A thorough comparative study has been performed by Staedler et al. (2013). Table 2 summarises the application areas and effects of various heavy metal stains.

\subsubsection{Palaeontological samples}

Palaeontological specimens (i.e., fossils) may need to be isolated from rock matrices before scanning in cases where the specimen and the matrix show a similar X-ray absorption. Fossils can be extracted from their matrix mechanically by washing, wet sieving and the use of several tools such as needles, knives and chisels (Green 2001; Sutton 2008) or chemically, depending on the chemical composition of the surrounding matrix. For example, fossils embedded in calcareous rocks can be isolated using sulphuric acid (Vodrážka 2009), phosphatic fossils can be extracted using acetic acid (Jeppsson et al. 1999) and plant mesofossils in clay or mud stones can be extracted in water with sodium carbonate, potassium hydroxide or hydrogen peroxide (Wellman \& Axe 1999). The maceration procedures of palaeontological specimens usually involve physical breakdown, removal of calcareous material, removal of siliceous material, removal of other inorganic material, oxidation, sieving, cleaning and concentrating the organic rich residue (Green 2001). A detailed manual for extraction techniques in palaeontology can be found in Green (2001). However, potential damage of the specimen using chemical extraction methods must be considered (Sutton 2008). If there is no possibility of extraction of the fossil and the contrast between the specimen and the matrix is too low, a synchrotron phase-contrast imaging may be a better solution for the visualisation of such specimens (Sutton et al. 2014). Specimens in amber can be scanned directly without any particular preparation.

\subsubsection{Geological (mineral) samples}

Strictly speaking, the only preparation that is absolutely necessary for scanning geological specimens is to ensure that the object fits inside the field of view and that it does not move during the scan (Ketcham \& Carlson 2001). Since the full scan field is a cylinder, it is suggested to scan an object of cylindrical geometry, either by using a coring drill to obtain a cylindrical sample of the geological material being scanned, or by packing the object in a cylindrical container with either X-ray-transparent filler or with material of similar density (Ketcham \& Carlson 2001).

For some applications the sample can also be treated to enhance the contrast between the different structures. Examples include injecting soils and reservoir rocks with NaI-laced fluids to reveal fluid-flow characteristics (Wellington \& Vinegar 1987), injecting sandstones with Woods metal to map out the finescale permeability, immersion in caesium chloride to visualise connected porosity of crystalline rocks (Kuva et al. 2018) and soaking samples in water to emphasize areas of differing permeability, which can help to reveal fossils (Zinsmeister \& De Nooyer 1996).

\subsection{Scanning containers and scanning mediums}

At the end of the staining procedure, the sample is removed from the solution and washed in distilled water or ethanol (depending on the contrast agent solvent). However, Staedler et al. (2018) immediately fixed the plant specimens with 1\% PTA in formalin-acetic acid-alcohol (PTA/FAA) without washing 
the samples with ethanol. If specimens are stained or naturally dense they can be scanned in liquid or gel media (e.g., water, ethanol, agarose). If they are to be scanned in air, excess fluid should be blotted away in order to prevent motion artefacts during scanning due to the accumulation of fluid on the bottom of the container (Gignac et al. 2016). Then, the specimen is placed in a sample holder and stabilised in a vertical position for the scanning procedure. The choice of the appropriate sample holder depends on the sample size, the morphology of the specimen and the material of the sample holder.

Micro-CT companies usually provide a range of several sample holders to the users. It is essential that specimens do not move, settle or wobble during scanning; even a small shift can ruin the image data and necessitate a re-scan (Sutton et al. 2014). Nevertheless, users often create new sample holders according to their needs in order to prevent movement of the specimen during scanning. Glass containers are rarely used since they have a high X-ray absorption; however, glass presents a higher contrast with the background compared to the plastic container, therefore allowing more accurate delineation of the region of interest which corresponds to the inner part of the container (Paquit et al. 2011). Materials such as polypropylene, styrofoam and florist foam have low X-ray absorption, making them ideal as sample holders. It is also quite common to use pins and clips in order to stabilise the specimen; however, care must be taken in order not to damage museum samples. Sealable plastic bags from which air has been pressed out can be used to prevent drying of specimens (Gignac et al. 2016). Small specimens can be placed in test tubes, aliquot tubes, plastic straws or micropipette tips $(200,1000,5000 \mu \mathrm{L})$ (Metscher 2011; Alba-Tercedor 2012; Staedler et al. 2013; Gignac et al. 2016) (Figs 7, 8B-D). The bottom end of pipette tips can be cut off in order to drag down the samples and to stabilise them by entering a preparation needle (Staedler et al. 2018). Paraffin wax can be used in the lower end of the pipette tip as a seal and to stabilise the sample, while Parafilm ${ }^{\circledR}$ can be used to seal the upper end of the tip (Staedler et al. 2013; Fig 8C). The lower end of pipette tips can also be heat-sealed if they need to be filled with a liquid medium surrounding the specimen. Batch scanning can help to scan large numbers of small samples at the same time and thus decrease overall scanning time: individual samples mounted in pipette
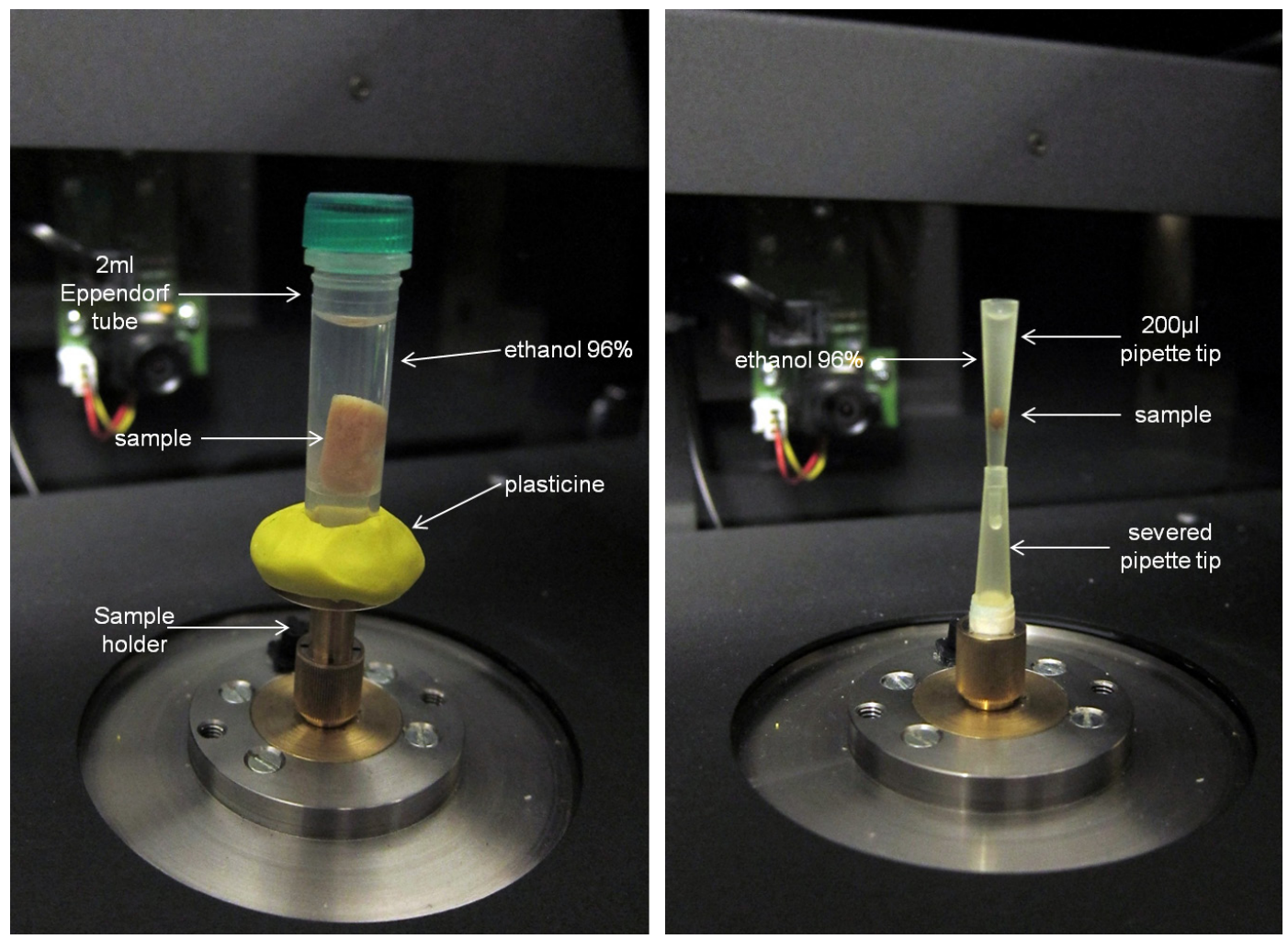

Fig. 7. Setup of scanning containers. Images by HCMR micro-CT lab. 
tips can be mounted in a $1 \mathrm{ml}$ syringe tube and stabilised with resin or epoxy glue (Staedler et al. 2013, 2018; Fig. 8).

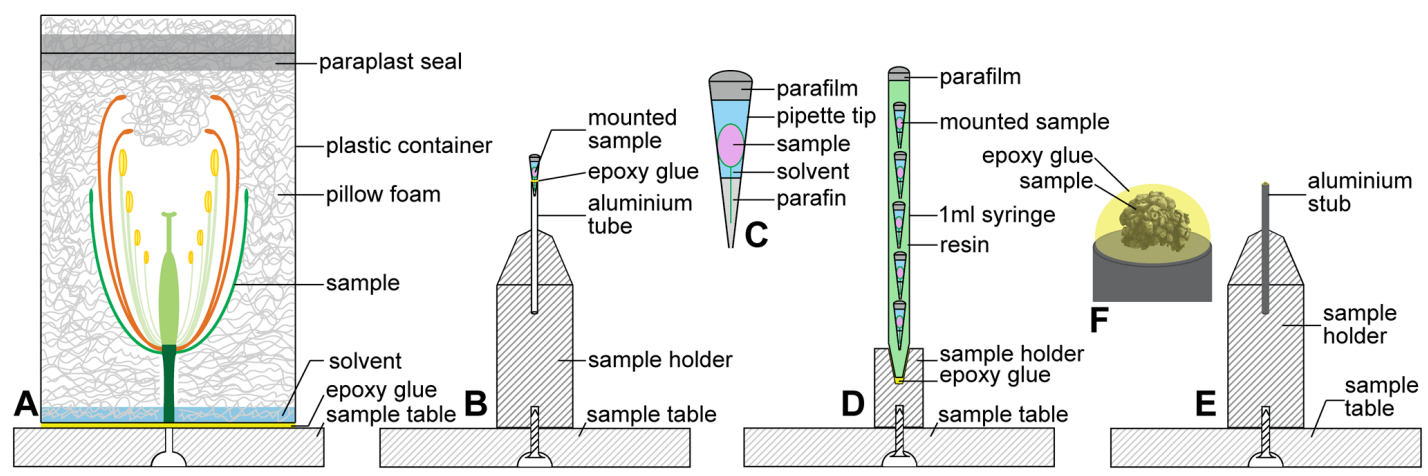

Fig. 8. Sample mounting techniques for plant specimens of different sizes. A. Large samples ( $>10 \mathrm{~mm})$. B-D. Medium-sized samples $(1-10 \mathrm{~mm})$. E-F. Small samples $(<1 \mathrm{~mm})$. Image from Staedler et al. 2013, reproduced under a CC-BY license.

Specimens can be submerged in fluid (e.g., formalin, ethanol or water) during scanning to prevent desiccation (Gignac et al. 2016). Ethanol is less dense than water and provides greater tissue contrast in comparison to water (Metscher 2009a). Scanning small specimens within a liquid medium prevents them from getting stuck on the container's walls. Care must be taken to remove bubbles from the liquid medium in the sample holder as they can create a blurring effect (Metscher 2009a). Agarose can also be used as a scanning medium for small specimens (Metscher 2011). The use of air as a scanning medium gives excellent results for unstained or dried specimens or for studying the internal structure of specimens. However, scanning in air is not recommended when studying the external morphology of specimens previously immersed in liquid, since the small amount of liquid that will remain on the external surface will be visible as an additional layer in the reconstruction images (Fig. 9).

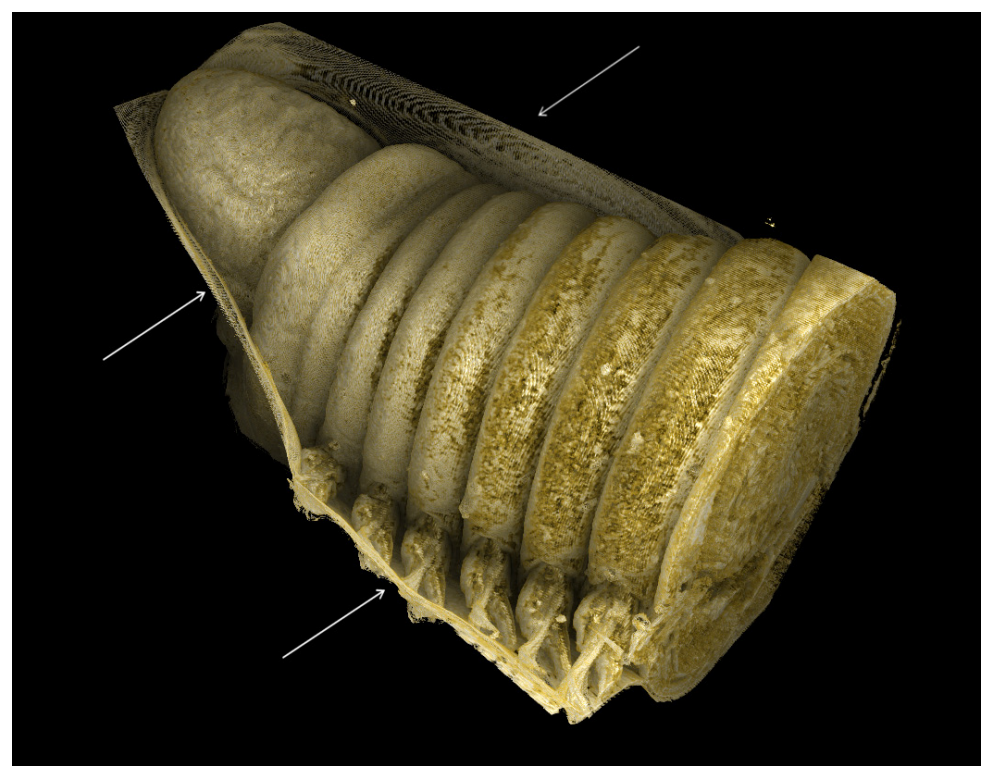

Fig. 9. External morphology of the polychaete Lumbrineris latreilli Audouin \& Milne Edwards, 1834. Specimen had been preserved in ethanol and was subsequently blotted dry on a tissue and scanned in air. The remaining ethanol (shown by arrows) can be observed clinging to the anterior end of the polychaete. Image by HCMR micro-CT lab, CC-BY Sarah Faulwetter. 
Large plant samples $(>10 \mathrm{~mm})$ can be mounted in acrylic foam and scanned in a solvent atmosphere, whereas medium-sized plant samples are best scanned immersed in the solvent (Staedler et al. 2013; Fig. 8A-B). Red and brown algae are easily scanned after having being dried in air. Scanning of the more filamentous green algae and seagrasses within a liquid medium creates artefacts, because their leaves have a low X-ray absorption. Personal experiments showed that staining with PTA or iodine could not improve the resolution. Chemical drying of filamentous algae (e.g., HMDS) and scanning in air can have satisfactory results, but due to shrinkage this method is not suggested when aiming to study the internal leaf structure.

Palaeontological specimens are usually scanned in air. However, a celluloid film in organic water-soluble glue is suitable as a scanning medium for isolated microfossils (Görög et al. 2012). Isolated specimens can be also fixed on plastic holders by nail polish (or any other reversible fixing matter). For combined SEM and micro-CT studies SEM holders can be used. However, fixation of fossils must be on a thick layer of nail polish to avoid contact or close placement of the observed fossil and the metallic holder, which can occlude the view of the sample. Larger specimens are fixed in specially prepared holders made of plastic or polystyrene. The main concern is to prevent potential movements of the fossil during the radiography process. Sutton et al. (2014) mentioned that different X-ray penetration between the different axes of a palaeontological sample could cause noise and artefacts and they suggest to bury the specimens in a substance such as flour for low density samples and sand for more dense samples.

\subsection{Scanning process}

Scanning settings differ in terms of voltage, exposure time, magnification and resolution depending on the scope of study, the material of the specimen, the specimen size and the instrument used. A careful balance between all the scanning parameters is necessary to ensure an ideal result and a best practice protocol.

\subsubsection{Calibrating the system}

In order to achieve micrometer precision, the incident beam needs to be thin, focused and stable during the acquisition. This calibration of the source includes a software-driven warm-up and focusing. Depending on the scanning system, the user should set the main parameters, including the metal of the source target (if the instrument has this option), the amount of filtration, the source intensity (in $\mathrm{mA}$ ) and the source voltage (in $\mathrm{kV}$ ). The source voltage should be set up in a way that the beam will have sufficient energy to penetrate the specimen and reach the detector. Furthermore, the source intensity should not be too high as the detector may be saturated. On a projection image, the dynamic range (max-min gray value) has to be maximised. A good contrast on the set of projections leads to a good contrast on the final CT image. Too much transmission will reduce the contrast between different densities, while a low transmission will increase the noise level in the images. The contrast should be checked over a complete rotation of the specimen. Adjustment of filter and voltage settings should aim at a minimum transmission between 10 and $50 \%$.

Scanning of unstained soft tissues usually does not require the use of filters, as they are characterised by a high X-ray transmission. An exception could be a sample which is characterised by a combination of soft and dense structures (e.g., a vertebrate organism), where the use of a filter may be helpful. Dense structures, such as bones, shells and other calcified structures, are characterised by a high X-ray absorption, as they contain elements with high atomic number (Schambach et al. 2010). Such structures appear dark on the images and they have low X-ray transmission, so the use of filters during scanning is necessary. These filters can be made of aluminium, copper or a combination of the two. Filters reduce artefacts caused from beam hardening effects (Meganck et al. 2009; Abel et al. 2012), while the spread of the X-ray energy distribution is reduced (see Section 3.6). However, the use of filters shifts the grayscale values downwards, resulting in less contrast between tissues (Meganck et al. 2009). Contrast between tissues can be achieved by decreasing the voltage and in addition, the use filters in cases of dense structures is recommended for artefact reduction. 


\subsubsection{Placing the specimen}

The specimen is placed on a rotating platform between the X-ray source and the detector. It has to be centred vertically and horizontally along the detector. A high-precision rotating mount may help to centre small specimens. When acquiring a specific region of interest, this region has to be centred instead of the whole specimen. The specimen must not touch either the source or the detector at any time during a complete rotation.

The magnification depends on the distance between the source, the specimen and the detector. The final image voxel size $V$ results from the equation $V=p \times s s / s d$, where $p$ is the detector pixel size, $s s$ the source to specimen distance and $s d$ the source to detector distance. The distances $s s$ and $s d$ may be automatically set by the system or may need a calibration. When the positions of the detector and the rotating platform are set, the calibration usually consists in acquiring a set of radiographs of a calibration object placed on the rotating platform. A greater magnification and resolution could decrease beam-hardening effects (see Chapter 3.6), but will increase scanning duration. A big specimen size can prevent achieving high magnification and resolution while a smaller field of view is required for the identification of the smallest structures (Dixon et al. 2018). For this reason, micro-CT datasets acquired at different resolutions can be combined in order to provide more information (Dixon et al. 2018 and examples therein).

\subsubsection{Setting up the detector parameters}

The calibration of the detector is software-driven (but may need regular initiation by the user) and includes the acquisition of two types of images:

the dark field image is the resulting image when no X-radiation is emitted. This signal comes from the dark current in the photodiodes of the detector. This image is an offset that will be subtracted from every radiograph.

the open field images are the response of the detector pixels to the incident beam when no specimen is placed in the system. The software may require a couple of images at different beam intensities or only one for the maximum beam intensity.

In case some pixels are defective, their response will strongly differ from that of their neighbouring ones. When they are detected, a defective map is built and these pixels are ignored during an acquisition. Their values are replaced by an interpolation of the values of non defective neighbouring pixels. The defect map should be computed once a month.

Several parameters can usually be changed to influence the imaging process; however, not all scanner models offer the same options. A few important parameters are listed below.

The exposure time $E$ relies on the same principle as the photographic exposure time. It controls the amount of time (in seconds) during which the X-rays will be captured. The detector should collect enough photons at each angle to ensure a good contrast on the radiograph. The effective dynamic range of the image is proportional to the exposure time if it is not saturated, and hence the short exposure results in the low signal-to-noise ratio. High density or thick specimens (e.g., fossils) will need a longer exposure time because fewer photons will be transmitted through them. However, excessively high exposure times may saturate the detector panel (i.e., raise brightness above its maximum measurable threshold). The scanning duration is obviously longer when the exposure times are longer. The use of higher voltage can result in a decrease of the exposure time.

A way to ensure a sufficient contrast without ending up with long scans is to use a binning parameter. Instead of having single cells (or pixels) collecting X-rays on the detector, the signal is acquired using 'bins' of 4 adjacent pixels (for a $2 \times 2$ binning). The X-ray flux per (binned) pixel is four times higher and the exposure time can be reduced accordingly. The pixel size and the resulting voxel size are twice as 
large in linear dimension (and the resulting volume image is $1 / 8$ as large). Binned acquisition results in a well-contrasted fast scan, but at the price of lower resolution.

An averaging parameter $A$ (frame averaging) may be set to improve the image quality. A set of images will be acquired for every angle and only the mean image will be recorded. A higher number of frames increases the signal-to-noise ratio. Therefore, it is usually recommended to increase the frame averaging for high dense samples when the signal-to-noise ratio is too low.

Depending on the detector employed, a pausing parameter $P$ can be used to prevent an afterimage effect. The detector photodiodes need a few $\mathrm{ms}$ to get cleared of the image. If the acquisition is too fast, residual information from the previous image can appear on the next image. The pausing parameter therefore helps to fully discard the signal from the previous image. It also ensures that the specimen is perfectly still after the rotation.

The number $N$ of radiographic images needed to perform a reconstruction can be estimated by measuring the maximum width $W$ of the projected specimen on a radiograph (in pixels) using the formula $N=$ $\pi \times W$ (for a $360^{\circ}$ scan; Fig. 10). Note that to determine the maximum width the specimen should be rotated, as irregularly shaped specimens may have different widths at different angles. Acquiring less than $N$ projection images will provide an incomplete dataset for the reconstruction algorithm. The reconstruction will be still possible, but its quality will be degraded.

The total scanning time $T$ (in seconds) can be computed with the following formula: $T=N \times(P+(E \times A))$.

Other scanning settings include the selection of the rotation step, random movement and $180 / 360^{\circ}$ scan. The selection of an increased rotation step is useful when the scanning duration needs to be reduced but it can result in images of reduced quality and increased noise. Random movement can be activated to reduce ring artefacts, but should not be used when the position of the samples is not secured or when the pixel sizes are very small. The full $360^{\circ}$ rotation is selected for scans where the sample consists of a combination of high dense materials inside low dense materials and helps to avoid depletion artefacts. The half $\left(180^{\circ}\right)$ rotation can be used when is it necessary to reduce the scanning time. The simultaneous scan of multiple samples (batch scan) can be used to reduce the overall scanning duration. A short scan duration is beneficial when specimens are scanned in air and therefore dehydration and shrinkage need to be avoided.
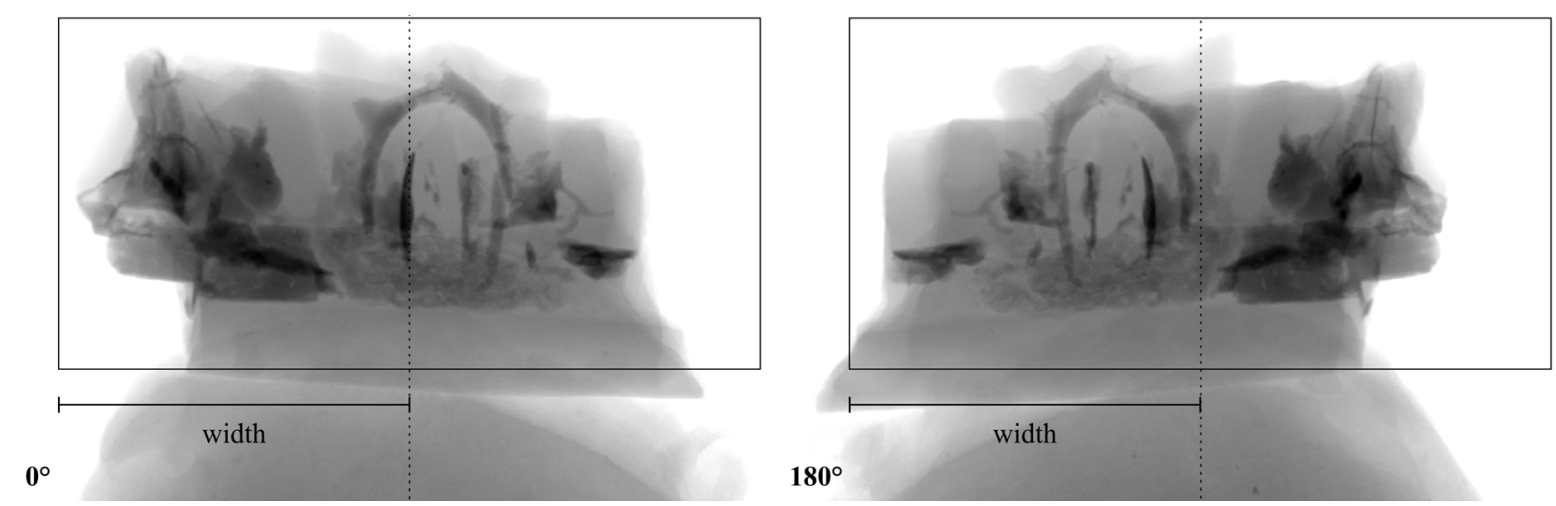

Fig. 10. Measuring the maximum width $\mathrm{W}$ (in pixels) of the projected specimen (as the distance from the rotation axis - dotted line - to the farthest end of the sample) to calculate the number of radiographs needed. This measurement is done for the angular position of the rotating platform where the projected specimen is the widest. For a complete rotation, the projected specimen would stay within the limits of the rectangle. Photo by MNHN. 
Examples regarding the scanning parameters of zoological, botanical, geological and palaeontological samples are included in Tables 3-6.

Table 3. Examples of scanning parameters for zoological samples.

\begin{tabular}{|c|c|c|c|c|c|c|}
\hline Specimen & $\begin{array}{c}\text { Voltage } \\
(\mathrm{kV})\end{array}$ & $\begin{array}{c}\text { Current } \\
(\mu \mathrm{A})\end{array}$ & Filter & System & Source & Reference \\
\hline $\begin{array}{c}\text { Alligator mississippiensis } \\
\text { (vertebrate) }\end{array}$ & $150-200$ & $130-145$ & copper & $\begin{array}{l}\text { GE phoenix } \\
\text { v|tome|x s } 240\end{array}$ & molybdenum & Gignac \& Kley 2014 \\
\hline $\begin{array}{c}\text { Dromaius novaehollandiae } \\
\text { (vertebrate) }\end{array}$ & $130-180$ & $145-190$ & copper & $\begin{array}{c}\text { GE phoenix } \\
\text { v|tome|x s240 }\end{array}$ & molybdenum & Gignac \& Kley 2014 \\
\hline Polychaeta (invertebrates) & 60 & 167 & none & SkyScan 1172 & tungsten & Faulwetter et al. 2013a \\
\hline $\begin{array}{c}\text { Apporectodea caliginosa } \\
\text { Apporectodea trapezoides } \\
\text { (anterior part - invertebrates) }\end{array}$ & $65-70$ & 100 & none & Skyscan 1173 & tungsten & Fernández et al. 2014 \\
\hline $\begin{array}{l}\text { Ommatoiulus avatar } \\
\quad \text { (invertebrate) }\end{array}$ & 60 & 67 & none & $\begin{array}{c}\text { Zeiss/Xradia } \\
\text { MicroXCT-200 }\end{array}$ & tungsten & Akkari et al. 2015 \\
\hline Snake embryos (vertebrates) & 40 & 100 & none & $\begin{array}{c}\text { Zeiss/Xradia } \\
\text { MicroXCT-200 }\end{array}$ & tungsten & van Soldt et al. 2015 \\
\hline
\end{tabular}

Table 4. Examples of scanning parameters for botanical samples.

\begin{tabular}{|c|c|c|c|c|c|c|}
\hline Specimen & $\begin{array}{c}\text { Voltage } \\
(\mathbf{k V})\end{array}$ & $\begin{array}{c}\text { Current } \\
(\mu \mathrm{A})\end{array}$ & Filter & System & Source & Reference \\
\hline $\begin{array}{c}\text { root samples of } \\
\text { Asplenium theciferum }\end{array}$ & 50 & unknown & none & $\begin{array}{c}\text { in-house nano-CT } \\
\text { at University of } \\
\text { Ghent }\end{array}$ & unknown & Leroux et al. 2009 \\
\hline Xylem of Laurus & 50 & 275 & none & $\begin{array}{c}\text { Nanotom } 180 \text { XS; } \\
\text { GE }\end{array}$ & unknown & Cochard et al. 2015 \\
\hline macadamia nuts-in-shell & 60 & unknown & unknown & SkyScan 1172 & tungsten & $\begin{array}{l}\text { Plougonven et al. } \\
2012\end{array}$ \\
\hline $\begin{array}{c}\text { Flower of Bulbophyllum } \\
\text { bicoloratum }\end{array}$ & 50 & 100 & unknown & $\begin{array}{l}\text { Xradia Micro- } \\
\text { XCT-200 }\end{array}$ & tungsten & Gamisch et al. 2013 \\
\hline
\end{tabular}

Table 5. Examples of scanning parameters for geological samples.

\begin{tabular}{|c|c|c|c|c|c|c|}
\hline Specimen & Voltage (kV) & $\underset{(\mu \mathrm{A})}{\text { Current }}$ & Filter & System & Source & Reference \\
\hline Meteorite & $120-160$ & $60-100$ & unknown & $\begin{array}{c}\text { Nikon } \\
\text { Metrology HMX ST } 225\end{array}$ & tungsten & Hezel et al. 2013 \\
\hline Meteorite & 180 & 120 & unknown & $\begin{array}{c}\text { Nikon } \\
\text { Metrology HMX ST } 225\end{array}$ & tungsten & Needham et al. 2013 \\
\hline Meteorite & 200 & 160 & unknown & $\begin{array}{c}\text { Nikon } \\
\text { Metrology HMX ST } 225\end{array}$ & tungsten & Griffin et al. 2012 \\
\hline Crystalline rock & 100 & 80 & $\begin{array}{l}\text { aluminium } \\
\text { and copper }\end{array}$ & SkyScan 1172 & tungsten & Kuva et al. 2018 \\
\hline
\end{tabular}


KEKLIKOGLOU K. et al., Micro-computed tomography for natural history specimens

Table 6. Examples of scanning parameters for palaeontological samples.

\begin{tabular}{ccccccc}
\hline Specimen & $\begin{array}{c}\text { Voltage } \\
(\mathbf{k V})\end{array}$ & $\begin{array}{c}\text { Current } \\
(\boldsymbol{\mu A})\end{array}$ & Filter & System & Source & Reference \\
\hline Fossils in amber & 60 & unknown & none & from University of Ghent & unknown Dierick et al. 2007 \\
\hline Fossils in amber & 120 & unknown & $\begin{array}{c}1 \mathrm{~mm} \\
\text { aluminium }\end{array}$ & from University of Ghent & unknown & $\begin{array}{c}\text { Kehlmaier } \text { et al. } \\
2014\end{array}$ \\
\hline $\begin{array}{c}\text { Xandarella spectaculum } \\
\text { (Arthropoda) in slab }\end{array}$ & 90 & 120 & $0.3 \mathrm{~mm} \mathrm{Cu}$ & Phoenix GE Nanotom & tungsten & Liu et al. 2015 \\
\hline $\begin{array}{c}\text { Lignified plant mesofossils } \\
\text { Charcoalified plant } \\
\text { mesofossils }\end{array}$ & 80 & 124 & $\begin{array}{c}0.5 \mathrm{~mm} \\
\text { aluminium }\end{array}$ & SkyScan 1172 & tungsten & Kvaček et al. \\
2016
\end{tabular}

\subsection{Reconstruction}

The reconstruction workflow varies among the different scanning systems as each system usually has its own software and most reconstruction steps are automated (Sutton et al. 2014). However, the setting of some reconstruction parameters is necessary and depends on the scope of the reconstruction and the scanning quality. Concerning the scanning quality, misalignment during the acquisition, noise and ring artefacts may be corrected or improved by using the appropriate reconstruction parameters.

Prior to the reconstruction procedure, some systems can check the projection images for potential movements during the scanning procedure. The alignment of the projection images may fix these movements. If sample movements cannot be corrected through the reconstruction procedure, the scanning process should be repeated.

Following the alignment of the projection images, the reconstruction software creates a histogram with the frequency the grayscale values representing the density distribution of the micro-CT dataset. The specific range of the histogram values can display different parts of the organisms (Fig. 11). Generally, the peaks in the histogram values represent different structures concerning the different densities. Dense structures such as bones and shells are represented by higher grayscale values compared to soft tissues. The user can choose to restrict the range of values, to suppress or include specific densities, in order to emphasize different structures in the reconstruction of the sample. The range of the grayscale values can also be taken into consideration in order to avoid noise and to isolate unwanted structures (e.g., sample holder).

During the reconstruction procedure, the reconstruction can be restricted to a specific area of the specimen by creating a region of interest (ROI). For example, the reconstruction of the jaws of a polychaete can be achieved by the creation of a ROI which comprises only these target structures (Fig. 12). This method 


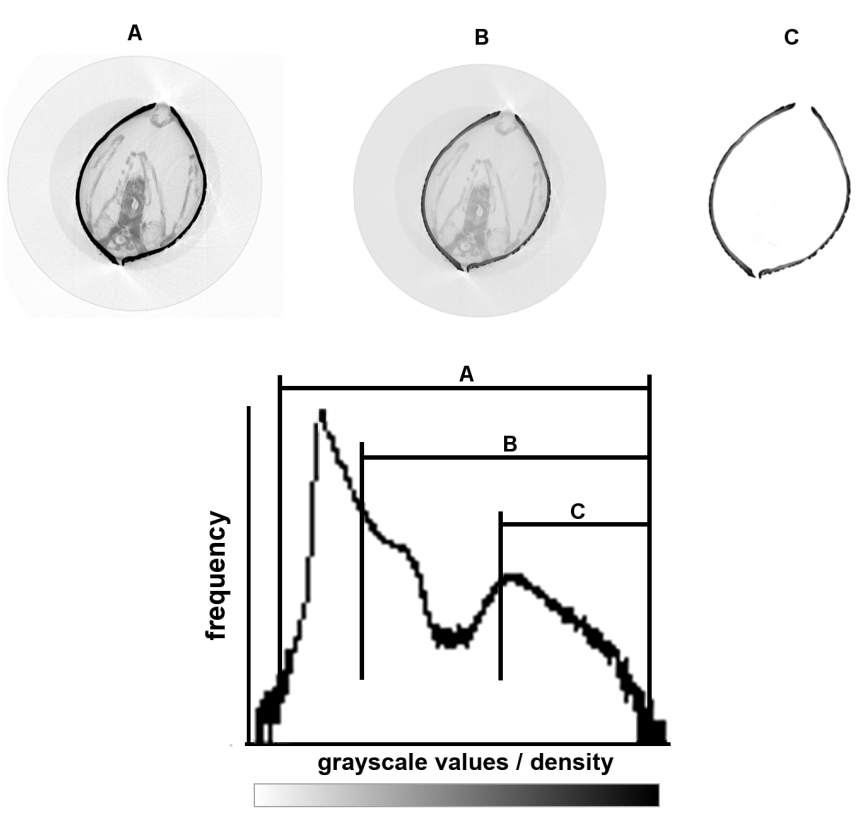

Fig. 11. Histogram of the grayscale value frequency of the scanned specimen (bivalve Musculus costulatus (Risso, 1826). Each peak represents a different structure (in terms of density) of the scanned bivalve. Bright grayscale values (representing low densities) are located at the left side of the histogram, darker values (representing high values) at the right side of the histogram. A. The selection of a range including all peaks, reveals the more detailed morphology of the bivalve (both soft/low density and hard/high density structures). B. A restricted range of histogram values removes structures with brighter values (= low densities). C. A restricted range of histogram values including only one peak reveals only the darkest values (= most dense structures) of the bivalve which correspond to the shell. Image by HCMR micro-CT lab.

can minimise the time of the reconstruction procedure and the size of the reconstructed dataset. The reconstruction duration also depends on the computational resources and capacities, the size of the dataset and the algorithm used (Sutton et al. 2014).

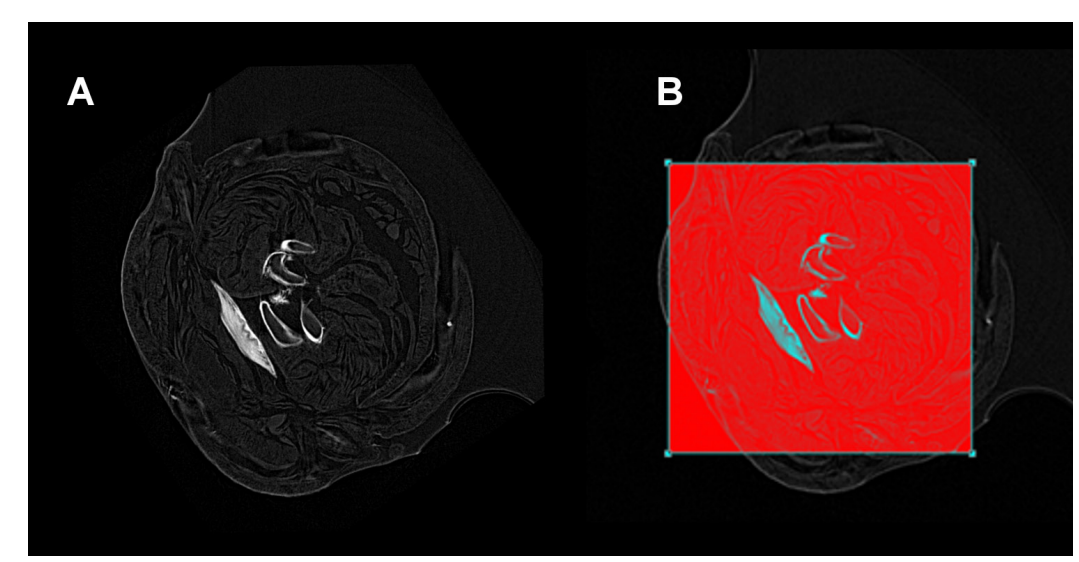

Fig. 12. Cross-section image without (A) and with (B) a selection of a region of interest (red square) for the reconstruction of polychaete jaws. Image by HCMR micro-CT lab. 
KEKLIKOGLOU K. et al., Micro-computed tomography for natural history specimens

Reconstructed data should ideally be saved without any compression or down-sampling (i.e., as 16 bit TIFF files). However, these files are large, so if storage space is an issue or data are to be shared, the creation of compressed image formats (e.g., 8 bit PNG, JPG) can be considered - but always taking into account the detail of information required for the planned analyses. The best lossless image format is TIFF as it can also store metadata (e.g., voxel size, specimen info, scan parameters); however, different systems offer different options.

\subsection{Visualisation and post-processing}

The reconstructed images can be visualized in 3D using volume rendering software. A variety of products are available (see Table 7). The creation of interactive 3D volumes allows the users to explore the dataset from any direction and to manipulate its appearance by changing the rendering parameters (Ruthensteiner et al. 2010). The 3D visualisation of specimens may be used for taxonomic purposes, as specific structures can be visualised in their original orientation and shape (see Faulwetter et al. 2013a). A volume can be visualised through volume rendering or through extracting an isosurface (Sutton et al. 2014). Details related to these visualisation methods are presented below.

Table 7 (continued on next page). 3D Volume Rendering software (modified table from Walter et al. 2010 and Abel et al. 2012).

\begin{tabular}{|c|c|c|}
\hline Software & $\begin{array}{l}\text { Licence } \\
\text { Type }\end{array}$ & URL \\
\hline Amira & commercial & www.amira.com \\
\hline $\begin{array}{c}\text { Arivis } \\
\text { (web-based } \\
\text { software) }\end{array}$ & commercial & http://vision.arivis.com/ \\
\hline BioImageXD & free & http://www.bioimagexd.net \\
\hline Blender & free & www.blender.org \\
\hline $\begin{array}{l}\text { Brain Maps } \\
\text { (web-based } \\
\text { software) }\end{array}$ & free & http://brainmaps.org \\
\hline CTVox & free & https://www.bruker.com/products/microtomography/micro-ct-software/3dsuite.html \\
\hline Dragonfly & $\begin{array}{l}\text { free licences } \\
\text { available for } \\
\text { researchers } \\
\text { with non- } \\
\text { commercial } \\
\text { activities/ } \\
\text { commercial }\end{array}$ & http://www.theobjects.com/dragonfly/ \\
\hline DRISHTI & free & http://sf.anu.edu.au/Vizlab/drishti/ \\
\hline $\begin{array}{l}\text { Fiji (Is Just } \\
\text { ImageJ) }\end{array}$ & free & http://fiji.sc/ \\
\hline Huygens & commercial & http://www.svi.nl \\
\hline ImageJ & free & https://imagej.nih.gov/ij/ \\
\hline Image-Pro & commercial & http://www.mediacy.com \\
\hline Imaris & commercial & http://www.bitplane.com/ \\
\hline
\end{tabular}


Table 7 (continued).

\begin{tabular}{|c|c|c|}
\hline Software & $\begin{array}{l}\text { Licence } \\
\text { Type }\end{array}$ & URL \\
\hline Mimics & commercial & www.materialise.com/mimics \\
\hline Octopus & commercial & https://octopusimaging.eu/ \\
\hline $\begin{array}{l}\text { Open } \\
\text { Inventor }\end{array}$ & commercial & http://www.openinventor.com/ \\
\hline Simpleware & commercial & www.simpleware.com \\
\hline $\begin{array}{l}\text { Slice:Drop } \\
\text { (web-based } \\
\text { software) }\end{array}$ & free & http://slicedrop.com/ \\
\hline SPIERS & free & https://spiers-software.org/ \\
\hline tomviz & free & http://www.tomviz.org/ \\
\hline $\begin{array}{l}\text { VG Studio } \\
\text { Max }\end{array}$ & commercial & www.volumegraphics.com \\
\hline Volocity & commercial & http://www.improvision.com \\
\hline VolViewer & free & http://cmpdartsvr3.cmp.uea.ac.uk/wiki/BanghamLab/index.php/VolViewer \\
\hline VTK & free & http://www.vtk.org/ \\
\hline
\end{tabular}

The post-processing of micro-CT datasets can include simple analyses (e.g., density estimation through the calculation of the grayscale values, porosity, thickness) or advanced morphometric analysis (e.g., geometric morphometrics). The latter requires segmentation of the image (isolation of features of interest and creation of a geometric surface model - see below).

\subsubsection{Volume Rendering}

The volume rendering procedure assigns colour and opacity to each voxel according to the grayscale values of the sample (Kniss et al. 2002). Some ranges of the histogram can be set to be transparent, mostly to exclude the voxels of the surrounding medium or container. Whenever a structure can be well-defined by its density/grey level on an histogram, it is easily isolated on a volume rendering image by setting everything else transparent (Fig. 13). Advanced rendering parameters give the user the opportunity to apply artificial colours and brightness in order to create a realistic/useful rendering.

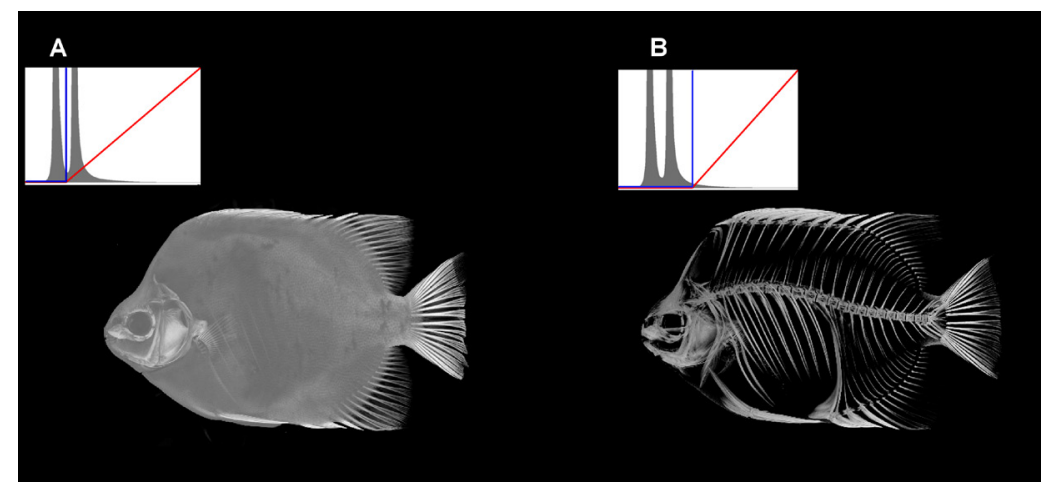

Fig. 13. Volume rendering of a specimen where the gray level coding for (A) air and (B) air+soft tissues are transparent. Histograms of the grayscale values are included for both images where the selected threshold is indicated by the blue line and the opacity curve is indicated by the red line. Image by MNHN. 


\subsubsection{Isosurface rendering}

An isosurface is a geometric mesh connecting 3D points of a constant intensity within a volume (Fig. 14). The thresholding procedure (or binarisation) of the slices, where the grayscale images are transformed to black and white images, is important for the creation of the 3D model while all voxels are connected above the thresholding value (for software options see Table 8). The 3D model construction is based on the marching cubes algorithm (Lorensen \& Cline 1987). The calculation might be timeconsuming, depending on the size of the data and the computer capacities. The resulting triangle-mesh can be visualised and it is suitable for analysis (e.g., shape analysis, volume, geometric morphometrics, or finite-element modelling). For software packages related to 3D analysis see Table 9.

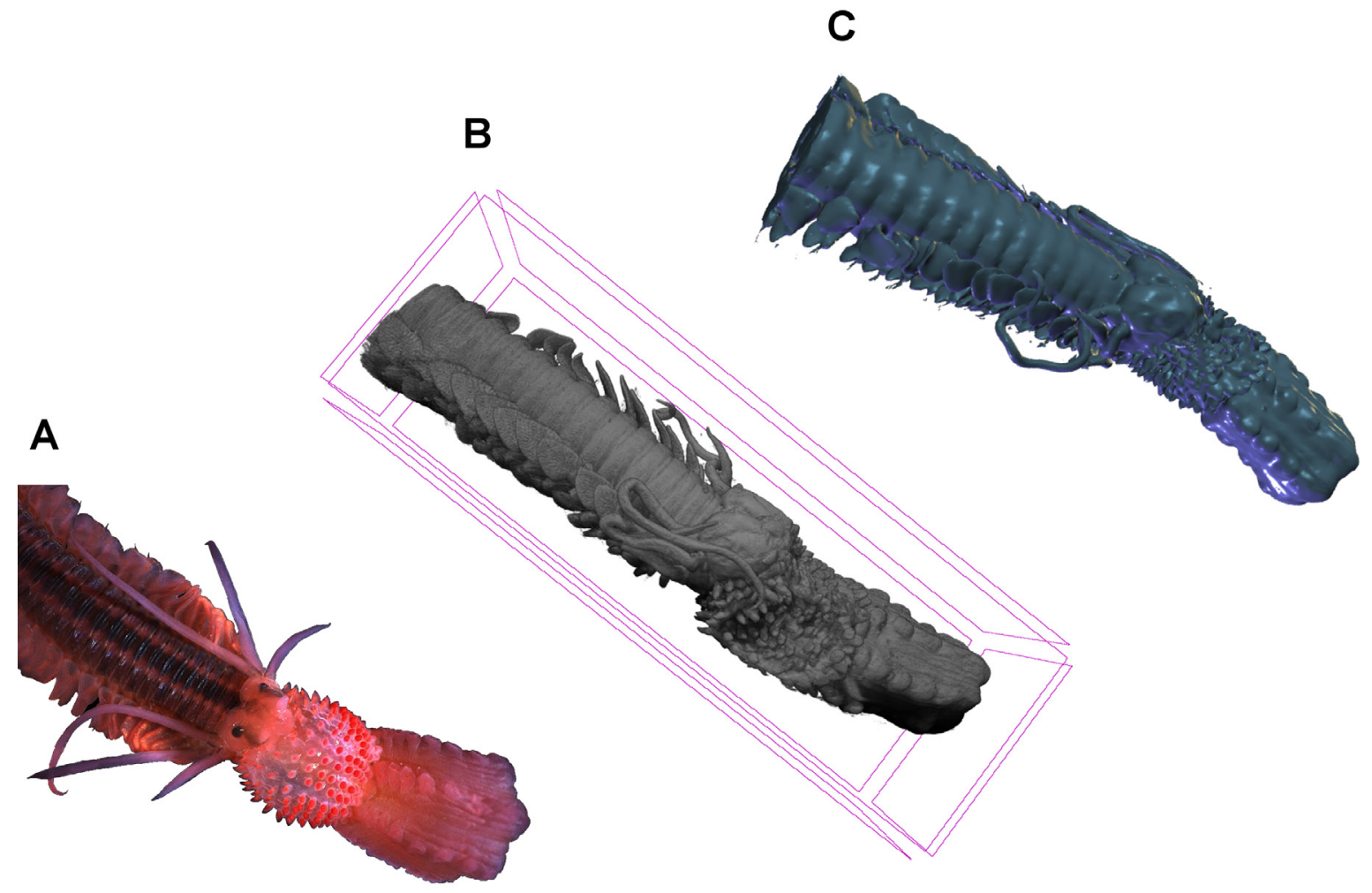

Fig. 14. A marine worm (Polychaeta, Phyllodocidae, Phyllodoce). A. Photograph (CC-BY-SA Hans Hillewaert). B. Volume rendering. C. Isosurface rendering. Images B and C by the HCMR micro-CT lab.

Table 8. Segmentation software (modified table from Walter et al. 2010 and Abel et al. 2012).

\begin{tabular}{ccc}
\hline Software & Licence Type & URL \\
\hline Amira & commercial & www.amira.com \\
BioImageXD & free & http://www.bioimagexd.net \\
Dragonfly & free licences available & http://www.theobjects.com/dragonfly/ \\
& for researchers with non- & \\
commercial activities/ & Commercial & \\
DRISHTI & free & http://sf.anu.edu.au/Vizlab/drishti/ \\
ilasti & free & http://ilastik.org/ \\
Mimics & commercial & www.materialise.com/mimics \\
Octopus & commercial & https://octopusimaging.eu/ \\
Simpleware & commercial & www.simpleware.com \\
SPIERS & free & https://spiers-software.org/ \\
VG Studio Max & commercial & www.volumegraphics.com \\
\hline
\end{tabular}


Table 9. 2D/3D analysis software (modified table from Walter et al. 2010 and Abel et al. 2012).

\begin{tabular}{ccc}
\hline Software & Licence Type & URL \\
\hline Amira & commercial & www.amira.com \\
Arivis (web-based software) & commercial & http://vision.arivis.com/ \\
BioImageXD & free & http://www.bioimagexd.net \\
Fiji (Is Just ImageJ) & free & http://fiji.sc/ \\
GOM Inspect & free & http://www.gom.com/nl/3d-software/gom-inspect.html \\
Huygens & commercial & http://www.svi.nl \\
ImageJ & free & https://imagej.nih.gov/ij/ \\
Image-Pro & commercial & http://www.mediacy.com \\
Imaris & commercial & http://www.bitplane.com/ \\
MeshLab & free & http://www.meshlab.net/ \\
MorphoJ & free & www.simpleware.com \\
Simpleware & commercial & www.stratovan.com \\
Stratovan Checkpoint & commercial & http://www.tomviz.org/ \\
tomviz & free & www.volumegraphics.com \\
VG Studio Max & commercial & http://www.improvision.com \\
Volocity & commercial & http://www.vtk.org/ \\
VTK & free &
\end{tabular}

\subsubsection{Segmentation}

The main drawbacks of volume rendering and isosurface rendering are that neighbouring structures cannot be discerned if their densities are too homogeneous and their borders not contrasted enough. In these cases it is difficult to discern a specific structure among voxels of similar grey value (for example: visualising specific organs within the body where all organs are of similar densities). Segmentation is the process of selecting ('labelling') voxels of interest in order to visualise them separately of the whole dataset (or to generate a 3D model of these user-defined structures) (Fig. 15). The segmentation procedure

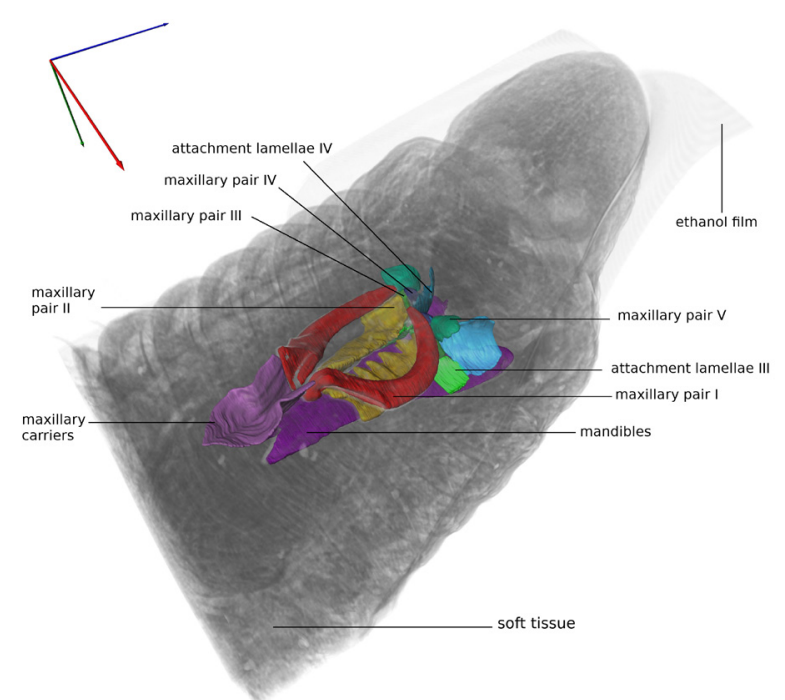

Fig. 15. Polychaete specimen (Lumbrineris latreillii Audouin \& Milne Edwards, 1834) in a composite rendering showing the location of organs of interest within the animal. Soft tissues are volume-rendered, jaws were segmented individually and surface-rendered in different colours. The coloured arrows at the upper left corner indicate the orientation of the scanned specimen in three views ( $\mathrm{x}, \mathrm{y}$ and $\mathrm{z}$ axes). Image by HCMR micro-CT lab, CC-BY Sarah Faulwetter. 
can be achieved either manually, semi-automatically or automatically - a large number of algorithms exist for automatic segmentation. Segmentation can be used to include the removal of unwanted objects, to highlight certain structures with colour or to virtually dissect the sample (Sutton et al. 2014).

\subsection{Troubleshooting}

Micro-CT scanning is prone to artefacts which can degrade the quality of micro-CT images and the degree of image distortion can make the micro-CT datasets unusable (Barrett \& Keat 2004). Artefacts can be created by several processes during the acquisition of micro-CT images. The most common artefacts which are encountered on the micro-CT images are: a) beam hardening artefacts, b) ring artefacts, c) noise, d) partial volume, e) motion artefacts and f) metal artefacts. The avoidance or the correction of these artefacts is important to improve the resulting micro-CT image, but sometimes the effects may be irreversible, so that the scan will have to be repeated.

\subsubsection{Beam hardening artefacts}

Beam hardening usually occurs when an object consists of different parts with different attenuation coefficients (especially with high densities). This refers to the fact that the beam which penetrates the object becomes harder (increased average energy) as the lower energy X-rays are absorbed more rapidly than the higher-energy X-rays (Barrett \& Keat 2004). The result of the beam hardening effect is that the object appears to be denser (increased brightness) at the edges than the centre (decreased brightness) creating cupping artefacts (Roche et al. 2010; Abel et al. 2012; Fig. 16). A simple approach to solve this

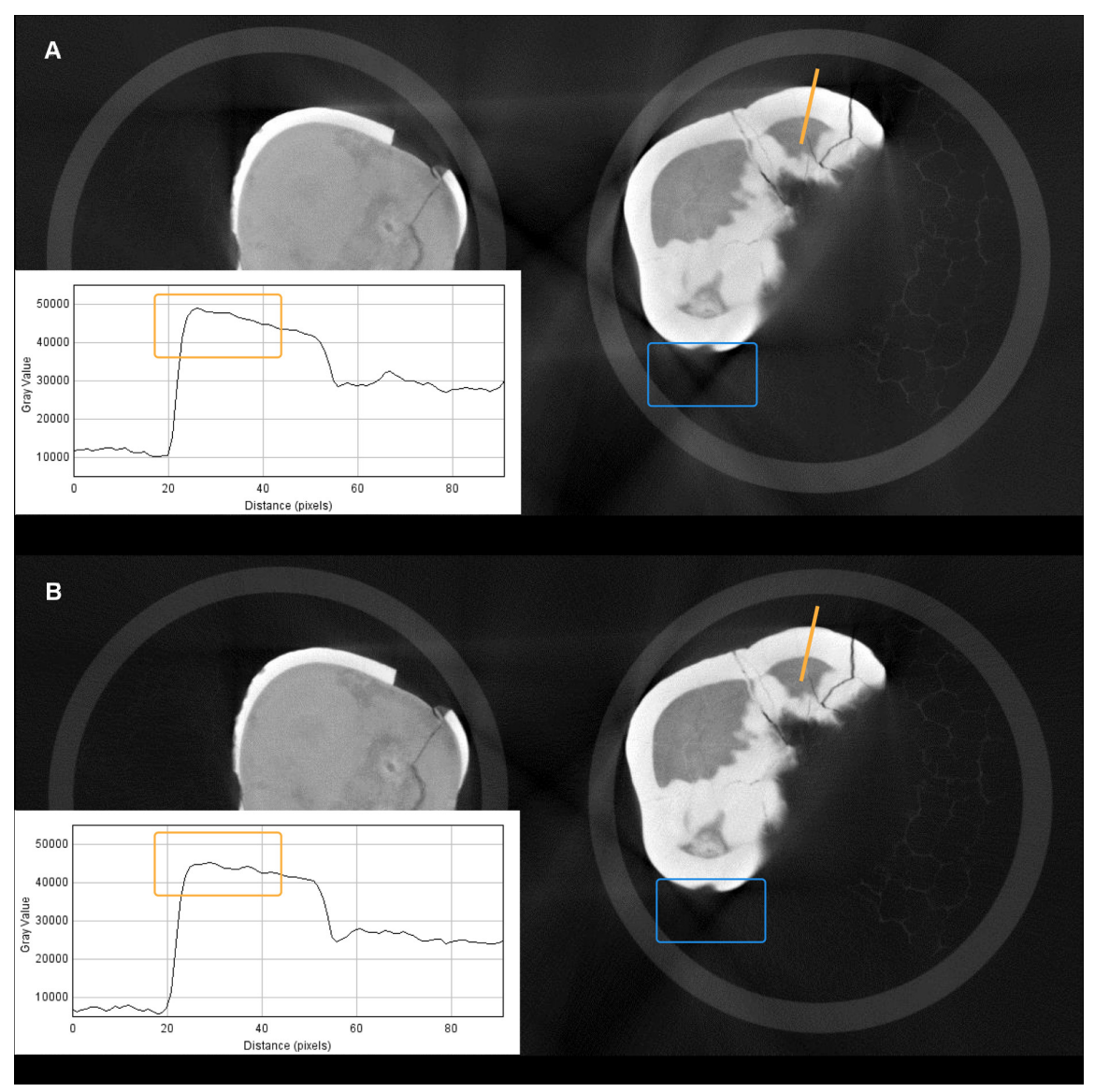

Fig. 16. Scan of teeth without (A) and with (B) software beam hardening correction. In yellow, cupping artefacts increase the reconstructed density at the edges (see plots of gray values along the yellow lines) and decrease it in the centre of the object. In blue, streaking artefacts create dark or white lines between structures. Images by MNHN. 
problem is to use an X-ray beam of higher energy to ensure that beam hardening is negligible, but this solution is applicable only for small samples (Ketcham \& Carlson 2001). Beam hardening effects can also create streaking artefacts which are shown as dark and light streaks around very dense structures (Fig. 16). According to Sutton et al. (2014), the reduction of the streaking artefacts can be achieved by using different scanning media (e.g., water, sand) which act as a filter and smoothen the effect, as well as through an increase of projection images and a decrease of the exposure time. Beam hardening artefacts can also be minimised by using a metal filter (e.g., aluminium, copper) (Ketcham \& Carlson 2001; Barrett \& Keat 2004; Meganck et al. 2009; Abel et al. 2012; Sutton et al. 2014), which removes the low energy photons during the scanning procedure. However, this can attenuate the X-ray intensity to some degree, thus leading to greater image noise unless longer acquisition times are used (Ketcham \& Carlson 2001). Concerning cupping artefacts, the use of a combination of aluminium and copper filters is the most effective way for the reduction of these kind of artefacts (Meganck et al. 2009; Hamba et al. 2012). Beam hardening effects can be also reduced to some extent by using the beam hardening correction of the reconstruction software, if provided (Fig. 16).

\subsubsection{Ring artefacts}

Ring artefacts are light and dark circles (circular artefacts) on the reconstructed images (Fig. 17A) as a result of calibration deficiency of the detector where the X-ray sensitivities of the detector elements are distinguished (Davis \& Elliott 1997; Barrett \& Keat 2004; Sutton et al. 2014). In some occasions ring artefacts are caused by changes in temperature or beam strength, and this can be solved by carefully controlling experimental conditions or by frequent recalibrations (Ketcham \& Carlson 2001; Barrett \& Keat 2004). The reduction of ring artefacts can be also achieved through a flat-field correction (Barrett \& Keat 2004; Sutton et al. 2014), although such artefacts may still persist as a result of the beam hardening effect and the high-spatial-frequency variations in the thickness of the scintillator detector (Vågberg et al. 2017). Furthermore, depending on the system, ring artefacts can be reduced by using the selection of the 'ring artefacts correction' during the reconstruction (Fig. 17B) or the selection of the 'random movement' option during the scanning procedure (Sutton et al. 2014).

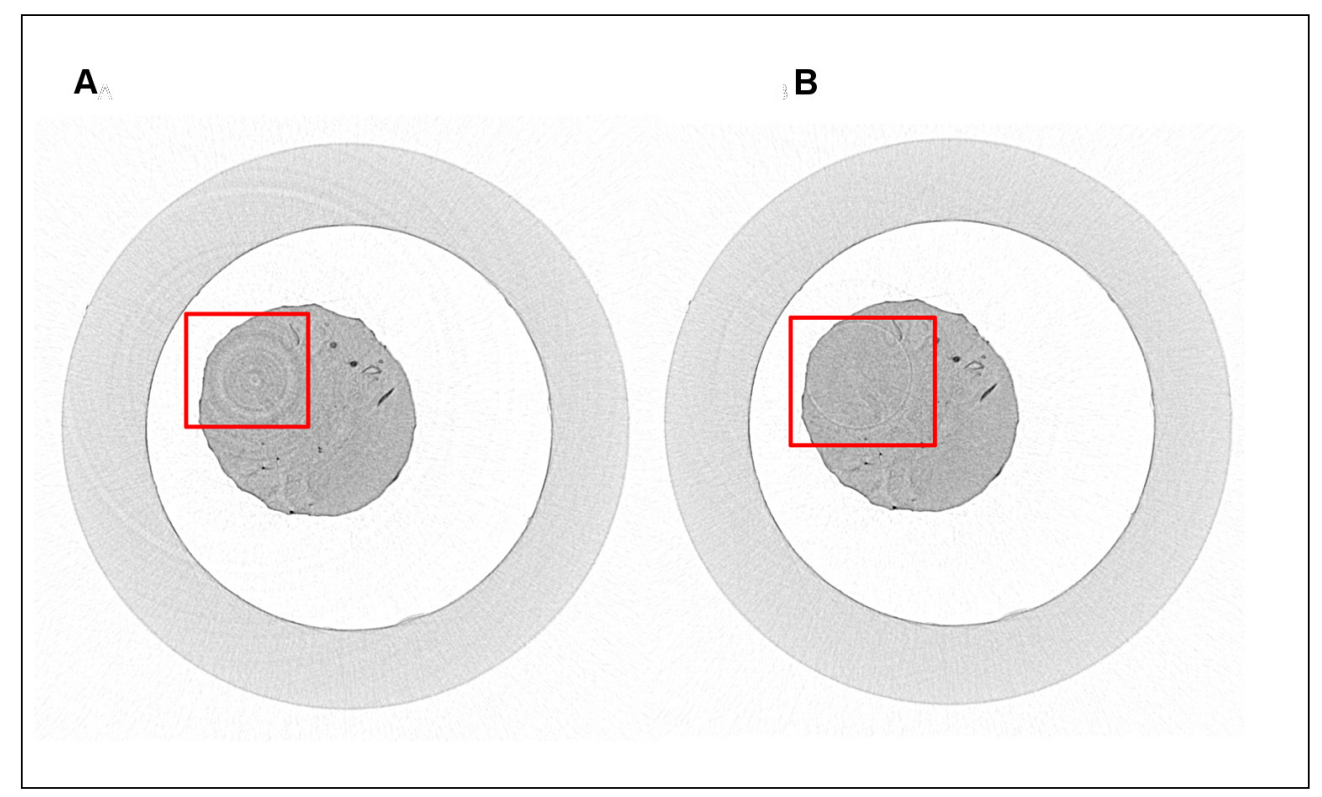

Fig. 17. Scan of a marine worm (polychaete) without (A) and with (B) ring artefacts correction during the reconstruction procedure. The red square indicates the presence of ring artefacts which are reduced in (B) following the ring artefacts correction. Images by HCMR micro-CT lab. 


\subsubsection{Noise}

Noise (or quantum noise) is caused due to statistical error of low photon counts and it is presented as scattered bright and dark streaks in the slices (Fig. 18A) (Boas \& Fleischmann 2012). This kind of artefact can be minimised by using higher beam intensities (increased $\mathrm{mAs}$ ) which result in better signal-to-noise ratios (SNR) (Boas \& Fleischmann 2012; Sutton et al. 2014). Furthermore, an increased source voltage (Kachelrieß 2008; Hsieh 2009; Boas \& Fleischmann 2012) and an augmented number of projection images (Sutton et al. 2014) may reduce noise. Low exposure times can result in high noise, so increased exposure times and the use of filters may reduce these artefacts in dense samples (Sutton et al. 2014). Furthermore, frame averaging improves the SNR (Sutton et al. 2014). Noise can also be created by physical limitations of the system (e.g., electronic noise in the detector panel), but the reduction of this kind of noise by the operators is difficult (Hsieh 2009). Additional noise can be introduced during the reconstruction procedure. The selection of appropriate reconstruction algorithms and parameters (e.g., selection of Gaussian filter) can minimise the noise effect (Fig. 18B) (Hsieh 2009; Sutton et al. 2014).

A

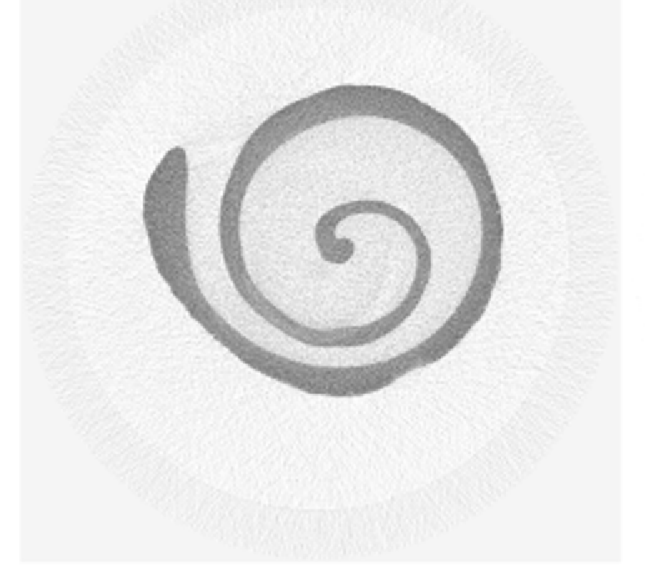

B

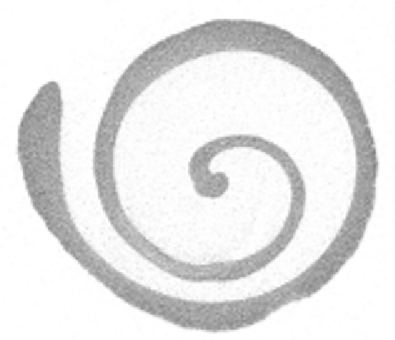

Fig. 18. Scan of a bivalve with (A) and without (B) noise after the selection of the appropriate parameters during the reconstruction procedure. Images by HCMR micro-CT lab.

\subsubsection{Partial volume}

The partial volume effect creates artefacts through the fact that the average attenuation coefficient within a voxel represents an average grayscale value (Barrett \& Keat 2004; Abel et al. 2012; Sutton et al. 2014). The result of the partial volume effect is shading artefacts in the image (Barrett \& Keat 2004). Sutton et al. (2014) mention that if anatomical structures are close to the voxel size, then the partial volume effect will be more intense. The use of maximum magnification can decrease partial volume artefacts, but if this effect still remains after adjusting the magnification the use of a detector with greater dimensions may be needed (Sutton et al. 2014).

\subsubsection{Motion artefacts}

Sample motion during the image acquisition creates artefacts which appear as shades or streaks in the reconstructed images (Fig. 19) (Barrett \& Keat 2004). Motion artefacts can be reduced by calculating and correcting the $\mathrm{X} / \mathrm{Y}$ pixel shifts during the reconstruction procedure (Salmon et al. 2009). However, ideally, sample movements should be minimised by stabilising the sample in an appropriate sample holder (see Section 3.2). Similar artefacts can also occur as a result of sample shrinkage; in this case an $\mathrm{X} / \mathrm{Y}$ correction cannot be performed. The use of a liquid as a scanning medium or the use of Parafilm ${ }^{\circledR}$ can prevent sample shrinkage and therefore the resulting artefacts. 


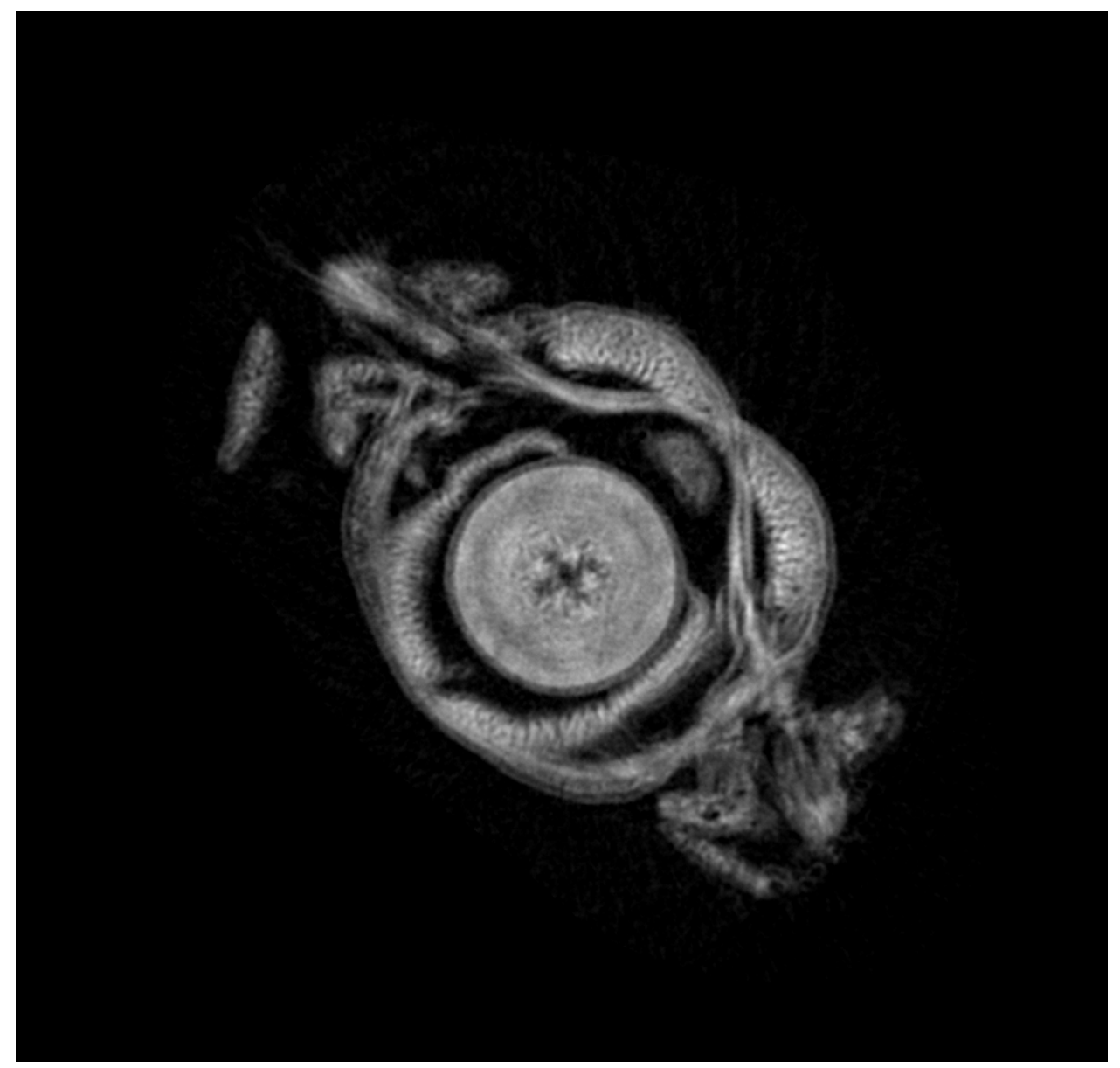

Fig. 19. Scan of a marine worm (polychaete) with motion artefacts. The structures are not clearly defined due to specimen movement during the scanning procedure. Image by HCMR micro-CT lab.

\subsubsection{Metal artefacts}

Micro-CT imaging of natural history specimens can be challenging when the specimen contains metal particles which are visualised in the form of a 'metal artefact'. These metal particles are common in many geological samples as natural inclusions or part of the chemical composition of the sample. However, metal is also used as a support medium when skeleton parts are assembled in their natural structure. Metal pins are also used to mount entomological samples to mount these in an insect drawer. The metal artefact is especially observed when there is a large difference between the attenuation of the metal part and the sample of interest (Figs 20-21). Usually, the artefact is less obvious when scanning at higher $\mathrm{kVp}$ or when the difference in attenuation is less pronounced (e.g., bone and metal) (Fig. 22). Scanning at high $\mathrm{kVp}$ is not possible for soft bodied samples like insects. Metal artefacts may be the result of several causes like noise, beam hardening, non-linear partial volume effect, and scatter (de Man 2001). Visually, the metal artefact looks like an overexposed part on the micro-CT image slice with many streaks and star-like bright lines (Figs 20B, 22B). In some cases reconstruction software contains a built-in Metal-Deletion-Technique (Boas \& Fleischmann 2012) that reduces or completely removes the metal artefact. Tests with this algorithm in the Xact reconstruction software (RX Solutions) proved successful for a leopard skull bearing metal screws, but failed for a scan with a pinned beetle. 

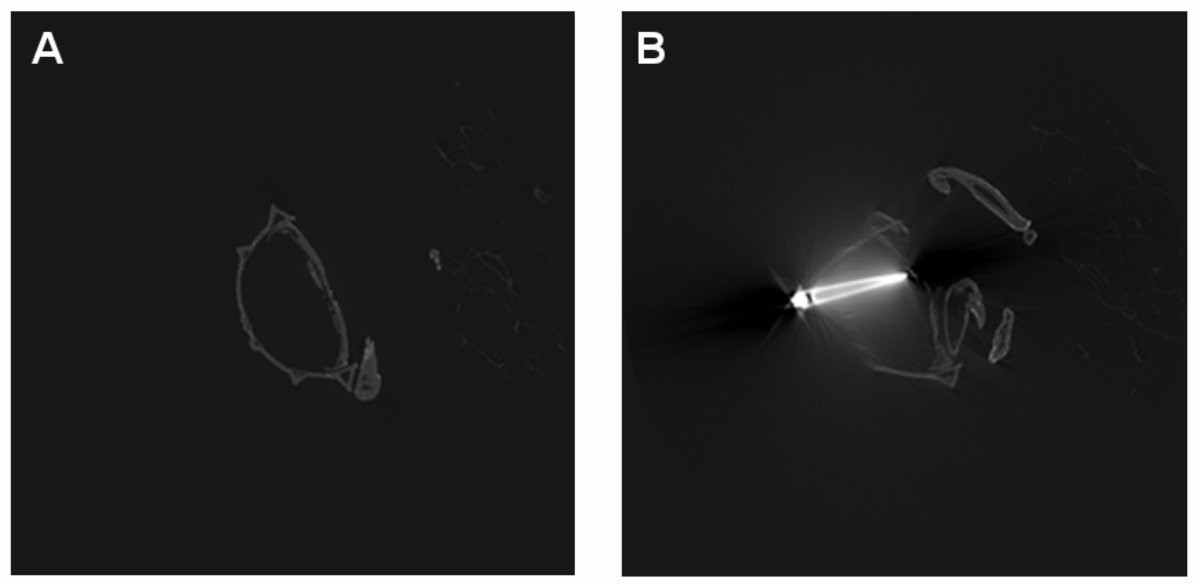

Fig. 20. A. Part of a pinned Omorgus gigas (Harold, 1872) beetle a few hundred slices away from the pinned area. B. The normal morphology of the beetle is no longer visible due to the metal artefact appearing in the pinned area. Image by the Royal Belgian Institute of Natural Sciences (RBINS) / DIGIT-3 Belspo, CC-BY-NC-ND Jonathan Brecko.
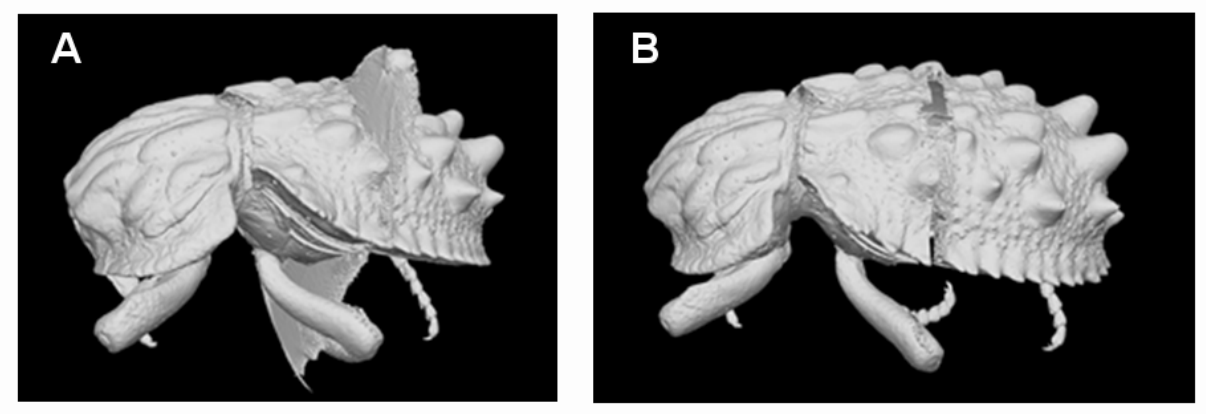

Fig. 21. A. 3D model of the Omorgus gigas (Harold, 1872) beetle after a quick segmentation, including the metal artefact. B. 3D model of the same specimen after manual removal of the pin in the Dragonfly software (http://www.theobjects.com/dragonfly/). Clicking on the image opens the 3D model. Photo courtesy of the Royal Belgian Institute of Natural Sciences (RBINS) / DIGIT-3 Belspo, CC-BY-NC-ND Jonathan Brecko.
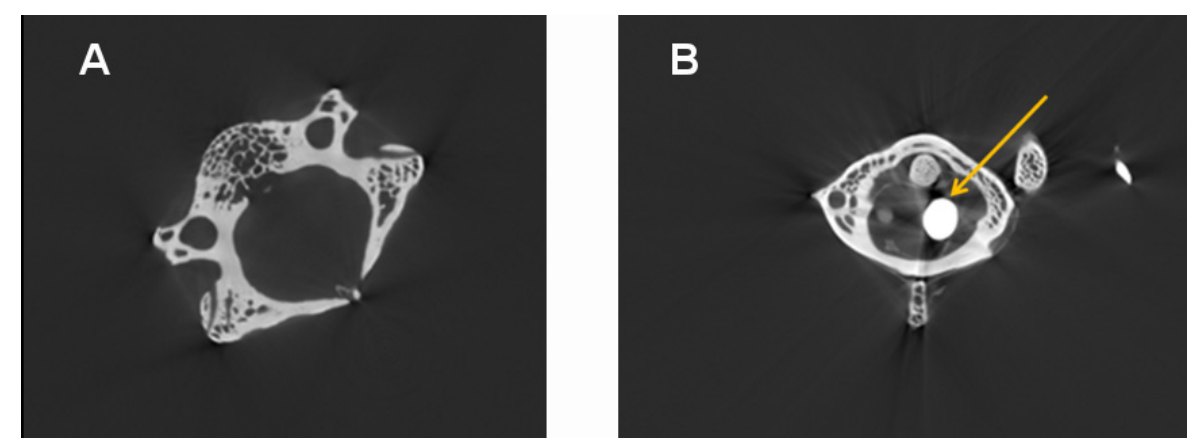

Fig. 22. A. Monkey vertebra without metal support. B. A metal artefact (yellow arrow) is created due to the metal rod used to support a series of vertebrae on a mounted skeleton. Photo courtesy of the Royal Belgian Institute of Natural Sciences (RBINS)/DIGIT-3 Belspo, CC-BY-NC-ND Jonathan Brecko. 


\section{Use cases}

\subsection{Zoological samples}

The identification of zoological specimens is usually based on external, internal or on the combination of external and internal morphological characteristics. The 3D nature of the different structures is important for the classification of the organisms (Boistel et al. 2011; Faulwetter et al. 2013a). The creation of 3D models at a resolution of a few microns, the accessibility of micro-CT scanners, the low cost and the use of these datasets for morphometric, functional, ecological and developmental analysis reveal the utility of this technology for zoological studies (Faulwetter et al. 2013a; Fernández et al. 2014). According to Boistel et al. (2011), different scans - which are referred to as 'morphoscans' - should be included in a reliable 3D library with reference models (or gold standards) including intra-species variations and key references established by the community.

Micro-CT is characterised as a non-destructive technology, but potential damage of genetic material due to the X-ray radiation should be considered. Concerning preserved zoological specimens, studies on the effect of X-rays on bird skins (Paredes et al. 2012) and on invertebrates (Faulwetter et al. 2013a) revealed that exposure to X-rays did not cause damage to the specimen DNA, at least not to the investigated gene (i.e., 16S rRNA). Paredes et al. (2012) speculated that the preservation procedures used on the specimen may cause more damage to the DNA quality than the X-rays. Similar studies on the effects of the microCT technology on the DNA quality of a variety of organisms in different preservation conditions should be carried out before this technology can be safely used on valuable museum specimens and especially on type material (Paredes et al. 2012; Faulwetter et al. 2013a).

Micro-CT technology has been used in morphological and anatomical studies, such as the creation of a 3D interactive model of the jaw musculature of the American alligator, from which several researchers who are interested in feeding ecology and evolutionary morphology have profited (Holliday et al. 2013). Embryonic imaging as well as the quantitative analysis of the organs and tissues of chick embryos has been achieved through micro-CT (Kim et al. 2011), revealing the benefits of this technique for developmental biology (Metscher 2009b; Kim et al. 2011).

Another example of the use of micro-CT in zoological specimens is the assessment of the effects of ocean acidification on calcified structures of marine invertebrates, revealing the utility of this technique in ecological studies (Keklikoglou et al. 2015; Chatzinikolaou et al. 2017). Furthermore, Faulwetter et al. (2013a) have shown advantages of the technique for taxonomic studies through the 3D visualisation of polychaetes. The latter authors demonstrated the importance of the micro-CT technique in the creation of 'cybertypes', as a potential addition to the current type material of the collections, with implications in our traditional ways of carrying out systematics and for the International Code of Zoological Nomenclature (Godfray 2007).

\subsection{Botanical samples}

Micro-computed tomography can be still considered as an under-used technique in botanical research (Staedler et al. 2013). Botanical samples often contain soft tissues such as leaves, flowers or fruit tissues with a low X-ray attenuation, and imaging of such parts may require contrast enhancement to increase the quality of images. Best results are usually obtained from samples that consist of different tissue types with different densities, such as seeds, fruits, woods, etc, as these allow a better discrimination between individual organs (Leroux et al. 2009). Usually, secondary cell walls are more easily detected than soft tissues (Leroux et al. 2009).

The technique is very suitable for visualising delicate anatomical structures such as embryos, meristems, flowers, and even individual cell walls (Dhondt et al. 2010; van der Niet et al. 2010; Johnson et al. 2011). 
KEKLIKOGLOU K. et al., Micro-computed tomography for natural history specimens

The applications for micro-CT in botanical research are very diverse. Among the earliest applications of micro-CT in botany were root studies (e.g., Crestana et al. 1986), and the literature in this field is abundant (see review in Mooney et al. 2012). Roots, but also whole plants, can in many cases also be scanned in vivo. This has allowed researchers to perform growth and repair experiments in living studies, and even record time-lapse 3D images (e.g., Brodersen et al. 2010, 2013; Dhondt et al. 2010; Paquit et al. 2011; Knipfer et al. 2015). However, the ionising effect of $\mathrm{X}$-rays has to be taken into account, which may cause growth inhibition or untypical developments (e.g., Dhondt et al. 2010), so in vivo studies need to be planned carefully.

Micro-CT has furthermore been used for morphometric analyses of plants, which form the background for e.g., comparative morphology (van der Niet et al. 2010; Wang et al. 2015), food production (Li et al. 2011) or to address evolutionary questions (Miller \& Venable 2003). Due to the high resolution of modern micro-CT scanners - and the large and well-defined cell structures in many plant tissues - cellular structures can often be discerned in plant scans. These fine structures aid in understanding physiological and functional processes in plants (Gamisch et al. 2013; Pajor et al. 2013; McElrone et al. 2013), as cellular architecture profoundly affects the physiology of plant tissues (Pajor et al. 2013). Finally, apart from studying soft plant tissues, micro-CT has been extensively used to study the density and porosity of woods, including plant hydraulics and xylem studies (e.g., Brodersen et al. 2011; Cochard et al. 2015; see also Brodersen \& Roddy 2016 for an overview).

\subsection{Palaeontological samples}

Morphological information on fragile, rare and valuable palaeontological specimens has become accessible through micro-CT imaging (Abel et al. 2012). Palaeontological specimens are usually embedded in sediment or in amber. The investigation of these inclusions using scanning electron microscopy (SEM) or transmission electron microscopy (TEM) provides high quality images, but these methods require the destruction of the material (Greco et al. 2011; Görög et al. 2012). The internal structure of palaeontological specimens is frequently important for their taxonomic classification (Görög et al. 2012). For palaeontological objects, such as pyritised fossils which are difficult to conserve, microCT seems to be the only solution for the visualisation of their internal morphology, as this technique does not require the removal of the conservation matrix (DeVore et al. 2006). Palaeontological specimens in sedimentary rock or amber matrix can thus be 'virtually' extracted using micro-CT (Abel et al. 2012; Konietsko-Meier \& Schmitt 2013).

The choice of micro-CT for visualising palaeontological specimens should take into account the required energy that is needed to penetrate such dense samples as well as the required contrast between specimen and matrix (Sutton et al. 2014). Furthermore, the size of the fossils and the size of the structures to be visualised might be an important constraint for the choice of this technology. Micro-CT is suitable for the majority of fossils whose size ranges from $2 \mathrm{~mm}$ to $200 \mathrm{~mm}$ (depending on the micro-CT system) (Sutton et al. 2014). According to Rahman \& Smith (2014), micro-CT is suitable for fossil groups such as vertebrates, invertebrates, plants, microfossils, trace fossils and for a variety of their preservation types (including altered preservation, cast, mold, original and permineralisation).

The use of micro-CT in palaeontological collections is mostly related to the 3D visualisation and 3D analysis of specimens for taxonomic (e.g., Penney et al. 2007; Briguglio \& Benedetti 2012), evolutionary (e.g., Koenigswald et al. 2011; Garwood et al. 2014), histological (e.g., Konietsko-Meier \& Schmitt 2013) and palaeoecological purposes (e.g., Wan et al. 2014; Yang et al. 2015). Micro-CT has been used to study the fossil inclusions of amber and this technology has revealed features and internal structures which are important for the taxonomical classification of such specimens (Dierick et al. 2007; Kvaček et al. 2018a). Furthermore, an example of the utility of micro-CT in morphological and paleobiological studies is the study of the skeleton of an Eocene-Oligocene primate which allowed 
the visualisation of features related to the life history, locomotion and diet (Franzen et al. 2009). The digital restoration of the 3D morphology of the Ediacara fossil Pteridinium simplex Gürich, 1930 using micro-CT revealed information concerning its ecology and its phylogenetic affinity (Meyer et al. 2014). Micro-CT has successfully been used for studies of plant and insect mesofossils (Kvaček et al. 2016; Heřmanová et al. 2017; Kvaček \& Heřmanová 2017; Kvaček et al. 2018a, 2018b). Application of the method for lignified fossil plants embedded in sediment is not always easy. However, if the fossil is not completely compressed and contrast between the fossil and the sediment is high enough, it can be successful (Kvaček \& Heřmanová 2017; Kvaček et al. 2018b). Charcoalified plant fossils consist of charred organic matter and air, providing excellent contrast between the air filling internal parts of cells and the charcoalified cell walls. The use of micro-CT to study the anatomy of fruits, seeds and insect eggs has been proved as a fast and user friendly tool for investigating their internal structures, which are crucial for their interpretation (Kvaček et al. 2016; Kvaček \& Heřmanová 2017).

\subsection{Geological (mineral) samples}

Geological applications of X-ray computed tomography include interior examination of one-of-a-kind fossils or meteorites, textural analysis of igneous and metamorphic rocks, geometric description and quantification of porosity and permeability in rocks and soils, and any other application demanding three-dimensional data that formerly required physical serial sectioning (Ketcham \& Carlson 2001). Micro-CT scans of rocks are virtual models with grayscale values representing primarily the X-ray attenuation of different minerals or other features, such as pores, in the rock (Wellington \& Vinegar 1987). This method offers the means to study the internal materials and geometrics of rare or valuable specimens, such as meteorites, fossils or archaeological artefacts, which should not be destructively sectioned. Even in cases where sectioning is allowed, the use of micro-CT can eliminate the time spent and the laboriousness traditionally faced during the serial sectioning of geological specimens. The digital character of a micro-CT dataset allows interactive manipulation of the data, better visualisation and animation and easier measurement of dimensions (Carlson et al. 2003; Abel et al. 2011).

Micro-CT is a useful tool for the visualization of fractures, pores or layers which are characterised by different densities (Cnudde et al. 2006). According to Stanley (1992), among the types of rocks that can be examined using micro-CT are:

- igneous rocks formed by cooling and hardening of molten material (magma), which are composed by interlocking grains, each consisting of a particular mineral).

- rocks formed from sediments (mineral grains) that are deposited at the earth's surface by water, ice or air.

- metamorphic rocks formed by the alteration of rocks within the earth under conditions of high temperature and pressure, which are characterised by minerals and textures arrayed in parallel wavy layers.

- crystalline rocks which are igneous and metamorphic rocks formed at high temperatures.

High-resolution X-ray computed tomography has been used to reveal the sizes and the three-dimensional spatial disposition of porphyroblasts in metamorphic rocks, which can indicate the atomic-scale processes that control crystal nucleation and growth (Denison et al. 1997). Petroleum engineers have used CT data to study two-fluid coreflood experiments in reservoir lithologies (Wellington \& Vinegar 1987). Meteorite investigations have progressed from solely finding inclusions to mapping out the shape and size distributions of their mineralogical components, providing textural clues about their origins (Kuebler et al. 1999). The 3D images produced using micro-CT technology allow the study of the real $3 \mathrm{D}$ petrography of meteorites and the visualization of a larger percentage of the meteorite (Hezel et al. 2013).

Another example of the use of micro-CT in petrology studies is the analysis of temporal, geographical and species-specific variations in flaked stone tool morphology, which attempts to explain the evolution 
of cognition, culture and human behaviour. Abel et al. (2011) studied flaked stone tools used by early humans from at least 2.6 million years ago. Using micro-CT, they were able to visualise the key features of percussion, which distinguish flakes intentionally made by humans (artefact) from the ones created naturally (geofact). Also, they could recreate missing flakes from refitted groups of material by visualising void spaces (Abel et al. 2011).

\section{Data curation}

Given the importance of virtual specimens for future research - especially if datasets are designated as cybertypes for species descriptions (see e.g., Akkari et al. 2015) - data management (or curation) of micro-CT datasets should be performed with the same care as curating physical specimens. Currently, however, there are no universally accepted guidelines or standards concerning the curation, documentation and dissemination of micro-CT datasets. A recent overview and set of recommendations has been provided by Davies et al. (2017). A few general suggestions are listed below, which should be taken into consideration by micro-CT laboratories wanting to develop or improve data management practices.

Generally, data management/curation activities can be classified into three broad categories: a) documentation; b) data organization, storage and archival practices and c) data dissemination.

\subsection{Documentation}

The documentation of the dataset through metadata is crucial. Metadata place the dataset into context, make it discoverable and retrievable, provide information on provenance, terms for re-use and document the steps performed to create the dataset. The required level of detail of the metadata is determined by a variety of factors, such as internal guidelines of the institution, every-day practices of the laboratory and demands of users, trying to strike a balance between the need for a full documentation of the dataset with a high level of detail, and the effort, time and costs required to create this documentation.

Currently, no metadata standards or formats exist specifically for natural history specimens imaged through micro-CT. Several existing standards could be adapted to adequately describe these data, such as the DICOM (Digital Imaging and Communications in Medicine; http://dicom.nema.org), ISA-TAB (Investigation-Study-Assay; http://isa-tools.org/; Sansone et al. 2012) or HDF5 (Hierarchical Data Format 5; https://www.hdfgroup.org/) format. DICOM is a file format and data exchange protocol extensively used in medical imaging and contains the metadata embedded together with the images. While the metadata can be adapted to individual needs, and thus could be tailored towards 3D natural history specimen data, DICOM is not straightforward to learn, dedicated software is required and DICOM is not produced directly by many scanner models. The ISA-TAB standard provides flexible options to describe protocols and parameters and to combine metadata terms. It has at least once been applied to document micro-CT data (Stoev et al. 2013), although in a simplified form. The Hierarchical Data Format (HDF5) is a generic format suitable for large datasets comprised of heterogeneous subsets, including user-defined embedded metadata. The HDF5 format has been used for tomographic data (e.g., De Carlo et al. 2018; Mancini et al. 2018), but its use requires some expertise and dedicated software is needed.

However, many laboratories may decide to store metadata in a custom-made database or even in text files that are distributed along with the data. While a central database which includes documentation for all datasets allows for efficient search and retrieval of the datasets and enhances discoverability, care needs to be taken when data are re-distributed. In this case the metadata need to be extracted from the database and included together with the image files (e.g., as a text file, or embedded in, e.g., DICOM or HDF5 files). In the case of custom-made documentation systems, metadata should at least include:

- unique identifier for the dataset. Ideally, this should be a globally unique identifier, but in case the datasets are used only internally, they can be unique within the lab/institution 
- description of specimen, including a link to an identifier for the specimen, e.g., a catalogue number

- purpose of dataset

- person(s) involved (for each action, if this level of detail is required)

- preparations of specimen (e.g., staining) which influence the results

- date/time of scanning and all scanning parameters (often recorded automatically by the machine)

- description of/Link to the storage location of the dataset(s)

- usage restrictions/licenses/copyright

- information on provenance / changes / version of the dataset (or a "last modified" date)

- links to or identifiers of derived publications or datasets

\subsection{Data organisation, storage and archival practice}

While careful metadata annotation can help to organise and retrieve the actual datasets, management of the actual files is equally important. Tomography data pose certain challenges due to their large volume, requiring adequate long-term storage, reliable backup systems and mechanisms to organise and retrieve files on storage media.

Depending on the responsibilities of the laboratory, different data products may have to be managed: In some laboratories, only the raw data (projection images) are kept, and everything from the reconstructed cross sections to images, analyses and other derivative data falls under the responsibility of the customer/ scientist; other practices include keeping also the reconstructed set of images and/or derivative data. A file organisation and storage system should take these responsibilities into account by organising data in a consistent directory structure with consistent file names which can be intuitively and comfortably understood and used (e.g., Yakami et al. 2011; Faulwetter et al. 2015).

Disk storage space and long-time archival practice has to be carefully accounted for. Several options for storage exist, but all of them have advantages and disadvantages:

- external and portable hard disks are easy to use but not very reliable. If hard disks are used, those supporting RAID (Redundant Array of Independent Disks) technology can provide extra protection against data loss.

- Network Attached Storage (NAS) servers are currently the best option. They can provide scalability and fault tolerance beyond that of discrete hard disks.

- tape library storage is still a common backup option, but recovery of data can be time-consuming and difficult.

- off-site storage (i.e., in the cloud) should be considered as protection against local disasters, but the large datasets (often several terabyte of data) result in long transmission times over the internet. Whether online storage is a feasible option will therefore depend on the practices of the laboratory (e.g., frequency and volume of data produced; type of data to be archived).

Laboratories with limited storage capabilities may also consider using data compression methods (see, e.g., Mancini et al. 2018 for an overview).

\subsection{Data dissemination and publication}

\subsubsection{Data publication}

The publication of research data, either to underpin scientific publications or as a general good practice of data sharing, has gained increasing acceptance over the last years. Sharing tomography data, however, can be still a challenge due to the large data volume. Data can be shared either through an institutional file sharing server or be published through a public repository. Available repositories differ in their scope and features. The choice depends on the type and size of the data to be shared, on whether journal policies apply (e.g., when data accompany a research article) and potentially on institutional practices. An overview of repositories is given in Table 10. 
Table 10. Overview of repositories for 3D data.

\begin{tabular}{|c|c|c|}
\hline Data repository & Scope / Restrictions & URL \\
\hline DigitalMorphology & $\begin{array}{l}\text { primarily hosts data from the Digimorph group } \\
\text { and collaborators; for contributions the project } \\
\text { administrators should be contacted. Available data } \\
\text { are QuickTime animations of CT stacks, movies of } \\
\text { 3D volume rendering of specimens and STL surface } \\
\text { models. }\end{array}$ & http://digimorph.org \\
\hline Dryad & $\begin{array}{l}\text { generic data repository. Not tailored towards large } \\
\text { files, although they are accepted. Charges a publishing } \\
\text { fee (currently } \$ 120 \text { per dataset), unless waivers apply. } \\
\text { All data are released under a CC-Zero waiver (public } \\
\text { domain, copyright removed). Assigns DOIs to the } \\
\text { data. }\end{array}$ & http://www.datadryad.org \\
\hline Figshare & $\begin{array}{c}\text { generic data repository. Supports files up to } 5 \text { GB free } \\
\text { (beyond that, institutional services can be purchased). } \\
\text { License can be chosen by user. Assigns DOIs to the } \\
\text { data. }\end{array}$ & https://figshare.com \\
\hline GigaDB & $\begin{array}{l}\text { accepts almost only data accompanying articles in } \\
\text { GigaScience. Data can, however, be described as a } \\
\text { DataNote and then included in the repository. Focuses } \\
\text { on large-size data, i.e., volumetric data. Encourages } \\
\text { publication of projection and reconstructed data. All } \\
\text { data are released under a CC-Zero waiver (public } \\
\text { domain, copyright removed). Assigns DOIs to the } \\
\text { data. }\end{array}$ & http://gigadb.org/ \\
\hline $\begin{array}{l}\text { LifewatchGreece } \\
\text { micro-CT } \\
\text { vlab }\end{array}$ & $\begin{array}{l}\text { accepts volumetric micro-CT datasets, provides } \\
\text { extensive metadata and on-the-fly viewer of } \\
\text { volumetric datasets. Several features, e.g., raw data } \\
\text { download, still under construction. Does not assign } \\
\text { DOIs. }\end{array}$ & https://microct.portal.lifewatchgreece.eu \\
\hline MorphDBase & $\begin{array}{l}\text { media database which also develops ontologies that } \\
\text { describe morphological terminology. Not specifically } \\
\text { targeted at 3D data but accepts media files in general. }\end{array}$ & https://www.morphdbase.de \\
\hline Morphomuseum & $\begin{array}{l}\text { publishes data accompanying journal articles in } \\
\text { MorphoMuseum, but not only. Focuses on surface } \\
\text { models, but volume data can also be published if they } \\
\text { accompany surface data. Focus on vertebrates, but } \\
\text { does not explicitly exclude other taxa. Assigns DOIs. } \\
\text { Only license available is CC-BY-NC. }\end{array}$ & https://morphomuseum.com/ \\
\hline Morphosource & $\begin{array}{l}\text { targeted at 3D biodiversity data (volumetric and } \\
\text { surface). File formats include tiff, dicom, stanford ply, } \\
\text { and stl. Does not assign DOIs automatically. Choice } \\
\text { of license. }\end{array}$ & http://morphosource.org \\
\hline Phenome10K & $\begin{array}{c}\text { provides free 3-D image data of biological and } \\
\text { paleontological specimens to the academic } \\
\text { and educational (non-commercial) community. } \\
\text { Supports all types of 3-D images, including surface } \\
\text { scans, CT-scans and MRIs accompanied by their } \\
\text { metadata, and images can be downloaded as STL files. } \\
\text { Does not assign DOIs. Only license available is CC- } \\
\text { BY-NC. }\end{array}$ & http://phenome10k.org/ \\
\hline
\end{tabular}


Both volumetric datasets (reconstructed images and/or projection images) as well as surface models can be shared and are of interest to the scientific, cultural/artistic and education/science communication community. When sharing data, a suitable licence should be chosen that allow others to re-use and process the data. Creative Commons licenses (http://www.creativecommons.org), ideally CC-BY (attribution required) or even CC-Zero (release into the public domain) are the most suitable licenses for sharing scientific data (Hagedorn et al. 2011).

\subsubsection{Tools for outreach and interaction with $3 D$ data}

Apart from making 3D datasets available for download, tools exists for remote on-the-fly interaction of users with the data. These tools are useful for giving users an overview of the data without having to download them first, and/or provide a suitable tool for outreach and education.

Surface models can easily be rendered in a browser (e.g., 3D Hop, http://vcg.isti.cnr.it/3dhop/)and allow the user to interact (rotate, zoom, change colours or lights) with them, and multiple technological solutions and ready-made portals exist (e.g., WebGL, Java, Flash). Rendering volumetric data online is still a challenge, and solutions are limited. Arivis Web View (https://www.arivis.com/de/imaging-science/arivis-webview) is a commercial solution and provides online $2 \mathrm{D}$ and $3 \mathrm{D}$ rendering even via limited bandwidth. 3D slicer (https://www.slicer.org/) is free software which likewise allows online rendering of volume data, with a variety of features to control opacity and colouring.

In addition to browser-based tools, several applications for mobile phones exist as well (e.g., the free CTVox app, https:/www.bruker.com/products/microtomography/micro-ct-software/3dsuite.html; ImageVis3D, http://www.sci.utah.edu/cibc-software/imagevis3d.html; Volumize, http://www.volumize.be/; or DroidRender https://www.facebook.com/droidrender). These applications do, however, not work on the full high-resolution dataset, but on a downscaled version, as neither memory nor graphics cards on mobile devices are as powerful as those on dedicated desktop computers.

Another tool for interaction with 3D data, and especially suited for exhibitions, are touch-screen based volume rendering software packages which provide a simplified user interface, allowing children and non-technical users to explore 3D datasets. A commercial solution is the InsideExplorer (http://www.interspectral.com/inside-explorer/), which also provides support in setting up exhibitions. Similar features, but without technical support, are provided by the DrishtiPrayog software (http://nci.org.au/systems-services/scientific-visualisation/visualisation-services/drishti-prayog/).

\section{Acknowledgements}

The creation of this handbook was funded by the EU FP7 programme SYNTHESYS3 (FP7 -312253) and further supported by the LifeWatchGreece infrastucture (ESFRI - 384676) and BIOIMAGINGGR (ESFRI - 5002755). The authors would like to thank all the SYNTHESYS participants for their contribution to this handbook and especially Vincent S. Smith (Natural History Museum, UK) and Elspeth M. Haston (The Royal Botanic Garden Edinburgh, UK) for their support, and Alex Ball and Farah Ahmed (Natural History Museum, UK) for their suggestions. The authors would also like to thank Thaddaeus Buser and one anonymous reviewer for providing comments and suggestions that improved the manuscript.

\section{References}

Abel R.L., Parfitt S., Ashton N., Lewis S.G., Scott B. \& Stringer C. 2011. Digital preservation and dissemination of ancient lithic technology with modern micro-CT. Computers \& Graphics 35 (4): 878884. https://doi.org/10.1016/j.cag.2011.03.001 
KEKLIKOGLOU K. et al., Micro-computed tomography for natural history specimens

Abel R.L., Laurini C.R. \& Richter M. 2012. A palaeobiologist's guide to 'virtual' micro-CT preparation. Palaeontologia Electronica 15 (2): 6T.

Akkari N., Enghoff H. \& Metscher B.D. 2015. A new dimension in documenting new species: highdetail imaging for myriapod taxonomy and first 3D cybertype of a new millipede species (Diplopoda, Julida, Julidae). PLoS ONE 10 (8): e0135243. https://doi.org/10.1371/journal.pone.0135243

Alba-Tercedor J. 2012. Studying the anatomy of wet specimens of mayflies of the genus Baetis (Insecta: Ephemeroptera) by scanning them into a liquid with the Skyscan 1172 high resolution micro-CT. SkyScan microCT 2012 User Meeting, Belgium: 188-191. Skyscan, Brussels.

Alba-Tercedor J. \& Sánchez-Tocino L. 2011. The use of the SkyScan 1172 high-resolution micro-CT to elucidate if the spicules of the "sea slugs" (Mollusca: Nudibranchia, Opisthobranchia) have a structural or a defensive function. SkyScan microCT 2011 User Meeting, Belgium: 113-121. Skyscan, Leuven.

Barrett J.F. \& Keat N. 2004. Artifacts in CT: recognition and avoidance 1. Radiographics 24 (6): 16791691. https://doi.org/10.1148/rg.246045065

Betz O., Wegst U., Weide D., Heethoff M., Helfen L., Lee W.K. \& Cloetens P. 2007. Imaging applications of synchrotron X-ray phase-contrast microtomography in biological morphology and biomaterials science. I. General aspects of the technique and its advantages in the analysis of millimetre-sized arthropod structure. Journal of Microscopy 227 (1): 51-71. https://doi.org/10.1111/j.1365-2818.2007.01785.x

Blagoderov V., Kitching I.J., Livermore L., Simonsen T.J. \& Smith V.S. 2012. No specimen left behind: industrial scale digitization of natural history collections. ZooKeys 209: 133-146. https://doi.org/10.3897/zookeys.209.3178

Boas F.E. \& Fleischmann D. 2012. CT artifacts: causes and reduction techniques. Imaging in Medicine 4 (2): 229-240.

Boistel R., Swoger J., Kržič U., Fernandez V., Gillet B. \& Reynaud E.G. 2011. The future of three-dimensional microscopic imaging in marine biology. Marine Ecology 32 (4): 438-452. https://doi.org/10.1111/j.1439-0485.2011.00442.x

Bribiesca-Contreras F. \& Sellers W.I. 2017. Three-dimensional visualisation of the internal anatomy of the sparrowhawk (Accipiter nisus) forelimb using contrast-enhanced micro-computed tomography. PeerJ 5: e3039. https://doi.org/10.7717/peerj.3039

Briguglio A. \& Benedetti A. 2012. X-ray microtomography as a tool to present and discuss new taxa: the example of Risananeiza sp. from the late Chattian of Porto Badisco. Rendiconti Online Società Geologica Italiana 21: 1072-1074.

Brodersen C.R. \& Roddy A.B. 2016. New frontiers in the three-dimensional visualization of plant structure and function. American Journal of Botany 103: 1-5. https://doi.org/10.3732/ajb.1500532

Brodersen C.R., McElrone A.J., Choat B., Matthews M.A. \& Shackel K.A. 2010. The dynamics of embolism repair in xylem: In vivo visualizations using high-resolution computed tomography. Plant Physiology 154: 1088-1095. https://doi.org/10.1104/pp.110.162396

Brodersen C.R., Lee E.F., Choat B., Jansen S., Phillips R.J., Shackel K.A., McElrone A.J. \& Matthews M.A. 2011. Automated analysis of three-dimensional xylem networks using high-resolution computed tomography. The New Phytologist 191: 1168-1179.

https://doi.org/10.1111/j.1469-8137.2011.03754.x

Brodersen C.R., McElrone A.J., Choat B., Lee E.F., Shackel K.A. \& Matthews M.A. 2013. In vivo visualizations of drought-induced embolism spread in Vitis vinifera. Plant Physiology 161: 1820-1829. https://doi.org/10.1104/pp.112.212712 
Burrow C.J., Jones A.S. \& Young G.C. 2005. X-ray microtomography of 410 million-year-old optic capsules from placoderm fishes. Micron 36 (6): 551-557. https://doi.org/10.1016/j.micron.2005.05.005

Carlson W.D. \& Denison C. 1992. Mechanisms of porphyroblast crystallization: results from highresolution computed X-ray tomography. Science 257 (5074): 1236-1239.

https://doi.org/10.1126/science.257.5074.1236

Carlson W.D., Rowe T., Ketcham R.A. \& Colbert M.W. 2003. Applications of high-resolution X-ray computed tomography in petrology, meteoritics and palaeontology. In: Mees F., Swennen R., Van Geet M. \& Jacobs P. (eds) Applications of V-ray Computed Tomography in the Geosciences 215 (1): 7-22. Geological Society Special Publications, London. https://doi.org/10.1144/GSL.SP.2003.215.01.02

Chatzinikolaou E., Grigoriou P., Keklikoglou K., Faulwetter S. \& Papageorgiou N. 2017. The combined effects of ocean acidification and elevated temperature on the shell density of two gastropod species using micro-CT imaging. ICES Journal of Marine Science 74 (4): 1135-1149. https://doi.org/10.1093/icesjms/fsw219

Cnudde V., Masschaele B., Dierick M., Vlassenbroeck J., Van Hoorebeke L. \& Jacobs P. 2006. Recent progress in X-ray CT as a geosciences tool. Applied Geochemistry 21 (5): 826-832. https://doi.org/10.1016/j.apgeochem.2006.02.010

Cochard H., Delzon S. \& Badel E. 2015. X-ray microtomography (micro-CT): A reference technology for high-resolution quantification of xylem embolism in trees. Plant, Cell and Environment 38 (1): 201-206. https://doi.org/10.1111/pce.12391

Crestana S., Cesaero R. \& Mascarenhas S. 1986. Using a computer assisted tomography miniscanner in soil science. Soil Science 142: 56-61.

Davies T.G., Rahman I.A., Lautenschlager S., Cunningham J.A., Asher R.J., Barrett P.M., Bates K.T., Bengtson S., Benson R.B., Boyer D.M., Braga J., Bright J.A., Claessens L.P.A.M., Cox P.G., Dong X.-P., Evans A.R., Falkingham P.L., Friedman M., Garwood R.J., Goswami A., Hutchinson J.R., Jeffery N.S., Johanson Z., Lebrun R., Martinez-Pérez C., Marugán-Lobón J., O’Higgins P.M., Metscher B., Orliac M., Rowe T.B., Rücklin M., Sánchez-Villagra M.R., Shubin N.H., Smith S.Y., Starck J.M., Stringer C., Summers A.P., Sutton M.D., Walsh S.A., Weisbecker V., Witmer L.M., Wroe S., Yin Z., Rayfield E.J. \& Donoghue P.C.J. 2017. Open data and digital morphology. Proceedings of the Royal Society B 284: 20170194. https://doi.org/10.1098/rspb.2017.0194

Davis G.R. \& Elliott J.C. 1997. X-ray microtomography scanner using time-delay integration for elimination of ring artefacts in the reconstructed image. Nuclear Instruments and Methods in Physics Research Section A: Accelerators, Spectrometers, Detectors and Associated Equipment 394 (1): 157162. https://doi.org/10.1016/S0168-9002(97)00566-4

Davit Y., Iltis G., Debenest G., Veran-Tissoires S., Wildenschild D., Gérino M. \& Quintard M. 2011. Imaging biofilm in porous media using X-ray computed microtomography. Journal of Microscopy 242 (1): 15-25. https://doi.org/10.1111/j.1365-2818.2010.03432.x

de Carlo F., Gürsoy D., Ching D.J., Batenburg K.J., Ludwig W., Mancini L., Marone F., Mokso R., Pelt D.M., Sijbers J. \& Rivers M. 2018. TomoBank: a tomographic data repository for computational x-ray science. Measurement Science and Technology 29 (3): 034004. https://doi.org/10.1088/1361-6501/aa9c19 de Man B. 2001. Iterative Reconstruction for Reduction of Metal Artifacts in Computed Tomography. $\mathrm{PhD}$ Thesis, KULeuven, Belgium.

Denison C., Carlson W.D. \& Ketcham R.A. 1997. Three-dimensional quantitative textural analysis of metamorphic rocks using high-resolution computed X-ray tomography: Part I. Methods and techniques. Journal of Metamorphic Geology 15 (1): 29-44. https://doi.org/10.1111/j.1525-1314.1997.00006.x 
KEKLIKOGLOU K. et al., Micro-computed tomography for natural history specimens

DeVore M.L., Kenrick P., Pigg K.B. \& Ketcham R.A. 2006. Utility of high resolution x-ray computed tomography (HRXCT) for paleobotanical studies: an example using London Clay fruits and seeds. American Journal of Botany 93 (12): 1848-1851. https://doi.org/10.3732/ajb.93.12.1848

Dhondt S., Vanhaeren H., Van Loo D., Cnudde V. \& Inzé D. 2010. Plant structure visualization by highresolution X-ray computed tomography. Trends in Plant Science 15: 419-422.

https://doi.org/10.1016/j.tplants.2010.05.002

Dierick M., Cnudde V., Masschaele B., Vlassenbroeck J., Van Hoorebeke L. \& Jacobs P. 2007. Micro-CT of fossils preserved in amber. Nuclear Instruments and Methods in Physics Research Section A: Accelerators, Spectrometers, Detectors and Associated Equipment 580 (1): 641-643. https://doi.org/10.1016/j.nima.2007.05.030

Dixon L.E., Bencivenga S. \& Boden S.A. 2018. A new opening for wheat seed production. Journal of Experimental Botany 69 (3): 341-343. https://doi.org/10.1093/jxb/erx430

Faraj K.A., Cuijpers V.M., Wismans R.G., Walboomers X.F., Jansen J.A., van Kuppevelt T.H. \& Daamen W.F. 2009. Micro-computed tomographical imaging of soft biological materials using contrast techniques. Tissue Engineering Part C: Methods 15 (3): 493-499.

https://doi.org/10.1089/ten.tec.2008.0436

Faulwetter S., Vasileiadou A., Kouratoras M., Dailianis T. \& Arvanitidis C. 2013a. Micro-computed tomography: Introducing new dimensions to taxonomy. ZooKeys 263: 1-45.

https://doi.org/10.3897/zookeys.263.4261

Faulwetter S., Dailianis T., Vasileiadou A. \& Arvanitidis C. 2013b. Contrast enhancing techniques for the application of micro-CT in marine biodiversity studies. Microscopy and Analysis 27 (2): S4-S7.

Faulwetter S., Minadakis N., Keklikoglou K., Doerr M. \& Arvanitidis C. 2015. First steps towards the development of an integrated metadata management system for biodiversity-related micro-CT datasets. Bruker microCT 2015 user meeting, Belgium: 149-159. Bruker, Bruges.

Fernández R., Kvist S., Lenihan J., Giribet G. \& Ziegler A. 2014. Sine systemate chaos? A versatile tool for earthworm taxonomy: non-destructive imaging of freshly fixed and museum specimens using microcomputed tomography. PloS ONE 9 (5): e96617. https://doi.org/10.1371/journal.pone.0096617

Franzen J.L., Gingerich P.D., Habersetzer J., Hurum J.H., von Koenigswald W. \& Smith B.H. 2009. Complete primate skeleton from the middle Eocene of Messel in Germany: morphology and paleobiology. PLoS ONE 4 (5): e5723. https://doi.org/10.1371/journal.pone.0005723

Gamisch A., Staedler Y.M., Schönenberger J., Fischer G.A. \& Comes H.P. 2013. Histological and microCT evidence of stigmatic rostellum receptivity promoting auto-pollination in the Madagascan orchid Bulbophyllum bicoloratum. PLoS ONE 8 (8): e72688. https://doi.org/10.1371/journal.pone.0072688

Garwood R.J., Sharma P.P., Dunlop J.A. \& Giribet G. 2014. A Paleozoic stem group to mite harvestmen revealed through integration of phylogenetics and development. Current Biology 24 (9): 1017-1023. https://doi.org/10.1016/j.cub.2014.03.039

Gee C.T. 2013. Applying microCT and 3D visualization to Jurassic silicified conifer seed cones: a virtual advantage over thin-sectioning. Applications in Plant Sciences 1 (11): 1300039.

https://doi.org/10.3732/apps.1300039

Gignac P.M. \& Kley N.J. 2014. Iodine-enhanced micro-CT imaging: Methodological refinements for the study of the soft-tissue anatomy of post-embryonic vertebrates. Journal of Experimental Zoology Part B: Molecular and Developmental Evolution 322 (3): 166-176. https://doi.org/10.1002/jez.b.22561

Gignac P.M., Kley N.J., Clarke J.A., Colbert M.W., Morhardt A.C., Cerio D., Cost I.N., Cox P.G., Daza J.D., Early C.M., Echolsm M.S., Henkelman R.M., Herdina A.N., Holliday C.M., Li Z., 
Mahlow K., Merchant S., Müller J., Orsbon C.P., Paluh D.J., Thies M.L., Tsai H.P. \& Witmer L.M. 2016. Diffusible iodine-based contrast-enhanced computed tomography (diceCT): an emerging tool for rapid, high-resolution, 3-D imaging of metazoan soft tissues. Journal of Anatomy 228 (6): 889-909. https://doi.org/10.1111/joa.12449

Godfray H.C.J. 2007. Linnaeus in the information age. Nature 446: 259-260. https://doi.org/10.1038/446259a

Golding R.E. \& Jones A.S. 2007. Micro-CT as a novel technique for 3D reconstruction of molluscan anatomy. Molluscan Research 27: 123-128.

Görög Á., Szinger B., Tóth E. \& Viszkok J. 2012. Methodology of the micro-computer tomography on Foraminifera. Palaeontologia Electronica 15 (1): 1-15.

Greco M.K., Welz P.M., Siegrist M., Ferguson S.J., Gallmann P., Roubik D.W. \& Engel M.S. 2011. Description of an ancient social bee trapped in amber using diagnostic radioentomology. Insectes Sociaux 58 (4): 487-494. https://doi.org/10.1007/s00040-011-0168-8

Green O.R. 2001. A Manual of Practical Laboratory and Field Techniques in Palaeobiology. Springer Science \& Business Media, Berlin.

Griffin L.D., Elangovan P., Mundell A. \& Hezel D.C. 2012. Improved segmentation of meteorite microCT images using local histograms. Computers \& Geosciences 39: 129-134.

https://doi.org/10.1016/j.cageo.2011.07.002

Hagedorn G., Mietchen D., Agosti D., Penev L., Berendsohn W. \& Hobern D. 2011. Creative Commons licenses and the non-commercial condition: Implications for the re-use of biodiversity information. ZooKeys 150: 127-149. https://doi.org/10.3897/zookeys.150.2189

Hamba H., Nikaido T., Sadr A., Nakashima S. \& Tagami J. 2012. Enamel lesion parameter correlations between polychromatic micro-CT and TMR. Journal of Dental Research 91 (6): 586-591.

https://doi.org/10.1177/0022034512444127

Heřmanová Z., Dašková J., Ekrt B. \& Kvaček J. 2017. Zlivifructus gen. nov., a new member of the Normapolles complex. Review of Palaeobotany and Palynology 246: 177-184.

https://doi.org/10.1016/j.revpalbo.2017.06.012

Hezel D.C., Elangovan P., Viehmann S., Howard L., Abel R.L. \& Armstrong R. 2013. Visualisation and quantification of $\mathrm{CV}$ chondrite petrography using micro-tomography. Geochimica et Cosmochimica Acta 116: 33-40. https://doi.org/10.1016/j.gca.2012.03.015

Hsieh J. 2009. Computed Tomography: Principles, Design, Artifacts, and Recent Advances. SPIE Press, Bellingham, Washington. https://doi.org/10.1117/3.817303

Holliday C.M., Tsai H.P., Skiljan R.J., George I.D. \& Pathan S. 2013. A 3D interactive model and atlas of the jaw musculature of Alligator mississippiensis. PloS ONE 8 (6): e62806.

https://doi.org/10.1371/journal.pone.0062806

Jeppsson L., Anehus R. \& Fredholm D. 1999. The optimal acetate buffered acetic acid technique for extracting phosphatic fossils. Journal of Paleontology 73 (5): 964-972.

https://doi.org/10.1017/S0022336000040798

Johnson E., Dwarte D. \& Jones A. 2011. Specimen preparation for X-ray micro-computed tomography of plants. Microscopy and Microanalysis 17: 2010-2011. https://doi.org/10.1017/S1431927611002091

Kachelrieß M. 2008. Micro-CT. In: Semmler W. \& Schwaiger M. (eds) Molecular Imaging I. Handbook of Experimental Pharmacology 185/1: 23-52. Springer, Berlin/Heidelberg. 
KEKLIKOGLOU K. et al., Micro-computed tomography for natural history specimens

Kamenz C. \& Weidemann G. 2009. Heavy metal—A contrasting substance for micro-tomographical visualization of scorpion book lungs. Micron 40 (8): 911-917.

https://doi.org/10.1016/j.micron.2009.05.007

Kędzierski M., Uchman A., Sawlowicz Z. \& Briguglio A. 2015. Fossilized bioelectric wire - the trace fossil Trichichnus. Biogeosciences (Online) 12 (8): 2301-2309. https://doi.org/10.5194/bg-12-2301-2015

Kehlmaier C., Dierick M. \& Skevington J.H. 2014. Micro-CT studies of amber inclusions reveal internal genitalic features of big-headed flies, enabling a systematic placement of Metanephrocerus Aczél, 1948 (Insecta: Diptera: Pipunculidae). Arthopod Systematics \& Phylogeny 72 (1): 23-36.

Keklikoglou K., Chatzinikolaou E., Faulwetter S., Grigoriou P., Papageorgiou N., Queirós A., Rühl S. \& Schmidbaur H. 2015. Revealing effects of ocean acidification on the calcified structures of marine invertebrates through micro-computed tomography (micro-CT). Bruker microCT 2015 user meeting, Belgium: 21-31. Bruker, Bruges.

Keklikoglou K., Faulwetter S., Chatzinikolaou E., Michalakis N., Filiopoulou I., Minadakis N., Panteri E., Perantinos G., Gougousis A. \& Arvanitidis C. 2016. MicroCT ${ }_{\text {vlab }}$ : A web based virtual gallery of biological specimens using X-ray microtomography (microCT). Biodiversity Data Journal 4: e8740. https://doi.org/10.3897/BDJ.4.e8740

Ketcham R.A. \& Carlson W.D. 2001. Acquisition, optimization and interpretation of X-ray computed tomographic imagery: applications to the geosciences. Computers \& Geosciences 27 (4): 381-400. https://doi.org/10.1016/S0098-3004(00)00116-3

Kim J.S., Min J., Recknagel A.K., Riccio M. \& Butcher J.T. 2011. Quantitative three-dimensional analysis of embryonic chick morphogenesis via microcomputed tomography. The Anatomical Record 294 (1): 1-10. https://doi.org/10.1002/ar.21276

Kim S.J., Xu W., Ahmad M.W., Baeck J.S., Chang Y., Bae J.E., Chae K.S., Jeong T.K., Park J.A. \& Lee G.H. 2015. Synthesis of nanoparticle CT contrast agents: in vitro and in vivo studies. Science and Technology of Advanced Materials 16: 055003. https://doi.org/10.1088/1468-6996/16/5/055003

Knipfer T., Eustis A., Brodersen C., Walker A.M. \& McElrone A.J. 2015. Grapevine species from varied native habitats exhibit differences in embolism formation/repair associated with leaf gas exchange and root pressure. Plant, Cell \& Environment 38 (8): 1503-1513. https://doi.org/10.1111/pce.12497

Kniss J., Kindlmann G. \& Hansen C. 2002. Multidimensional transfer functions for interactive volume rendering. IEEE Transactions on Visualization and Computer Graphics 8 (3): 270-285. https://doi.org/10.1109/TVCG.2002.1021579

Koenigswald W.V., Habersetzer J. \& Gingerich P.D. 2011. Morphology and evolution of the distal phalanges in primates. In: Lehmann T. \& Schaal S.F.K (eds) The World at the Time of Messel: Puzzles in Palaeobiology, Palaeoenvironment, and the History of Early Primates: 91-94. 22 ${ }^{\text {nd }}$ International Senckenberg Conference, Frankfurt am Main.

Konietzko-Meier D. \& Schmitt A. 2013. A histological study of a femur of Plagiosuchus, a Middle Triassic temnospondyl amphibian from southern Germany, using thin sections and micro-CT scanning. Netherlands Journal of Geosciences 92 (2-3): 97-108. https://doi.org/10.1017/S0016774600000020

Korte N. \& Porembski S. 2011. Anatomical analysis of turgescent and semi-dry resurrection plants: the effect of sample preparation on the sample, resolution, and image quality of X-ray micro-computed tomography $(\mu \mathrm{CT})$. Microscopy Research and Technique 74 (4): 364-369.

https://doi.org/10.1002/jemt.20917 
Krings M., Müller H., Heneka M.J. \& Rödder D. 2017. Modern morphological methods for tadpole studies. A comparison of micro-CT, and clearing and staining protocols modified for frog larvae. Biotechnic \& Histochemistry 92 (8): 595-605. https://doi.org/10.1080/10520295.2017.1369162

Kuebler K.E., McSween H.Y., Carlson W.D. \& Hirsch D. 1999. Sizes and masses of chondrules and metal-troilite grains in ordinary chondrites: possible implications for nebular sorting. Icarus 141 (1): 96-106. https://doi.org/10.1006/icar.1999.6161

Kuva J., Sammaljärvi J., Parkkonen J., Siitari-Kauppi M., Lehtonen M., Turpeinen T., Timonen J. \& Voutilainen M. 2018. Imaging connected porosity of crystalline rock by contrast agent-aided X-ray microtomography and scanning electron microscopy. Journal of Microscopy 270 (1): 98-109. https://doi.org/10.1111/jmi.12661

Kvaček J. \& Heřmanová Z. 2017. Fossil angiosperm fruit Allericarpus parvivalvis (Ericales) from the Coniacian of the Bohemian Cretaceous Basin. Journal of the National Museum (Prague), Natural History Series 186: 117-124.

Kvaček J., Doyle J.A., Endress P.K., Daviero-Gomez V., Gomez B. \& Tekleva M. 2016. Pseudoasterophyllites cretaceus from the Cenomanian (Cretaceous) of the Czech Republic - a possible link between Chloranthaceae and Ceratophyllum. Taxon 65 (6): 1345-1373.

https://doi.org/10.12705/656.8

Kvaček J., Barrón E., Heřmanová Z., Mendes M.M., Karch J., Žemlička J. \& Dudák J. 2018a. Araucarian conifer from late Albian amber of northern Spain. Papers in Palaeontology 4 (3): 1-14. https://doi.org/10.1002/spp2.1223

Kvaček J., Heřmanová Z., Bruthansová J.M.M., Karch J., Žemlička J. \& Dudák J. 2018b. Stutzeliastrobus bohemicus - basal Curessaceae conifer from the Cenomanian of the Bohemian Cretaceous Basin, Central Europe. Fossil Imprint 74: 179-188.

Leroux O., Leroux F., Bellefroid E., Claeys M., Couvreur M., Borgonie G., Van Hoorebeke L., Masschaele B. \& Viane R. 2009. A new preparation method to study fresh plant structures with X-ray computed tomography. Journal of Microscopy 233 (1): 1-4.

https://doi.org/10.1111/j.1365-2818.2008.03088.x

Li X., Pan Z., Upadhyaya S.K., Atungulu G.G. \& Delwiche M. 2011. Three-dimensional geometric modeling of processing tomatoes. Transactions of the American Society of Agricultural and Biological Engineers 54 (6): 2287-2296. https://doi.org/10.13031/2013.40642

Li Z., Clarke J.A., Ketcham R.A., Colbert M.W. \& Yan F. 2015. An investigation of the efficacy and mechanism of contrast-enhanced X-ray computed tomography utilizing iodine for large specimens through experimental and simulation approaches. BMC Physiology 15: 5.

https://doi.org/10.1186/s12899-015-0019-3

Liu Y., Scholtz G. \& Hou X. 2015. When a 520 million-year-old Chengjiang fossil meets a modern micro-CT-a case study. Scientific Reports 5: 12802. https://doi.org/10.1038/srep12802

Lorensen W.E. \& Cline H.E. 1987. Marching cubes: a high resolution 3D surface construction algorithm. ACM Siggraph Computer Graphics 21 (4): 163-169.

Mancini L., Kourousias G., Billè F., De Carlo F. \& Fidler A. 2018. About a method for compressing x-ray computed microtomography data. Measurement Science and Technology 29 (4): 044002. https://doi.org/10.1088/1361-6501/aaa0fa

McElrone A.J., Choat B., Parkinson D.Y., MacDowell A.A. \& Brodersen C.R. 2013. Using high resolution computed tomography to visualize the three dimensional structure and function of plant vasculature. Journal of Visualized Experiments 74: e50162. https://doi.org/10.3791/50162 
KEKLIKOGLOU K. et al., Micro-computed tomography for natural history specimens

Meganck J.A., Kozloff K.M., Thornton M.M., Broski S.M. \& Goldstein S.A. 2009. Beam hardening artifacts in micro-computed tomography scanning can be reduced by X-ray beam filtration and the resulting images can be used to accurately measure BMD. Bone 45 (6): 1104-1116. https://doi.org/10.1016/j.bone.2009.07.078

Metscher B.D. 2009a. MicroCT for comparative morphology: simple staining methods allow high-contrast 3D imaging of diverse non-mineralized animal tissues. BMC Physiology 9: 11. https://doi.org/10.1186/1472-6793-9-11

Metscher B.D. 2009b. MicroCT for developmental biology: A versatile tool for high-contrast 3D imaging at histological resolutions. Developmental Dynamics 238 (3): 632-640.

https://doi.org/10.1002/dvdy.21857

Metscher B.D. 2011. X-ray microtomographic imaging of intact vertebrate embryos. Cold Spring Harbor Protocols 12: 1462-1471. https://doi.org/10.1101/pdb.prot067033

Meyer M., Elliott D., Wood A.D., Polys N.F., Colbert M., Maisano J.A., Vickers-Rich P., Hall M., Hoffman K.H., Schneider G. \& Xiao S. 2014. Three-dimensional microCT analysis of the Ediacara fossil Pteridinium simplex sheds new light on its ecology and phylogenetic affinity. Precambrian Research 249: 79-87. https://doi.org/10.1016/j.precamres.2014.04.013

Miller J.S. \& Venable D.L. 2003. Floral morphometrics and the evolution of sexual dimorphism in Lycium (Solanaceae). Evolution 57 (1): 74-86. https://doi.org/10.1111/j.0014-3820.2003.tb00217.x

Mizutani R. \& Suzuki Y. 2012. X-ray microtomography in biology. Micron 43 (2-3): 104-115. https://doi.org/10.1016/j.micron.2011.10.002

Mizutani R., Takeuchi A., Hara T., Uesugi K. \& Suzuki Y. 2007. Computed tomography imaging of the neuronal structure of Drosophila brain. Journal of Synchrotron Radiation 14 (3): 282-287. https://doi.org/10.1107/S0909049507009004

Mizutani R., Takeuchi A., Akamatsu G., Uesugi K. \& Suzuki Y. 2008a. Element-specific microtomographic imaging of Drosophila brain stained with high-Z probes. Journal of Synchrotron Radiation 15 (4): 374-377. https://doi.org/10.1107/S0909049508003725

Mizutani R., Takeuchi A., Uesugi K., Takekoshi S., Osamura R.Y. \& Suzuki Y. 2008b. X-ray microtomographic imaging of three-dimensional structure of soft tissues. Tissue Engineering Part C: Methods 14 (4): 359-363. https://doi.org/10.1089/ten.tec.2008.0274

Mizutani R., Takeuchi A., Uesugi K., Takekoshi S., Osamura R.Y. \& Suzuki Y. 2009. Three-dimensional microstructural analysis of human brain tissue by using synchrotron radiation microtomographs. In: Westland T.B. \& Calton R.N. (eds) Handbook on White Matter: 247-277. Nova Science Publishers, New York.

Mooney S.J., Pridmore T.P., Helliwell J. \& Bennett M.J. 2012. Developing X-ray computed tomography to non-invasively image 3-D root systems architecture in soil. Plant and Soil 352: 1-22. https://doi.org/10.1007/s11104-011-1039-9

Needham A.W., Abel R.L., Tomkinson T. \& Grady M.M. 2013. Martian subsurface fluid pathways and 3D mineralogy of the Nakhla meteorite.Geochimica et Cosmochimica Acta 116: 96-110. https://doi.org/10.1016/j.gca.2012.07.004

Pajor R., Fleming A., Osborne C.P., Rolfe S.A., Sturrock C.J. \& Mooney S.J. 2013. Seeing space: visualization and quantification of plant leaf structure using X-ray micro-computed tomography: View Point. Journal of Experimental Botany 64 (2): 385-390. https://doi.org/10.1093/jxb/ers392 
Paquit V.C., Gleason S.S. \& Kalluri U.C. 2011. Monitoring plant growth using high resolution micro-CT images. Proceedings of SPIE-IS\&T Electronic Imaging 7877: 78770W. https://doi.org/10.1117/12.876719

Paredes U.M., Prys-Jones R., Adams M., Groombridge J., Kundu S., Agapow P.M. \& Abel R.L. 2012. Micro-CT X-rays do not fragment DNA in preserved bird skins. Journal of Zoological Systematics and Evolutionary Research 50 (3): 247-250. https://doi.org/10.1111/j.1439-0469.2012.00657.x

Paterson G.L., Sykes D., Faulwetter S., Merk R., Ahmed F., Hawkins L.E., Dinley J., Bal A.D. \& Arvanitidis C. 2014. The pros and cons of using micro-computed tomography in gross and microanatomical assessments of polychaetous annelids. Memoirs of Museum Victoria 71: 237-46.

Pauwels E., Van Loo D., Cornillie P., Brabant L. \& Van Hoorebeke L. 2013. An exploratory study of contrast agents for soft tissue visualization by means of high resolution X-ray computed tomography imaging. Journal of Microscopy 250 (1): 21-31. https://doi.org/10.1111/jmi.12013

Penney D., Dierick M., Cnudde V., Masschaele B., Vlassenbroeck J., Van Hoorebeke L. \& Jacobs P. 2007. First fossil Micropholcommatidae (Araneae), imaged in Eocene Paris amber using X-ray computed tomography. Zootaxa 1623: 47-53. https://doi.org/10.5281/zenodo.179249

Plougonven E., Srichamnong W., Srzednicki G. \& Léonard A. 2012. Characterisation of macadamia nuts using X-ray microtomography. SkyScan MicroCT User Meeting 2012, Belgium: 1-5. Skyscan, Brussels.

Presnell J.K. \& Schreibman M.P. 1997. Humason's Animal Tissue Techniques. Fifth edition. Johns Hopkins University Press, Baltimore/London.

Rahman I.A. \& Smith S.Y. 2014. Virtual paleontology: computer-aided analysis of fossil form and function. Journal of Paleontology 88 (4): 633-635. https://doi.org/10.1666/13-001I

Rivers M.L., Sutton S.R. \& Eng P.J. 1999. Geoscience applications of X-ray computed microtomography. In: Developments in X-Ray Tomography II (Vol. 3772): 78-86. SPIE's International Symposium on Optical Science, Engineering, and Instrumentation, Denver, CO, United States. https://doi.org/10.1117/12.363741

Roche R.C., Abel R.A., Johnson K.G. \& Perry C.T. 2010. Quantification of porosity in Acropora pulchra (Brook 1891) using X-ray micro-computed tomography techniques. Journal of Experimental Marine Biology and Ecology 396 (1): 1-9. https://doi.org/10.1016/j.jembe.2010.10.006

Rossi M., Casali F., Romani D., Bondioli L., Macchiarelli R. \& Rook L. 2004. MicroCT scan in paleobiology: application to the study of dental tissues. Nuclear Instruments and Methods in Physics Research Section B: Beam Interactions with Materials and Atoms 213: 747-750.

https://doi.org/10.1016/S0168-583X(03)01697-5

Ruthensteiner B., Baeumler N. \& Barnes D.G. 2010. Interactive 3D volume rendering in biomedical publications. Micron 41 (7): 886-e1. https://doi.org/10.1016/j.micron.2010.03.010

Salmon P.L., Liu X. \& Sasov A. 2009. A post-scan method for correcting artefacts of slow geometry changes during micro-tomographic scans. Journal of X-Ray Science and Technology 17 (2): 161-174.

Sansone S., Rocca-Serra P., Field D., Maguire E., Taylor C., Hofmann O., Fang H., Neumann S., Tong W., Amaral-Zettler L., Begley K., Booth T., Bougueleret L., Burns G., Chapman B., Clark T., Coleman L., Copeland J., Das S., de Daruvar A., de Matos P., Dix I., Edmunds S., Evelo C.T., Forster M.J., Gaudet P., Gilbert J., Goble C., Griffin J.L., Jacob D., Kleinjans J., Harland L., Haug K., Hermjakob H., Sui S.J.H., Laederach A., Liang S., Marshall S., McGrath A., Merrill E., Reilly D., Roux M., Shamu C.E., Shang C.A., Steinbeck C., Trefethen A., Williams-Jones B., Wolstencroft K., Xenarios I. \& Hide W. 2012. Toward interoperable bioscience data. Nature Genetics 44 (2): 121-126.

https://doi.org/10.1038/ng.1054 
KEKLIKOGLOU K. et al., Micro-computed tomography for natural history specimens

Schambach S.J., Bag S., Schilling L., Groden C. \& Brockmann M.A. 2010. Application of micro-CT in small animal imaging. Methods 50 (1): 2-13. https://doi.org/10.1016/j.ymeth.2009.08.007

Schmidbaur H., Keklikoglou K., Metscher B.D. \& Faulwetter S. 2015. Exploring methods to remove iodine and phosphotungstic acid stains from zoological specimens. Micro-CT User Meeting, Belgium: 116-123. Bruker, Bruges.

Simons F.J., Verhelst F. \& Swennen R. 1997. Quantitative characterization of coal by means of microfocal X-ray computed microtomography (CMT) and color image analysis (CIA). International Journal of Coal Geology 34 (1): 69-88. https://doi.org/10.1016/S0166-5162(97)00011-6

Staedler Y.M., Masson D. \& Schönenberger J. 2013. Plant tissues in 3D via X-ray tomography: simple contrasting methods allow high resolution imaging. PLoS ONE 8 (9): e75295.

https://doi.org/10.1371/journal.pone.0075295

Staedler Y.M., Kreisberger T., Manafzadeh S., Chartier M., Handschuh S., Pamperl S., Sontag S., Paun O. \& Schönenberger J. 2018. Novel computed tomography-based tools reliably quantify plant reproductive investment. Journal of Experimental Botany 69 (3): 525-535.

https://doi.org/10.1093/jxb/erx405

Stanley S.M. 1992. Exploring Earth and Life Through Time. W H Freeman \& Co, New York.

Stoev P., Komerički A., Akkari N., Liu S., Zhou X., Weigand A.M., Hostens J., Porco D.\& Penev L. 2013. Transcriptomic, DNA barcoding, and micro-CT imaging data from an advanced taxonomic description of a novel centipede species (Eupolybothrus cavernicolus Komerički \& Stoev, sp. n.). GigaScience. https://doi.org/10.5524/100063

Stuppy W.H., Maisano J.A., Colbert M.W., Rudall P.J. \& Rowe T.B. 2003. Three-dimensional analysis of plant structure using high-resolution X-ray computed tomography. Trends in Plant Science 8 (1): 2-6. https://doi.org/10.1016/S1360-1385(02)00004-3

Sutton M.D. 2008. Tomographic techniques for the study of exceptionally preserved fossils. Proceedings of the Royal Society of London B 275 (1643): 1587-1593. https://doi.org/10.1098/rspb.2008.0263

Sutton M.D., Briggs D.E., Siveter D.J. \& Siveter D.J. 2001. Methodologies for the visualization and reconstruction of three-dimensional fossils from the Silurian Herefordshire Lagerstätte. Palaeontologia Electronica 4 (1): 1-17.

Sutton M., Rahman I. \& Garwood R. 2014. Techniques for Virtual Palaeontology. John Wiley \& Sons, New York.

Vågberg W., Larsson J.C. \& Hertz H.M. 2017. Removal of ring artifacts in microtomography by characterization of scintillator variations. Optics Express 25 (19): 23191-23198.

https://doi.org/10.1364/OE.25.023191

van der Niet T., Zollikofer C.P.E., de León M.S.P., Johnson S.D. \& Linder H.P. 2010. Three-dimensional geometric morphometrics for studying floral shape variation. Trends in Plant Science 15 (8): 423-426. https://doi.org/10.1016/j.tplants.2010.05.005

van Soldt B.J., Metscher B.D., Poelmann R.E., Vervust B., Vonk F.J., Muller G.B. \& Richardson M.K. 2015. Heterochrony and early left-right asymmetry in the development of the cardiorespiratory system of snakes. PLoS ONE 10 (1): e116416. https://doi.org/10.1371/journal.pone.0116416

Vodrážka R. 2009. A new method for the extraction of macrofossils from calcareous rocks using sulphuric acid. Palaeontology 52 (1): 187-192. https://doi.org/10.1111/j.1475-4983.2008.00829.x 
Walter T., Shattuck D.W., Baldock R., Bastin M.E., Carpenter A.E., Duce S., Ellenberg J., Fraser A., Hamilton N., Pieper S., Ragan M.A., Schneider J.E., Tomancak P. \& Hériché J.-K. 2010. Visualization of image data from cells to organisms. Nature Methods 7: S26-S41.

https://doi.org/10.1038/nmeth.1431

Wan B., Xiao S., Yuan X., Chen Z., Pang K., Tang Q., Guan C. \& Maisano J.A. 2014. Orbisiana linearis from the early Ediacaran Lantian Formation of South China and its taphonomic and ecological implications. Precambrian Research 255: 266-275. https://doi.org/10.1016/j.precamres.2014.09.028

Wang C.N., Hsu H.C., Wang C.C., Lee T.K. \& Kuo Y.F. 2015. Quantifying floral shape variation in 3D using microcomputed tomography: a case study of a hybrid line between actinomorphic and zygomorphic flowers. Frontiers in Plant Science 6: 724. https://doi.org/10.3389/fpls.2015.00724

Wellington S.L. \& Vinegar H.J. 1987. X-ray computerized tomography. Journal of Petroleum Technology 39: $885-898$.

Wellman C. \& Axe L. 1999. Extracting plant mesofossils and megafossils by bulk acid maceration. In: Jones T.P. \& Rowe N.P. (eds) Fossil Plants and Spores: Modern Techniques: 11-14. Geological Society, London.

Yakami M., Ishizu K., Kubo T., Okada T. \& Togashi K. 2011. Development and evaluation of a low-cost and high-capacity DICOM image data storage system for research. Journal of Digital Imaging 24 (2): 190-195. https://doi.org/10.1007/s10278-009-9267-8

Yang H., Chen Z.Q., Wang Y., Ou W., Liao W. \& Mei X. 2015. Palaeoecology of microconchids from microbialites near the Permian-Triassic boundary in South China. Lethaia 48 (4): 497-508. https://doi. org/10.1111/let.12122

Zinsmeister W.J. \& De Nooyer C. 1996. Computed tomography; non-destructive techniques for visualizing internal morphology of invertebrates. Geological Society of America, Abstracts with Programs 28 (7): 294.

Manuscript received: 12 September 2018

Manuscript accepted: 21 January 2019

Published on: 30 April 2019

Topic editor: Koen Martens

Desk editor: Kristiaan Hoedemakers

Printed versions of all papers are also deposited in the libraries of the institutes that are members of the EJT consortium: Muséum national d'Histoire naturelle, Paris, France; Meise Botanic Garden, Belgium; Royal Museum for Central Africa, Tervuren, Belgium; Royal Belgian Institute of Natural Sciences, Brussels, Belgium; Natural History Museum of Denmark, Copenhagen, Denmark; Naturalis Biodiversity Center, Leiden, the Netherlands; Museo Nacional de Ciencias Naturales-CSIC, Madrid, Spain; Real Jardín Botánico de Madrid CSIC, Spain; Zoological Research Museum Alexander Koenig, Bonn, Germany. 
KEKLIKOGLOU K. et al., Micro-computed tomography for natural history specimens

\section{Appendix}

\section{Glossary of terms}

A glossary of terms related with micro-CT technology and imaging has been compiled and presented in Table 11.

\section{List of institutions hosting a micro-CT}

A comprehensive list of academic and research institutions operating micro-CT systems is presented in Table 12 for SYNTHESYS3 partners (EU FP7 programme) and in Table 13 for collaborators all over the world.

\section{List of micro-CT manufacturers}

A list of micro-CT manufacturers and their company links is presented in Table 14.

\section{List of software}

An up-to-date list of software currently used for post-processing procedures is presented in Table 7 for $3 \mathrm{D}$ volume rendering, in Table 8 for segmentation, in Table 9 for $2 \mathrm{D} / 3 \mathrm{D}$ analysis and in Table 15 for $2 \mathrm{D}$ visualisation. 
Table 11 (continued on next page). Glossary of terms.

\begin{tabular}{ll}
\hline 3D & $\begin{array}{l}\text { Three-dimensional } \\
\text { Charge-coupled device camera: a technology used in digital photography to } \\
\text { convert a light signal into a digital value. }\end{array}$ \\
Creative Commons licences & $\begin{array}{l}\text { A set of copyright-licences that describe which rights of the licenced material } \\
\text { are reserved and to what extent and under which condition the material can be } \\
\text { modified and shared. The licences are standardised, simple to understand and } \\
\text { computer-readable (http://www.creativecommons.org). }\end{array}$
\end{tabular}

CT

Computer tomography, a non-destructive imaging technique that converts projection views into orthogonal slices to calculate three-dimensional representations of the imaged object.

CTVox

A commercial volume rendering software developed by SkyScan/Bruker.

DICOM

Digital Imaging and Communications in Medicine: a standard providing format definitions and a communication protocol for the description and exchange of medical image data.

DOI

Digital Object Identifier: a digital identifier used to uniquely identify an object and retrieve metadata about it. Mostly applied to documents such as scientific papers, books, reports, etc. but not restricted to these - any digital object can be assigned a DOI.

Drishti

Free volume rendering software (http://sf.anu.edu.au/Vizlab/drishti).

Dryad/Datadryad

figshare

Flat-field correction

GB

GigaDB

HMDS

ISA-TAB

isosurface model

$\mathrm{keV}$
An online data repository to store data underlying scientific publications. Assigns DOIs to the submitted data so that they can be discovered and cited (http://datadryad.org).

An online data repository to store data underlying scientific publications. Assigns DOIs to the submitted data so that they can be discovered and cited (http://www.figshare.com).

A calibration procedure to improve the images created by the CCD camera. During the flat-field correction, defect pixels and camera artefacts are accounted for, and thus they can be removed in the final image.

Gigabyte: $10^{9}$ bytes. A byte is a unit of digital information, its multiples (kilo-, mega-, gigabyte) are often used to describe the size of a digital storage medium, file or dataset.

An online data repository to store data underlying scientific publications, specializing on very large datasets. Assigns DOIs to the submitted data so that they can be discovered and cited (http://www.gigadb.org).

Hexamethyldisilazane: a chemical used for drying specimens without affecting their morphology.

A newly proposed data format intended to facilitate integration of diverse datasets across various life-science disciplines (https://isa-tools.org/).

Geometrical, three-dimensional model consisting of surfaces of equal densities (often triangles).

Kilo electron volt 
Table 11 (continued).

\begin{tabular}{|c|c|}
\hline $\mathbf{k V}$ & Kilovolt \\
\hline $\mathbf{k V p}$ & Peak kilovoltage \\
\hline metadata & $\begin{array}{l}\text { Data about data. Ambiguous term, since data can be both "normal data" as } \\
\text { well as "metadata", depending on the context. Metadata help to understand the } \\
\text { context of the data as well as provide a means to integrate it with other data. }\end{array}$ \\
\hline $\boldsymbol{\mu} \mathbf{A}$ & Micro-ampere \\
\hline morphometric analysis & $\begin{array}{l}\text { Statistical analysis based on the shape and size of morphological characters } \\
\text { of organisms to detect similarities or significant differences between samples, } \\
\text { populations or species. }\end{array}$ \\
\hline OBJ & $\begin{array}{l}\text { Wavefront Object: a data format used to represent three-dimensional geometric } \\
\text { objects with the information of colour. }\end{array}$ \\
\hline pixel & The smallest unit of information in a digital image. \\
\hline projection image & $\begin{array}{l}\text { Also called shadow image or radiograph. Image that results from CT } \\
\text { imaging provides a grayscale side view of the specimen, with dense parts in } \\
\text { darker shades and less dense parts in lighter shades of grey. From a series of } \\
\text { projection images the cross-sections are calculated. }\end{array}$ \\
\hline PTA & $\begin{array}{l}\text { Phosphotungstic acid: an electron-dense stain used as a contrast agent in } \\
\text { histology and CT imaging. }\end{array}$ \\
\hline RAM & Random-access memory: a form of computer data storage for fast access. \\
\hline reconstruction & Algorithmic process of transforming projection images into cross sections. \\
\hline ROI & Region of Interest: User-specified region of an image. \\
\hline SEM & Scanning Electron Microscopy: a high-resolution imaging technique. \\
\hline $\begin{array}{l}\text { surface rendering, surface } \\
\text { model }\end{array}$ & See isosurface model. \\
\hline $\begin{array}{l}\text { transfer values, transfer } \\
\text { function }\end{array}$ & $\begin{array}{l}\text { In volume rendering, a definition of the colour and opacity values with which } \\
\text { each voxel should be displayed. }\end{array}$ \\
\hline type material, type specimen & $\begin{array}{l}\text { A biological reference specimen, usually kept in museums or biological } \\
\text { collections, to which the scientific name of that taxon is formally attached. }\end{array}$ \\
\hline URI & $\begin{array}{l}\text { Uniform Resource Identifier: a sequence of characters used to identify a web } \\
\text { resource. }\end{array}$ \\
\hline URL & $\begin{array}{l}\text { Uniform Resource Locator: often also synonymously used with 'web address', } \\
\text { a URL is a URI which also provides a means to access the resource. }\end{array}$ \\
\hline volume rendering & $\begin{array}{l}\text { A way of displaying three-dimensional data acquired through 3D-imaging } \\
\text { techniques such as CT or MRI. Depending on the transfer functions applied, } \\
\text { different densities of the sample can be visualised and optionally colour-coded. }\end{array}$ \\
\hline voxel & $\begin{array}{l}\text { Volume pixel: the smallest unit of information in a three-dimensional digital } \\
\text { space. }\end{array}$ \\
\hline
\end{tabular}




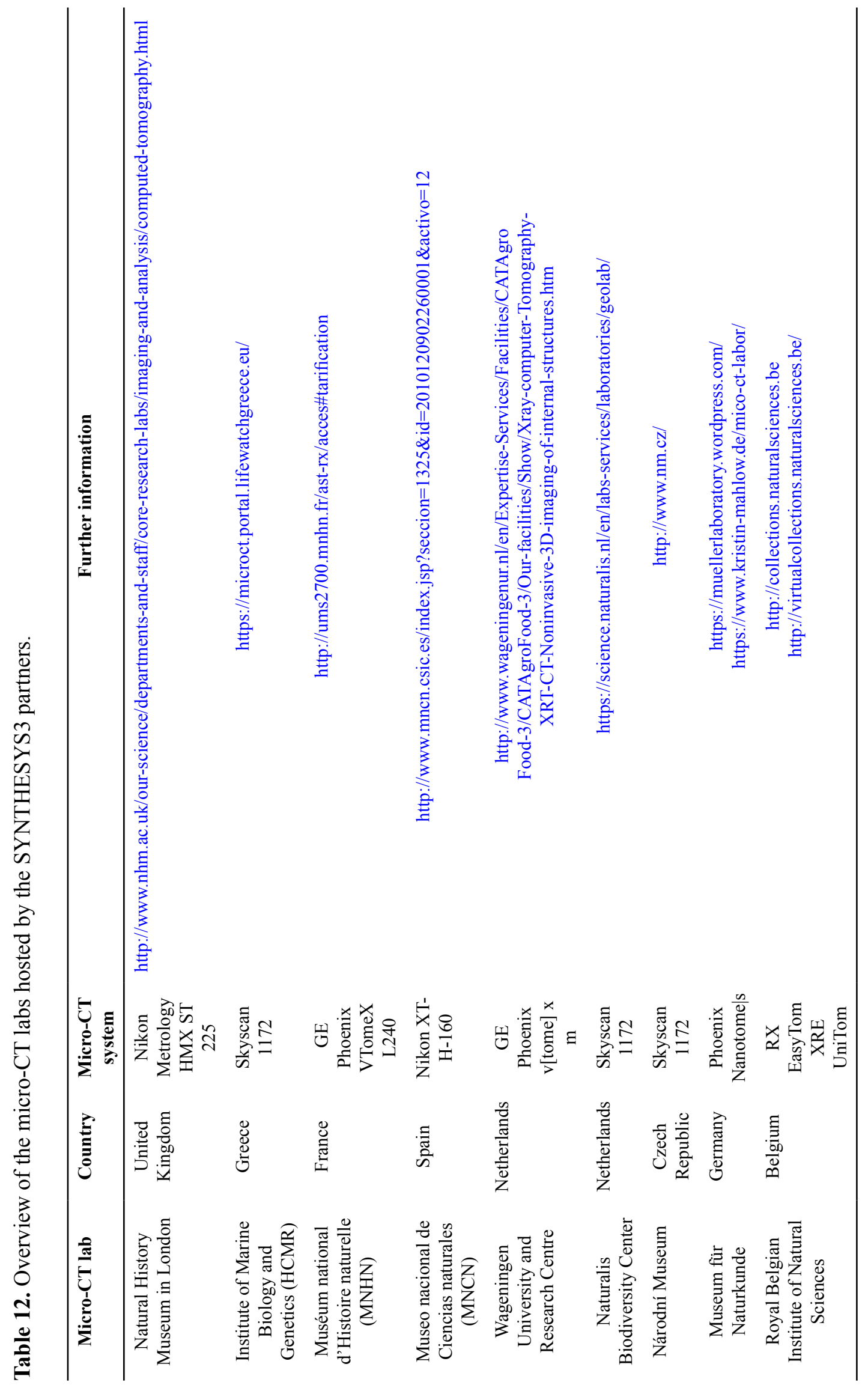




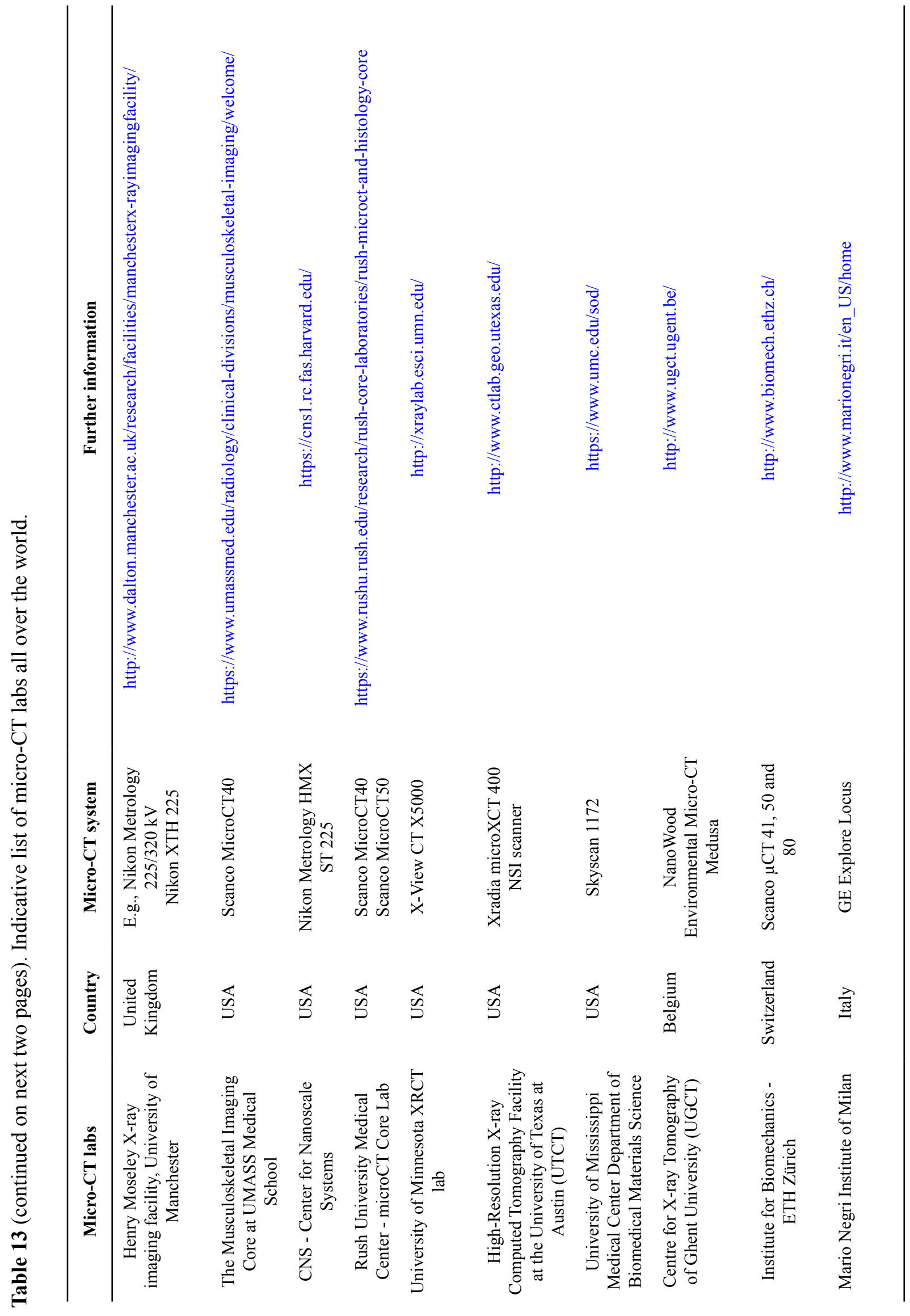




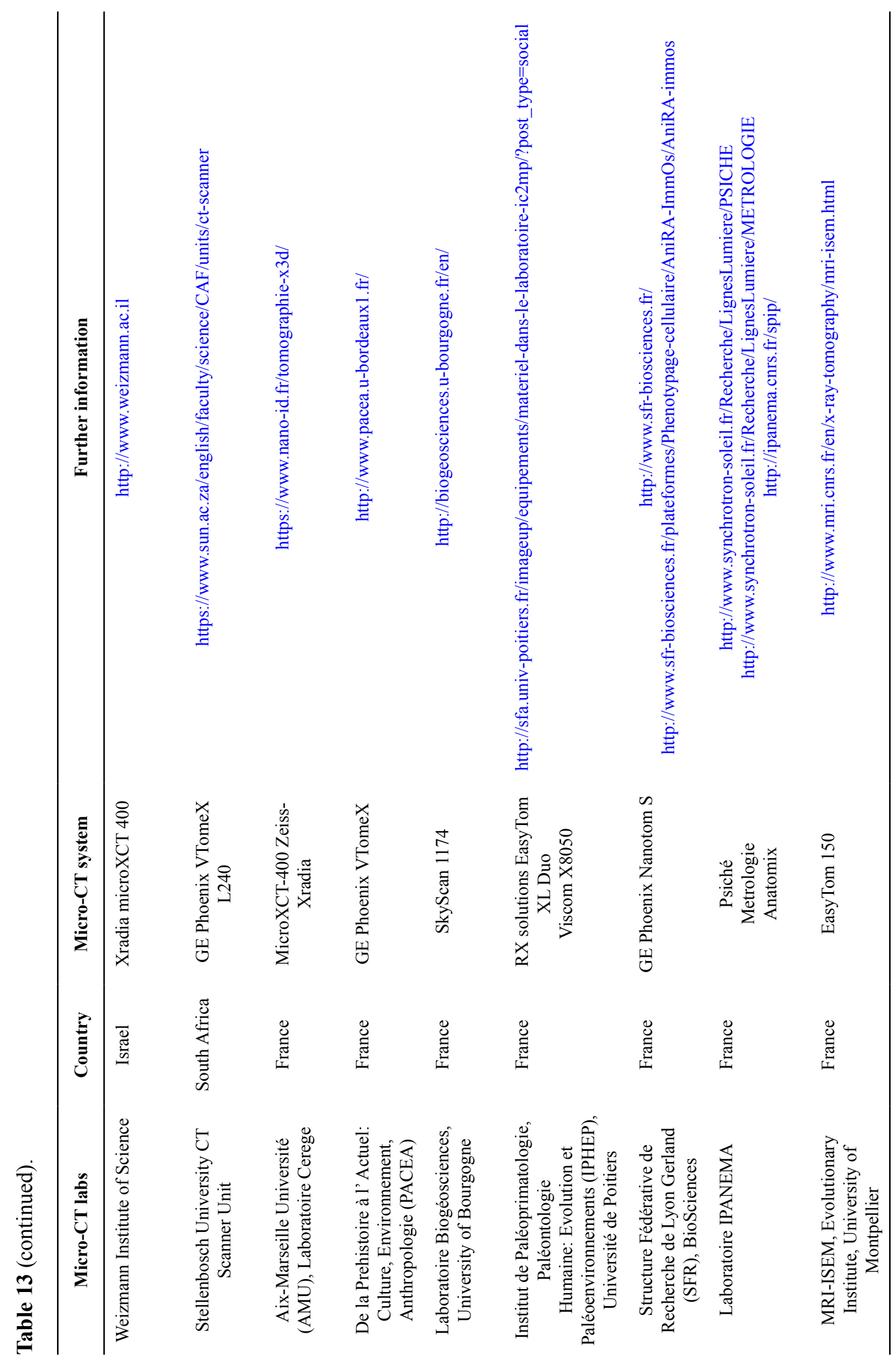




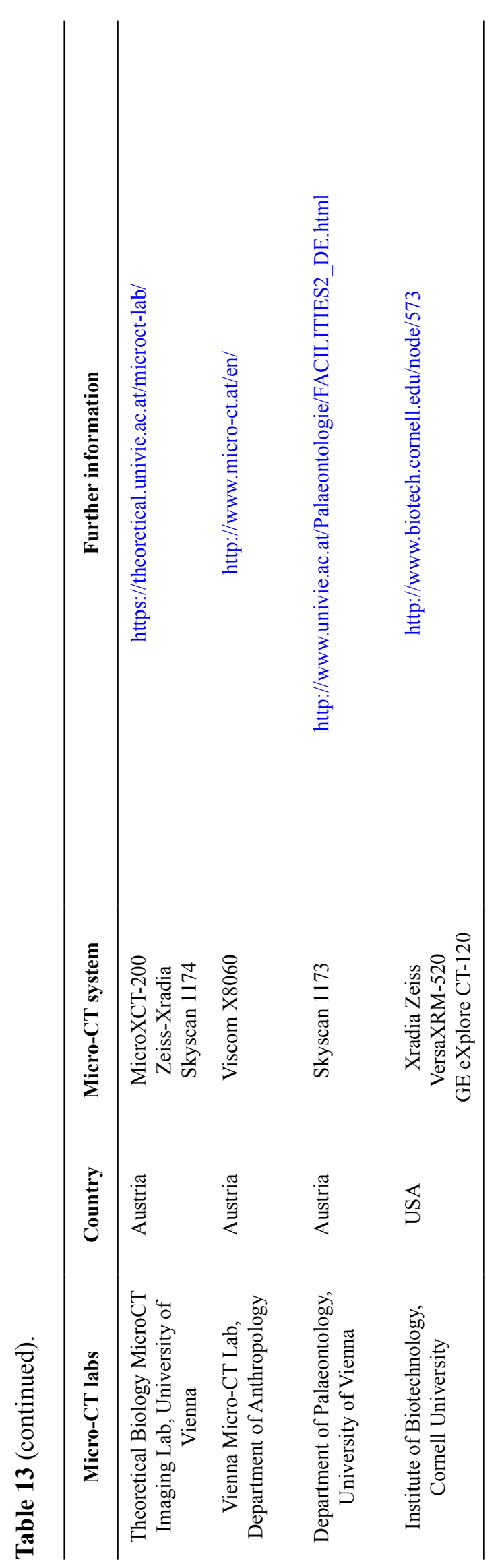


Table 14. MicroCT manufacturers and their company links (modified table from Schambach et al. 2010 and http://microctworld.net/).

\begin{tabular}{|c|c|}
\hline Company & Website \\
\hline Bruker (acquisition of Skyscan and Carestream) & $\begin{array}{c}\text { http://bruker-microct.com/home.htm } \\
\text { http://www.carestream.com/default.aspx?LangType=1033 }\end{array}$ \\
\hline CT imaging & http://www.ct-imaging.de/en/ \\
\hline Echo Medical Systems & http://www.echomri.com/ \\
\hline FEI (ThermoFisher) & http://www.fei.com/ \\
\hline GE Medical Systems & http://www.gehealthcare.com \\
\hline GE Measurement and Control Solutions & https://www.industrial.ai/ \\
\hline Hitachi Aloka Medical & http://www.hitachi-aloka.co.jp/english/ \\
\hline Mediso & http://www.mediso.hu/ \\
\hline Milabs & http://www.milabs.com/ \\
\hline NanoFocus Ray & http://www.nfr.kr/e_index.php \\
\hline Nikon Metrology & http://www.nikonmetrology.com/en_EU/ \\
\hline North Star Imaging (XviewCT) & http://www.xviewct.com/ \\
\hline Perkin Elmer & http://www.perkinelmer.com/ \\
\hline Prexion & http://www.prexion.com/ \\
\hline RX Solutions & http://www.rxsolutions.fr/ \\
\hline Scanco Medical & http://www.scanco.ch/ \\
\hline Sedecal & https://www.sedecal.com/en/ \\
\hline Siemens & http://www.siemens.com/entry/cc/en/ \\
\hline Stratec Medizintechnik GmbH & http://www.stratec-med.com \\
\hline Toshiba IT \& Control Systems Corporation & https://www.toshiba-itc.com/en/ \\
\hline TriFoil imaging (acquisition of Bioscan Inc.) & http://www.trifoilimaging.com/ \\
\hline Varian Medical Systems & https://www.varian.com \\
\hline Werth Messtechnik & http://www.werth.de/de/start/home.html \\
\hline Xstrahl & http://www.xstrahl.com/ \\
\hline XRE & https://xre.be/ \\
\hline YXLON International GmbH & http://www.yxlon.com/ \\
\hline Zeiss & http://www.xradia.com/ \\
\hline
\end{tabular}


KEKLIKOGLOU K. et al., Micro-computed tomography for natural history specimens

Table 15. Software for 2D visualisation (modified table from Walter et al. 2010 and Abel et al. 2012).

\begin{tabular}{|c|c|c|}
\hline Software & Licence Type & URL \\
\hline Amira & Commercial & www.amira.com \\
\hline Arivis (web-based software) & Commercial & http://vision.arivis.com/ \\
\hline BioImageXD & Free & http://www.bioimagexd.net \\
\hline Brain Maps (web-based software) & Free & http://brainmaps.org \\
\hline Dragonfly & $\begin{array}{l}\text { Free licences available } \\
\text { for researchers with non- } \\
\text { commercial activities/ } \\
\text { Commercial }\end{array}$ & http://www.theobjects.com/dragonfly/ \\
\hline Fiji (Is Just ImageJ) & Free & http://fiji.sc/ \\
\hline Huygens & Commercial & http://www.svi.nl \\
\hline ImageJ & Free & https://imagej.nih.gov/ij/ \\
\hline Image-Pro & Commercial & http://www.mediacy.com \\
\hline Imaris & Commercial & http://www.bitplane.com/ \\
\hline Mimics & Commercial & www.materialise.com/mimics \\
\hline Octopus & Commercial & https://octopusimaging.eu/ \\
\hline Simpleware & Commercial & www.simpleware.com \\
\hline Slice:Drop (web-based software) & Free & http://slicedrop.com/ \\
\hline SPIERS & Free & www.spiers-software.org \\
\hline tomviz & Free & http://www.tomviz.org/ \\
\hline VG Studio Max & Commercial & www.volumegraphics.com \\
\hline Volocity & Commercial & http://www.improvision.com \\
\hline VTK & Free & http://www.vtk.org/ \\
\hline
\end{tabular}

